\title{
MORTALIDADE NEONATAL EM \\ MARINGÁ - PR, 1997-2000
}

DEISE SERAFIM

Tese apresentada à área de concentração em Saúde Materno-Infantil da Faculdade de Saúde Pública da Universidade de São Paulo para obtenção do Grau de Doutor.

ORIENTADOR: PROF. DR. ARNALDO AUGUSTO FRANCO DE SIQUEIRA

Linha de Pesquisa: Saúde da criança, do adolescente e do jovem.

São Paulo

2002

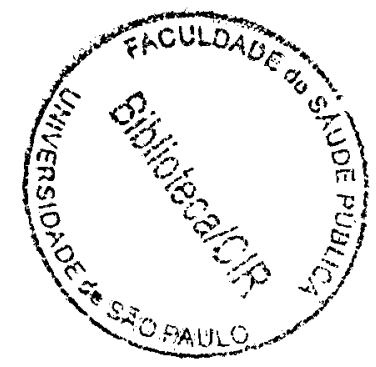


Dedico este trabalho:

À minha filha GIOVANNA, dádiva que eu agradeço; existência que me educa, me dá alegrias; me oportuniza o crescimento, a doação, tão importantes na relação com o filho.

À minha companheira de doutorado desde o útero até os 4 (anos), cujo futuro será brilhante como o é a sua pessoa. 


\section{AGRADECIMENTOS}

Ao Prof. Dr. Arnaldo Augusto Franco de Siqueira, pela oportunidade, pela orientação competente deste trabalho, pela confiança e apoio constante durante o nosso convívio e pela sábia condução de todo o processo.

À Prof ${ }^{a}$ Dra. Conceição A. de Mattos Segre, pela colaboração preciosa na avaliação do trabalho.

Ao Prof. Dr. Gabriel Alberto Brasil Ventura, pelas sugestões valiosas e enriquecimento da discussão dos resultados da pesquisa.

À Prof ${ }^{a}$ Dra. Ana Cristina d' Andretta Tanaka, pela imprescindivel colaboração desde a qualificação do projeto até a apreciação final do trabalho.

À Prof ${ }^{a}$ Dra. Regina Kazue Tanno de Souza, pelo exemplo profissional, pela acolhida e encorajamento nas dificuldades e pela inestimável contribuição durante o percurso de elaboração da tese.

Aos membros do Departamento de Saúde Materno-Infantil da Faculdade de Saúde Pública da USP, pela cordialidade e ajuda em todos os momentos.

À Universidade Estadual de Maringá e à Coordenação de Aperfeiçoamento de Pessoal de Nivel Superior (CAPES), pelo apoio financeiro e institucional, importantes para o aprimoramento profissional.

Ao secretário municipal de saúde, Dr. Paulo Roberto Donadio e diretores clínicos dos hospitais de Maringá que permitiram o acesso às fontes de dados.

Aos funcionários do Departamento de Pessoal e SAME dos hospitais de Maringá, pela gentileza e pronto atendimento na fase de consulta aos prontuários. 
Às enfermeiras e todo o pessoal da Coordenação de Epidemiologia da Secretaria Municipal de Saúde, em especial à Ivone, pela ajuda valiosa, pela paciência e confiança e, ainda, o contato agradável, na fase de coleta de dados.

Aos colegas do Departamento de Enfermagem da Universidade Estadual de Maringá, pelo carinho e incentivo constantes.

\section{À Thaís Aidar de Freitas Mathias e Taqueco Teruya Uchimura, pelo apoio e importante contribuição ao estudo.}

Aos meus pais pelo amor, paciência e compreensão manifestados continuamente e, também, às minhas irmãs Denise e Elaine pelo acompanhamento encorajador e carinhoso de todas as horas.

Ao meu esposo, Ailton, pelas "lições de vida", exemplo e incentivo constante na busca de conhecimentos e aprimoramento profissional.

À amiga Cristina Vilela de Carvalho, pelos elogios, pela demonstração de carinho, amizade e acompanhamento interessado na trajetória do doutorado.

À amiga Maria Regina Scholz, pelo carinho, incentivo e exemplo de desprendimento e dedicação ao trabalho.

Às acadêmicas de enfermagem Elaine Patrícia Massaki e Alessandra Medeiros Marin pela colaboração responsável na coleta de dados e solidariedade nos contratempos dessa fase.

À Franciele Emily Iamaguchi pelo empenho e participação competente na coleta e computação dos dados.

Às preletoras Ester Mitsuco Mukai e Teresa Sayoka Fugioka, pelo estímulo permanente e confiança em minha capacidade profissional. 


\section{RESUMO}

Serafim D. Mortalidade neonatal em Maringá - PR, 1997-2000. Maringá, 2002. [Tese de Doutorado - Faculdade de Saúde Publica da USP].

Objetivo. Identificar os fatores de risco para a mortalidade neonatal no município de Maringá-PR. Método. Estudo de caso-controle onde foram analisados os óbitos neonatais ocorridos em Maringá-PR, no período de janeiro de 1997 a dezembro de 2000. Foi considerado caso todo recém-nascido (RN) vivo, nascido em hospitais de Maringá, filho de mãe residente, de gestação única, cuja morte tenha ocorrido antes de completar 28 dias de vida. Os controles foram selecionados, por sorteio aleatório, entre os nascimentos hospitalares ocorridos em Maringá, no mesmo período, filhos de mães residentes, de gestações únicas e que sobreviveram ao período neonatal. A população de estudo foi de 120 casos e 240 controles. As variáveis estudadas referentes ao $\mathrm{RN}$ foram: sexo, peso ao nascer, duração da gestação, Apgar no $1^{\circ}$ e $5^{\circ}$ minutos, idade ao morrer e causa básica de morte; referentes à mãe: idade, escolaridade e estado conjugal; da assistência: número de consultas de pré-natal, tipo de parto, fonte financiadora e hospital de nascimento. Resultados. As mortes se concentraram no primeiro dia de vida $(52,5 \%)$ e as afecções do período perinatal foram as principais causas das mortes estudadas $(73,11 \%)$. Na análise univariada, apresentaram-se associados à mortalidade neonatal o sexo masculino $(\mathrm{OR}=1,93)$, o baixo peso $(<2500 \mathrm{~g}, \mathrm{OR}=98,62)$, a duração da gestação $<37$ semanas $(\mathrm{OR}=23,63)$, o Apgar no $1^{\circ}$ e $5^{\circ}$ minutos $\leq 6$ (OR=70,68 e $\mathrm{OR}=193,00$, respectivamente), a idade materna $<20$ anos $(O R=2,01)$ e $\geq 35$ anos $(O R=1,94)$, o nascimento em hospital público $(\mathrm{OR}=3,02)$ e a internação pelo $\mathrm{SUS}(\mathrm{OR}=1,99)$. Todavia, na análise multivariada, confirmaram-se como fatores de risco apenas o baixo peso ao nascer e escores de Apgar $\leq 6$ no $1^{\circ}$ e $5^{\circ}$ minutos. Conclusões. Os resultados do estudo indicaram como principais fatores de risco para a mortalidade neonatal o baixo peso ao nascer e a prematuridade. Esses fatores estão associados à necessidade de adequação da assistência oferecida à gestante, parturiente e neonato em Maringá.

Descritores: Mortalidade Neonatal. Fatores de Risco. Estudo de Caso-controle.

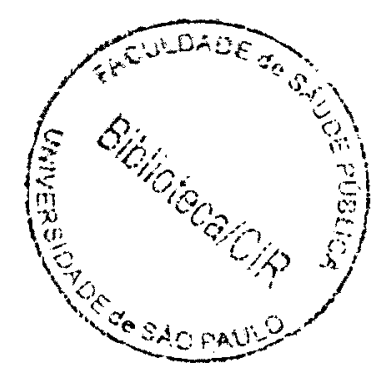




\section{SUMMARY}

SERAFIM D. Neonatal mortality in Maringá-Paraná, 1997-2000. Maringá, 2002. [Doctoral Thesis-USP School of Public Health].

Objective. To identify the risk factors for neonatal mortality in the city of MaringáPR. Method. Case-control study analyzing neonatal deaths occurring in Maringá-PR, during the period between January 1997 and December 2000. The study considers live newborn (RN) cases occurring in Maringá's hospitals; mothers are residents of Maringá, only single-gestation births are included and deaths occur before the completion of 28 days of life. The controls are randomly selected from newborn births in Maringa's hospitals during the same period; mothers are residents of Maringá, only single-gestation births are included and newborns survive the neonatal period. The study population includes 120 cases and 240 controls. The studied variables relating to newborns are: sex, birth weight, length of gestation, Apgar scores in the first and fifth minutes, age of death and basic cause of death; relating to the mother: age, educational level and matrimonial state; and relating to healthcare: number of prenatal consultations, type of delivery, healthcare financing and birth hospital. Results. The deaths are concentrated during the first day of life $(52,5 \%)$ and perinatal causes are responsible for the majority of all studied deaths $(73,11 \%)$. In the single-variable analysis, the results associate neonatal mortality with male sex $(\mathrm{OR}=1,93)$, birth weight below $2500 \mathrm{~g}(\mathrm{OR}=98,62)$, gestations less than 37 weeks $(\mathrm{OR}=23,63)$, Apgar scores in the first and fifth minutes $\leq 6(\mathrm{OR}=70,68$ and $O R=193,00$, respectively), mothers less than 20 years old $(O R=2,01)$ and 35 or more years old $(\mathrm{OR}=1,94)$, birth in public hospitals $(\mathrm{OR}=3,02)$ and publicly-financed healthcare (SUS) $(O R=1,99)$. Notwithstanding these findings, the only risk factors the results of the multivariable analysis confirm are low birth weight and Apgar scores $\leq 6$ in the first and fifth minutes. Conclusions. The results of the study indicate the need to adapt healthcare offered to pregnant women, both during and after delivery, to the risk factors (birth weight below $2500 \mathrm{~g}$ and gestations less than 37 weeks) associated with neonatal mortality in Maringá.

Keywords: Neonatal mortality. Risk factors. Case-control Study. 


\section{ÍNDICE}

1 INTRODUÇÃO

1.1 Relevância da mortalidade neonatal no contexto da mortalidade

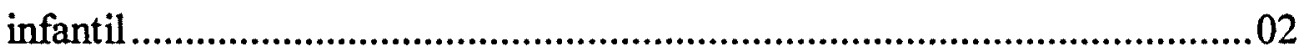

1.2 Situação da mortalidade neonatal no município de Maringá ......................08

1.3 Sistemas de informação ..............................................................11

1.3.1 Sistema de informação de mortalidade ........................................ 11

1.3.2 Sistema de informação sobre nascidos vivos .................................12

1.4 Caracterização da área de estudo........................................................ 14

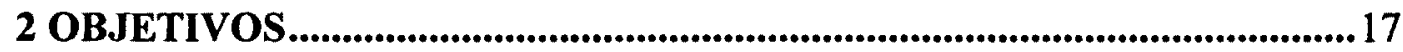

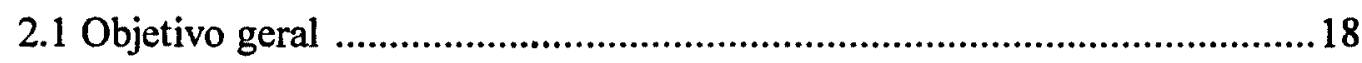

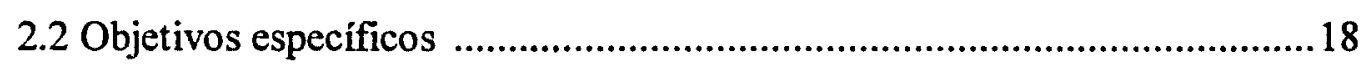

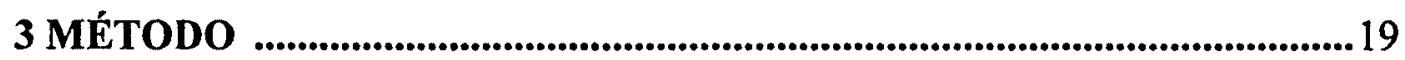

3.1 Delineamento do estudo..................................................................20

3.2 População e local de estudo ............................................................22

3.3 Fontes de dados ...........................................................................23

3.4 Procedimento de coleta de dados ....................................................24

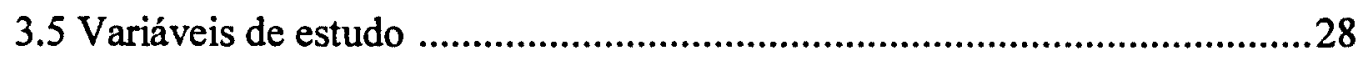

3.5.1 Variáveis relativas aos óbitos neonatais e ao RN ..........................28

3.5.2 Variáveis relativas à mãe..........................................................30

3.5.3 Variáveis relativas à assistência pré-natal e ao parto....................... 31

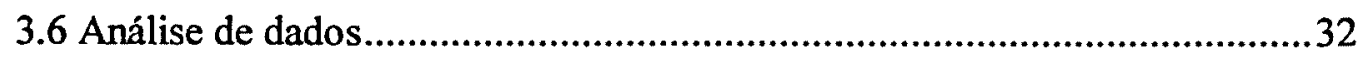

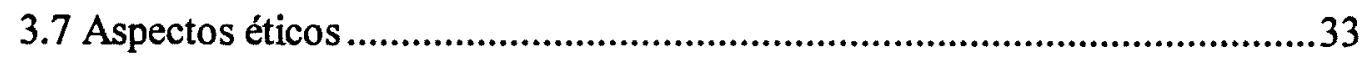

4 RESULTADOS E DISCUSSÃO ............................................................ 34

5 CONCLUSÃO E CONSIDERAÇÕES FINAIS ......................................82

6 REFERÊNCIAS 


\section{ANEXOS}

Anexo 1. Parecer do Comitê de Ética em Pesquisa da Faculdade de Saúde Pública da USP

Anexo 2. Parecer do Comitê Permanente de Ética em Pesquisa da Universidade Estadual de Maringá

Anexo 3. Solicitação de consentimento de consulta às fontes de dados

Anexo 4. Formulário de Pesquisa

Anexo 5. Declaração de Óbito (DO)

Anexo 6. Declaração de Nascido Vivo (DN)

Anexo 7. Declaração de Nascido Vivo (DN) (Modelo atual) 
1. INTRODUÇÃO 


\section{INTRODUÇÃO}

\subsection{Relevância da mortalidade neonatal no contexto da mortalidade infantil}

O coeficiente de mortalidade infantil é indicador consagrado das condições de saúde e socioeconômicas de uma população, sendo útil também para avaliação do impacto de determinadas ações de saúde (BARROS e VICTORA 1998).

A mortalidade infantil é dividida em mortalidade neonatal (mortes de crianças que ocorrem antes de completarem 28 dias de vida) e pós-neonatal (após os 28 dias de vida e antes de completar 1 ano de idade). Essa divisão cronológica permite avaliar indiretamente a importância das causas endógenas e exógenas do óbito. As primeiras estão relacionadas às condições de saúde desfavoráveis do recém-nascido $(\mathrm{RN})$ como, por exemplo, a imaturidade e as anomalias congênitas. $E$ as causas ditas exógenas estão relacionadas às condições ambientais hostis sobre crianças nascidas em boas condições e, portanto, passíveis de modificações se houver melhoria das condições de vida e de assistência à saúde do binômio mãe-filho (MONTEIRO e col. 1988).

O período neonatal é dividido em neonatal precoce, que inclui as mortes entre nascidos vivos que ocorrem durante os primeiros sete dias de vida $\mathrm{e}$ neonatal tardio, que considera as mortes entre nascidos vivos que ocorrem após o sétimo dia e termina com 28 dias completos de vida (OMS 1994).

Os investimentos empreendidos pelo governo brasileiro, nas últimas décadas, na promoção à saúde da mulher e da criança, resultaram em taxas menores de mortalidade infantil. De uma taxa média de mortalidade, em âmbito nacional, de 85 óbitos de menores de um ano por mil nascidos vivos (NV), no início dos anos 80 (MARANHÃO e col. 1999), observa-se, em 1999, um Coeficiente de Mortalidade 
Infantil (CMI) da ordem de 34,5 por mil NV (MELLO JORGE, GOTLIEB e LAURENTI 2001).

Apesar dessa redução progressiva nas taxas de mortalidade infantil no Brasil, se comparadas com os índices existentes em outros países, verifica-se que as taxas nacionais encontram-se elevadas.

Em estudo sobre a mortalidade infantil nos EUA, GOPAL e YU (1995) verificaram um declínio acentuado nas taxas de mortalidade nas quatro últimas décadas, causado, principalmente, pela diminuição de doenças como pneumonia, gripe, síndrome do desconforto respiratório, prematuridade e baixo peso ao nascer, anomalias congênitas e acidentes. Segundo estes autores, a previsão da mortalidade neonatal nos EUA é passar de uma taxa de 3,9 entre a população branca e 8,8 entre os negros, verificada nos últimos anos, para 2,6 e 6,5 , respectivamente, para o ano de 2010. Essa diferença acentuada entre a população estudada de negros e brancos é referente à raça, escolaridade e nível de renda. A projeção para os próximos 10 anos é que a desigualdade continue (GOPAL e YU 1995).

A queda mais pronunciada nas taxas de mortalidade infantil, mais especificamente das mortes ocorridas no período pós-neonatal, deve-se à maior facilidade de atingir as causas específicas de mortalidade de crianças após o primeiro mês de vida como: o controle do crescimento e desenvolvimento; controle da infecção respiratória, da desnutrição, de doenças diarréicas e das preveníveis por vacinação; promoção do aleitamento materno, entre outras medidas básicas de saúde. Mudanças como melhoria do acesso e qualidade dos serviços de saúde, ampliação do sistema público de abastecimento de água e saneamento básico, também influenciaram positivamente na redução das taxas de mortalidade infantil (MONTEIRO e col. 1988; LEAL 1996; BARROS e VICTORA 1998; MARANHÃO e col. 1999; DRAGOVICH e col. s/d).

De acordo com AERTS (1997), na realidade brasileira, o componente neonatal tem tido uma redução mais lenta de seus valores, ao contrário de países 
desenvolvidos, cujos coeficientes têm diminuído de maneira nítida. A partir de 1993, o predomínio do componente neonatal sobre o pós-neonatal é marcante. MARANHÃO e col. (1999) ressaltam que há uma tendência de estabilidade ou aumento da taxa de mortalidade neonatal até 1996, sendo que o incremento de cobertura de notificação de óbitos e maior informação sobre a assistência ao parto podem estar influenciando nesta realidade.

Em estudo realizado por MIÚRA, FAILACE e FIORI (1997) no Hospital de Clínicas de Porto Alegre, no período de 1984 a 1990, o coeficiente de mortalidade neonatal foi de 12,7 por mil NV. Esses autores comparam os resultados desta pesquisa com dados de outros hospitais, como aqueles do Hospital Regional da Asa Sul, em Brasilia, com mortalidade neonatal de 16 por mil nascimentos vivos, no periodo de 1985 - 1991 e, em 1982, com estatísticas da Maternidade Vila Nova Cachoeirinha, localizada em área com condições desfavoráveis e atendendo população específica, de taxa de neomortalidade de 17,2 por mil $\mathrm{NV}$.

Pesquisando a mortalidade neonatal no Estado do Rio de Janeiro, no período de 1979 a 1993, LEAL (1996) mostra uma redução diferenciada ao comparar o cinturão metropolitano, que apresentou uma queda de 26,3 em 1979 para 15,6 por mil NV em 1993, e a Capital, onde o índice se reduziu de 17,9 para 14,5. Essa autora ressalta que o decréscimo nos índices da mortalidade neonatal nesse periodo ocorreu, principalmente, para a mortalidade neonatal tardia (de 7 a 27 dias), enquanto para a mortalidade na primeira semana de vida o declínio foi menor, especialmente na proporção dos óbitos que aconteceram no primeiro dia de vida.

Em Porto Alegre, no ano de 1995, o coeficiente de mortalidade neonatal representou $52,2 \%$ da mortalidade infantil, sendo que $63,4 \%$ desses óbitos ocorreram na primeira semana de vida (AERTS 1997).

Em seu trabalho sobre mortalidade neonatal, ALMEIDA (1995) refere que no Estado de São Paulo, o componente neonatal passou de um coeficiente de 42,29 por mil NV, no ano de 1971 , para 17,03 por mil NV, em 1992. Essa autora 
ressalta que a representação destas taxas no coeficiente de mortalidade infantil teve um aumento de 47,0\% para 63,6\%. A proporção do componente neonatal precoce na mortalidade neonatal, em 1992, foi de 82,7\%. Esses dados evidenciam a importância de estudos que incluam os fatores de risco associados a características maternas e às condições da gestação e do parto.

Em termos epidemiológicos, risco indica a chance ou probabilidade de pessoas que estão sem uma doença ou agravo, serem expostas a certos fatores ("fatores de risco") e adquirirem esta doença (FLETCHER e col. 1990).

Fatores de risco são características ou circunstâncias que podem ser detectadas em indivíduos ou grupos e ligadas a uma probabilidade mais alta de acarretar condições indesejáveis (BACKETT 1985). Podem ser observáveis ou identificados antes do evento a que estão associados, possibilitando seu controle ou eliminação e impedindo o aparecimento do dano, e também, a identificação dos grupos de alto risco que devem receber atenção especial nos serviços de saúde (CESAR 1989).

Vários estudos têm contribuído para a identificação dos fatores de risco associados à mortalidade infantil. Publicação da Organização Mundial da Saúde -OMS (OMS 1978) utiliza o conceito de risco na área materno-infantil para definição das estratégias de reorganização dos serviços, chamando a atenção para a distribuição desigual dos danos à saúde entre os diferentes grupos populacionais.

Como explica CESAR (1989), a estratégia de risco propõe que os serviços de saúde sejam analisados frente às prioridades da sua área de atuação, dispensando uma atenção básica a todos os indivíduos, mas considerando o atendimento às necessidades de saúde dos grupos de risco.

Sobre a organização de serviços, ALBERMAN (1980) também reconhece que, para melhorar a saúde perinatal, é necessário planejar serviços obstétricos e neonatais especializados que atendam gestantes e crianças de alto risco. 
Esse autor lembra que é necessário melhor relação numérica e geográfica entre os centros de referência para gestações de alto risco e aqueles para o cuidado intensivo neonatal, pois acredita que há muito mais gestações de alto risco do que crianças necessitando de cuidado intensivo.

$\mathrm{Na}$ Inglaterra, além de sugerir a análise da mortalidade perinatal considerando-se o peso específico ao nascer e os principais subgrupos de doenças, WIGGLESWORTH (1980) enfatiza a importância da existência de assistência obstétrica e neonatal regionalizada com a finalidade de aumentar as chances de sobrevivência dos fetos ou neonatos.

Segundo declaração conjunta da OMS/UNICEF (1986), "os óbitos perinatais e neonatais estão diretamente relacionados à saúde da mulher durante a gestação e a ocorrências durante ou imediatamente após o parto". Como medidas de intervenção para a redução da mortalidade perinatal e neonatal, estes órgãos indicam a prevenção do tétano neonatal e outras infecções, melhoria dos cuidados obstétricos, melhoria nas condições maternas que afetam a saúde perinatal e o envolvimento da comunidade na assistência perinatal e neonatal.

Conforme TANAKA, SIQUEIRA e BAFILE (1989); MIÚRA, FAILACE e FIORI (1997), os altos coeficientes de mortalidade neonatal precoce em nossa realidade são um reflexo das más condições socioeconômicas e assistenciais que essa parcela vulnerável da população brasileira vivencia.

A ênfase na adequada assistência à gestante, à parturiente e ao recémnascido como importante medida para a redução dos índices de morbimortalidade neonatal implica em que os profissionais de saúde responsáveis pelo atendimento à gestante identifiquem fatores de risco materno e intercorrências clínicas e obstétricas que devem ser tratadas precocemente para evitar danos à saúde da mãe e do concepto.

Sendo assim, além da assistência pré-natal de qualidade, o 
atendimento adequado durante o trabalho de parto e parto é medida fundamental para garantir boas chances de sobrevivência do recém-nascido, principalmente aqueles de risco, como os prematuros e/ou de baixo peso. Ambiente adequadamente preparado com equipamentos necessários à assistência e equipe de saúde competente podem favorecer grandemente as condições de saúde do nascituro. Portanto, o acesso da gestante/parturiente a serviços de saúde, e a uma assistência de qualidade é condição essencial para evitar riscos à saúde da mãe e neonato.

A dificuldade de acesso à maternidade enfrentada por muitas mulheres no momento do parto, assim como a descontinuidade da assistência oferecida pelo Sistema Único de Saúde (SUS) à gestante e à parturiente, é uma problemática nacional e, como lembra TANAKA (1995), não se observam esforços por parte do sistema de saúde brasileiro de proporcionar a integração entre o pré-natal, parto e puerpério. Com isso, a gestante não tem sua vaga garantida na internação para o parto, tendo que se submeter, muitas vezes, a passar por vários hospitais até ser admitida. Nessa busca por uma vaga na hora do parto, chamada de "peregrinação" por TANAKA (1995), a vida da parturiente e de seu concepto está ameaçada.

Como enfatiza AERTS (1997), as chances de sobrevivência de uma criança têm relação estreita com o acesso à informação, aos serviços de saúde e à qualidade da atenção pré-natal, ao parto e neonatal, determinando a qualidade da vida futura daqueles que sobrevivem. Essa problemática deve ser solucionada com a máxima urgência, na tentativa de combater os possiveis agravos à saúde do neonato em decorrência da demora ou falta de atendimento no momento do parto e, conseqüentemente, reduzir a mortalidade neonatal devida a estas causas.

A análise da mortalidade neonatal segundo uma classificação de causa-específica é defendida pelo Comitê Internacional de Luta contra a Mortalidade Perinatal e Infantil (ICE), que sugere o seguinte agrupamento de causas: anomalias congênitas, condições relacionadas a hipóxia, condições relacionadas a prematuridade e infecções. Essa classificação facilitaria uma avaliação da eficácia e organização de serviços, subsidiando intervenções e, ainda, a comparação de índices 
em nivel internacional e nacional (DRAGOVICH e col. s/d).

No Brasil, a Fundação Sistema Estadual de Análise de Dados SEADE estabelece uma classificação da mortalidade neonatal precoce por causa, segundo critérios de evitabilidade como: reduzíveis por adequado controle da gravidez e do parto: hipóxia intra-uterina e asfixia ao nascer; reduzíveis por diagnóstico e tratamento precoce: outros problemas respiratórios após o nascimento; parcialmente reduziveis: crescimento fetal retardado e má nutrição fetal, imaturidade extrema, outros recém-nascidos de pré-termo, síndrome da angústia respiratória e outras reduziveis.

MARANHÃO e col. (1999) também apontam o processo de atendimento durante a gestação, parto, pós-parto e cuidados imediatos aos recémnascidos como empreendimentos essenciais no combate às mortes neonatais evitáveis.

Dessa maneira, a redução dos óbitos nesse periodo depende, fundamentalmente, de intervenções multissetoriais, a fim de favorecer as condições de vida e de saúde das mulheres e, conseqüentemente, garantir o nascimento seguro e a sobrevivência dos recém-nascidos (MARANHÃO e col. 1999).

\subsection{Situação da mortalidade neonatal no município de Maringá}

A evolução histórica da mortalidade infantil em Maringá, no período de 1979 a 2000, revela decréscimo progressivo das taxas, que passaram de 40,85 para 12,72 por mil NV, expressando uma redução da ordem de $68,86 \%$ no período de 21 anos (PARANÁ 1998; MARINGÁ 2002b). No âmbito do Estado do Paraná, a mortalidade infantil seguiu a mesma tendência, à semelhança dos demais Estados brasileiros, sendo que no período de 1979 a 1998, o coeficiente de mortalidade 
infantil passou de 56,35 para 20,70 por mil NV, expressando uma redução da ordem de 62,27\% (PARANÁ 1998).

WILLRICH (1999)," analisando esta tendência no Estado do Paraná, afirma que no ano de 1998 houve uma quebra na tendência de queda progressiva de mortes infantis, com ligeiro aumento nos valores. Atribui tal fato a uma provável melhora no sistema de informação, com redução da subnotificação existente nos anos anteriores. Ressalta, ainda, que após ter níveis de coeficientes de mortalidade infantil em torno de 20 por mil NV, nos anos de 97 e 98 , novas reduções seriam menos acentuadas, exigindo melhor qualidade e precisão dos dados para melhor identificar e valorizar adequadamente as mudanças.

Relativamente aos óbitos neonatais, este componente representou, em 2000, 80,35\% da mortalidade infantil em Maringá, com um coeficiente de mortalidade neonatal de 10,22 por mil NV (MARINGÁ 2002b). O patamar atualmente atingido pelo município, para o componente neonatal é inferior à média do Estado. Dados da Secretaria de Estado da Saúde (PARANÁ 1998) descrevem esse coeficiente por Regional de Saúde do Estado, no ano de 1997, com uma variação de 30,66 até 9,45, sendo a média do Estado de 18,10.

Estudos realizados em Maringá sobre a mortalidade infantil têm demonstrado, como em outras partes do país, uma evolução de declínio mais acentuado da mortalidade pós-neonatal em relação à neonatal. SOUZA (1992), em pesquisa realizada no ano de 1989 , constatou que a maioria $(77,3 \%)$ dos óbitos infantis ocorreu no período neonatal e as causas perinatais e anomalias congênitas foram as principais causas de morte. Enfatiza que a mortalidade neonatal apresentou uma redução pouco significativa durante o período de 1980/88, apesar do aumento importante na oferta de serviços, em especial ao grupo materno-infantil, e ressalta a necessidade de se avaliar a eficácia e a eficiência da assistência prestada, tanto no pré-natal como durante o parto, às mulheres que são atendidas nos serviços de saúde de Maringá. 
Para o ano de 1990, BERCINI (1993) constatou uma taxa de mortalidade neonatal, entre residentes em Maringá, de 19,4 por mil NV e coeficiente de mortalidade neonatal precoce de 17,8 por mil NV. Relaciona a situação observada à idade da criança, sexo, peso ao nascer, duração da gestação e deficiência na assistência ao pré-natal e ao parto.

Em relação à assistência pré-natal, SCOCHI (1996), considerando o aumento na oferta de serviços na rede básica de saúde, com a implantação dos programas de assistência materno-infantil no início da década no município de Maringá, constata uma elevada cobertura de assistência pré-natal oferecida pela rede de serviços de saúde do município. Ressalta, porém, que isso ocorreu mais pela valorização da gestante pelo pré-natal do que pelo interesse do serviço em captar essa clientela.

Além dos aspectos referentes ao pré-natal, merece destaque a relação entre o risco de mortes neonatais e o acesso à assistência ao parto. Segundo CARVALHO e col. (1998), a problemática da falta de leitos obstétricos à disposição do SUS tem levado parcela elevada de parturientes residentes em Maringá a procurarem atendimento em instituições de saúde de outros municípios. No estudo referente ao ano de 1997, as autoras constataram que $21,6 \%$ dos partos de residentes foram realizados em outros municípios. Os motivos relatados pelas mães para tal ocorrência foram a falta de vagas em maternidades do município de residência, custo elevado do atendimento e continuidade da assistência ao parto com o mesmo profissional que prestou atendimento pré-natal.

Dados divulgados pelo gestor municipal para os anos subseqüentes revelam um agravamento da situação em 1998, que registrou uma evasão de aproximadamente $25 \%$ entre as parturientes residentes no Município, acompanhadas por uma sensível melhora em 2000, ano em que o índice foi de 16,95\% (MARINGÁ, 2001c). Essa redução deveu-se ao convênio de cooperação técnica e financeira firmado entre a Prefeitura Municipal de Maringá e um hospital filantrópico do município, que visava à ampliação de atendimento pelo SUS em diversas áreas, entre 
as quais a obstétrica. Neste convênio, foi prevista a disponibilização de forma contínua de 21 leitos obstétricos para atendimento às gestantes encaminhadas pela Central de Leitos. Recentemente, em reunião extraordinária do Conselho Municipal de Saúde (20 de maio de 2002) foi aprovada a proposta de organização do serviço visando efetuar o pronto atendimento 24 horas às gestantes conforme Programa de Humanização no Pré-Natal e Nascimento, no âmbito do SUS, de acordo com a Portaria N. ${ }^{\circ} 569$ de $1 .^{\circ}$ de junho de 2000 (MINISTÉRIO DA SAÚDE 2000b).

Os resultados específicos ao município sobre a mortalidade neonatal em Maringá-PR permitem verificar que a situação em relação aos óbitos não difere muito de outras cidades do Brasil. Entre os determinantes, questiona-se a qualidade da assistência pré-natal (incluindo-se a detecção precoce e controle adequado das gestações de risco), as condições de assistência ao parto e assistência neonatal.

\subsection{Sistemas de informação}

\subsubsection{Sistema de informação de mortalidade}

Segundo LAURENTI (1991), as estatísticas de mortalidade representam uma das mais valiosas fontes de informação em saúde, o mais tradicional e um dos mais eficientes métodos para avaliação do estado de saúde das populações.

As informações sobre mortalidade, no Brasil, são publicadas por duas instituições: o Instituto Brasileiro de Geografia e Estatística (IBGE) e o Ministério da Saúde (MS). Porém, os dados configurados pelo IBGE não incluem a causa de óbito, a qual é encontrada no Sistema de Informação de Mortalidade do Ministério da Saúde (SIM-MS). Este Sistema de Informação foi implantado em 1975 e adota um modelo padronizado de registro do óbito para todo o país - a Declaração de Óbito (DO) (Anexo 5). 
As causas do óbito estão codificadas de acordo com as normas internacionais estabelecidas por estudiosos da OMS (1997). Ressalta-se que a implantação do SIM e a introdução do modelo padronizado da DO, para todo o país, provocaram um grande avanço na produção de informações sobre a mortalidade no Brasil. Com esse documento padronizado e individualizado, houve a possibilidade de se obterem informações de melhor qualidade e com a vantagem do problema poder ser comparado entre regiões ou entre a realidade do Brasil e outros países (MELLO JORGE 1990).

O Anuário "Estatísticas de Mortalidade, Brasil", publicado pelo MS, contém essas informações para residentes no país, estados e capitais, desde 1977, segundo sexo, idade e causa do óbito. Os dados de mortalidade para os municípios podem ser obtidos através de CD-ROM, distribuídos pela Fundação Nacional de Saúde do Ministério da Saúde.

Atualmente, as informações sobre os óbitos ocorridos em Maringá são registradas em três vias da última versão do impresso padronizado em nível nacional. A $1^{\mathrm{a}}$ via é recolhida e enviada pela Secretaria Municipal de Saúde à $15^{\mathrm{a}}$ Regional de Saúde (que congrega 29 municípios da Região Noroeste do Estado e cuja sede é em Maringá), onde as informações são inseridas no Sistema de Informações sobre Mortalidade (SIM) e repassadas para a Secretaria Estadual de Saúde.

\subsubsection{Sistema de informação sobre nascidos vivos}

Para melhorar os estudos sobre os nascidos vivos, a exemplo do SIM, o MS, em 1990, criou e implantou no país o Sistema de Informação sobre Nascidos Vivos (SINASC), tendo como base de coleta de dados a Declaração de Nascido Vivo (DN) (Anexos 6 e 7). Na DN são registradas as informações sobre características maternas, do recém-nascido, da gestação e do parto (MELLO JORGE e col. 1992). 
Com essas informações, tornou-se possível estudo mais detalhado da mortalidade neonatal.

MELLO JORGE e col. (1992) salientam a importância do SINASC que prevê que a DN seja preenchida nos hospitais onde ocorrem os partos ou onde são prestados os primeiros cuidados ao RN. Com isso, obtém-se maior cobertura dos eventos e fidedignidade do registro.

Como enfatiza ALMEIDA (1995), o SINASC permite que os dados sejam utilizados para produção de dados vitais e para a utilização em nível local, de atividades de vigilância ao recém-nascido.

A coleta de informações sobre nascidos vivos no município de Maringá é realizada diariamente nos hospitais pelos profissionais da Secretaria Municipal de Saúde, que visitam os berçários ou alojamento conjunto neonatal e recolhem a $1^{a}$ via das DNs. As informações contidas nesse documento são conferidas e, se necessário, antes de serem inseridas no SINASC, são devidamente corrigidas ou complementadas por meio de consulta aos registros em prontuários, livros de berçários ou das salas de parto dos hospitais ou de indagação aos profissionais responsáveis pelo atendimento ao parto e neonatal. No final de cada mês, as $1^{\text {as }}$ vias das DNs são comparadas com as $2^{\text {as }}$ vias enviadas, mensalmente, pelos cartórios, ocasião em que se verificam as taxas de sub-registro que, em 1989 , era de $9,1 \%$ no total de nascimentos, conforme estudo realizado por SOUZA (1992).

Desde a implantação do SINASC, as informações sobre nascimentos ocorridos em Maringá são de boa qualidade e cobertura, conforme constatado por PELLOSO (1995) em avaliação realizada simultaneamente ao processo de implantação. Assim sendo, elas têm servido de fonte de pesquisas acadêmicas e como subsídio à definição de políticas e ações de controle e promoção à saúde do binômio mãe-filho por parte dos gestores (MARINGÁ, 2002a). 


\subsection{Caracterização da área de estudo}

Maringá foi fundada em 10 de maio de 1947, como distrito de Mandaguari. Está localizada ao Norte do Estado do Paraná, a 434Km de Curitiba, a capital do Estado (Figura 1), sendo sede da Microrregião 9, que abrange 29 municípios de um total de $323 \mathrm{em}$ todo o Estado. Sua superficie total é de $473.064 .190 \mathrm{~m}^{2}$, sendo $131.224 .500 \mathrm{~m}^{2}$ em sua sede urbana, $264.748 \mathrm{~m}^{2}$ e $169.884 \mathrm{~m}^{2}$ em seus atuais distritos de Iguatemi e Floriano, respectivamente, e $341.405 .058 \mathrm{~m}^{2}$ em lotes rurais (MARINGÁ, 1996).

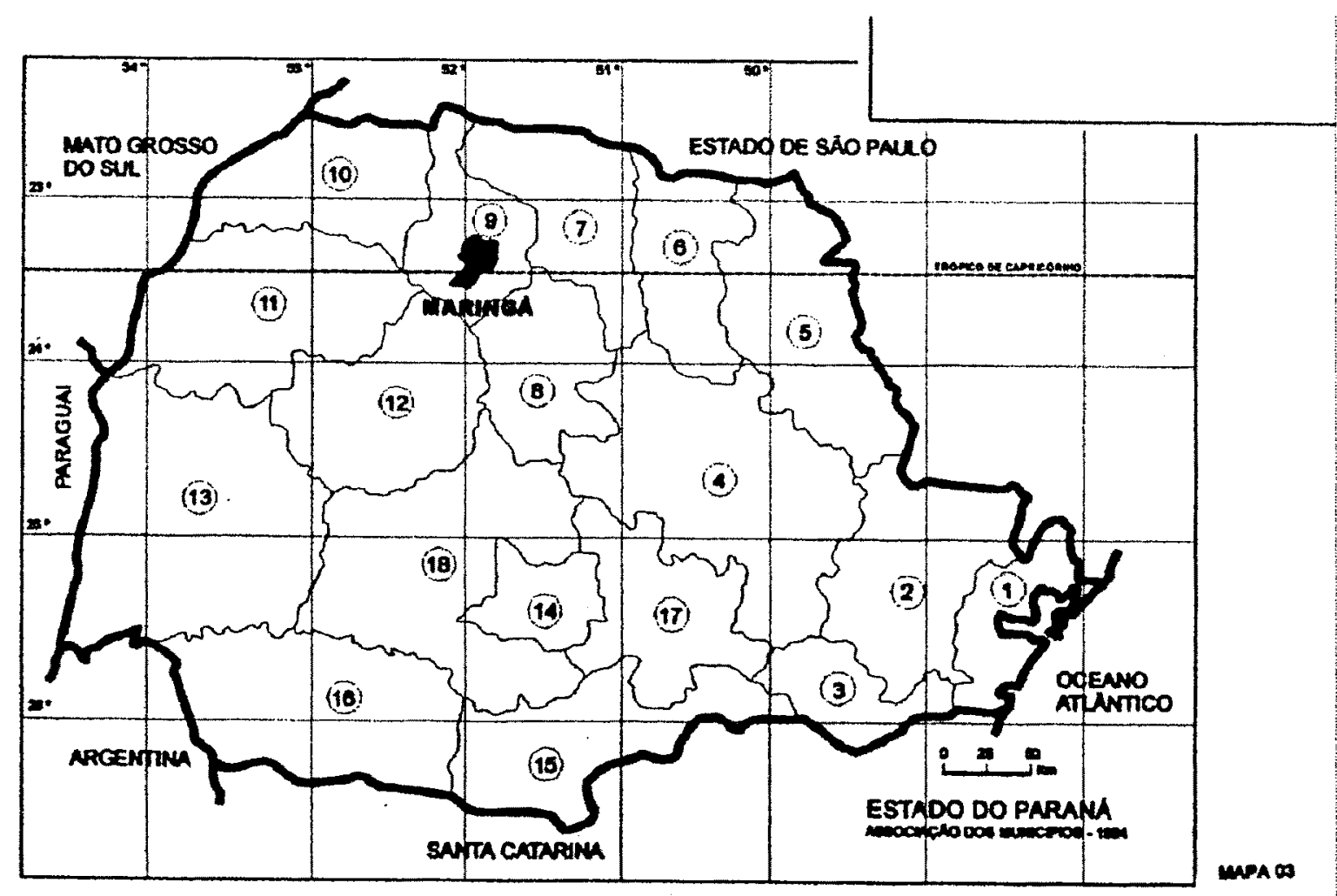

Figura 1 -- Microrregióes e fronteiras do Estado do Paraná.

No contexto estadual, Maringá ocupa o $3^{\circ}$ lugar em termos de população total, e é o $66^{\circ}$ município mais populoso do Brasil, com uma população de 288.465 habitantes (IBGE 2000), sendo 97,5\% urbana. A população feminina 
representa 150.026 pessoas. O número de habitantes por domicilio é de 3,4. Com um Índice de Desenvolvimento Humano de 0,794 e renda familiar mensal de 6,3 salários mínimos, apresenta uma taxa de crescimento anual de 1,86\% ao ano. Em torno de 99\% dos domicilios estão ligados à rede de abastecimento de água encanada e luz elétrica e têm coleta sistemática de lixo. A cobertura da rede de esgoto gira em torno de 70\% (MARINGÁ 2001b).

O setor primário constitui a base produtiva do município, com destaque para a cultura de soja, algodão, cana-de-açúcar e milho. No setor terciário, o comércio varejista e a prestação de serviços representam, respectivamente, $43,4 \%$ e $46,1 \%$ da economia.

Quanto à organização do Sistema de Saúde, Maringá é o município sede da $15^{\mathrm{a}}$ Regional de Saúde, que é uma unidade administrativa da Secretaria do Estado da Saúde do Paraná. A partir de maio de 1998, encontra-se na Gestão Plena do Sistema Municipal (MARINGÁ, 2001a). Por sua condição geográfica no Estado, o atendimento à saúde é procurado por número elevado de pessoas vindas de toda Região Noroeste do Paraná, e Sul do Estado de São Paulo.

A rede física de saúde no município é constituída por 24 Unidades de Saúde Municipal, das quais 20 Unidades Básicas de Saúde, 1 Unidade Mista (atendimento ambulatorial especializado e pronto atendimento 15 horas), 1 Unidade de Pronto Atendimento 24 horas, 1 Centro Integrado de Saúde Mental e 1 Hospital Municipal, inaugurado em abril de 2002, com 30 leitos clínicos de atendimento ao adulto e criança e projeção para expansão gradual da oferta, com capacidade de até 150 leitos (MARINGÁ 2001a, 2001b, 2002b). Está localizado também no município - Centro Regional de Saúde - CRS, órgão público de gestão estadual que presta serviço especializado para Maringá e região.

Além disso, conta com vários serviços ambulatoriais contratados. Com relação aos leitos hospitalares, contava, em 2001, com 698 leitos à disposição do SUS, dos quais 364 da área psiquiátrica. Este número de leitos está abaixo das 
necessidades dos aproximadamente $70 \%$ da população que dependem do SUS no município, sendo o déficit mais acentuado nas áreas de ortopedia, traumatologia e UTI neonatal. A partir da implantação do Hospital Municipal, a assistência hospitalar passou a ser prestada por 10 hospitais, sendo 7 privados com 812 leitos, 1 filantrópico com 150 leitos, o Hospital Universitário com 96 leitos e o Hospital Municipal com 30 leitos ativados (MARINGÁ 2001a).

Em relação às atividades dos profissionais da área de saúde, a proporção do número de médicos é de 14,96 para cada 10.000 habitantes, bem acima da proporção proposta pela OMS de 5. Esta relação de profissionais e número de habitantes é mais significativa na especialidade de ginecologia e obstetrícia, seguida pela de pediatria. Quanto aos dentistas, a proporção é de 12,89 para cada 10.000 habitantes (a recomendação da OMS é de 2,3).

Especificamente ao setor público, a maior concentração de profissionais é no Hospital Universitário, que conta com mais de 600 trabalhadores, e na Secretaria Municipal de Saúde, com aproximadamente 1500 servidores, muitos dos quais contratados recentemente por ocasião da implantação do Hospital Municipal e das 57 Equipes de Saúde da Familia. O Programa Saúde da Família (PSF), implantado em 1999, com alcance de $70 \%$ da população, responde pelo incremento de mais de 400 profissionais, o que propiciou a expansão da cobertura de serviços em nível básico. 
2. OBJETIVOS 


\section{OBJETIVOS}

\subsection{Objetivo geral}

- Identificar fatores de risco para a mortalidade neonatal no município de Maringá.

\subsection{Objetivos específicos}

- Descrever os óbitos neonatais segundo o ano de ocorrência, o local de nascimento e do óbito, idade ao morrer e a causa básica de morte.

- Caracterizar os casos e os controles segundo variáveis do $\mathrm{RN}$, da mãe, da assistência pré-natal e do parto.

- Verificar, dentre as variáveis de estudo, aquelas que representam fator de risco para a mortalidade neonatal. 
3. MÉTODO 


\section{MÉTODO}

\subsection{Delineamento do estudo}

Estudo epidemiológico do tipo caso-controle, onde foram analisados os óbitos neonatais (casos) e os recém-nascidos sobreviventes (controles), verificando-se associaç̃̃es do tipo fator de risco.

Devido a limitações éticas e de custo, a investigação epidemiológica, na maioria das vezes, impõe estudos não-experimentais. Entre estes, os principais são os estudos de seguimento (ou de coortes) e os estudos de caso-controle. Nos estudos de seguimento, os sujeitos são selecionados com referência a seu estado de exposição a uma potencial causa de doença e, nos estudos de caso-controle, os sujeitos são selecionados em relação a seu estado de doença (ROTHMAN 1987).

De acordo com KELSEY, THOMPSON e EVANS (1986), um estudo de caso-controle visa a verificar se indivíduos selecionados por terem uma doença (casos), diferem, significativamente, em relação à exposição a um dado fator de risco, de um grupo de indivíduos comparáveis, mas que não possuem a doença (controles). As proporções de casos e controles que foram expostos a possíveis fatores de risco são, então, determinadas e comparadas. Nesse tipo de estudo, portanto, a pesquisa é realizada após o fato ter ocorrido, isto é, parte-se do efeito para se chegar às causas.

Como explicam ALMEIDA FILHO e ROUQUAYROL (1990), em estudos de caso-controle, procura-se verificar se as associações do tipo fator de risco, pressentidas ou calculadas com relação aos indivíduos afetados (no caso em estudo, das mortes neonatais selecionadas), são confirmadas pela ausência ou menor ocorrência do fator entre os não-afetados, isto é, no grupo de crianças sobreviventes selecionadas e comparáveis. Estes estudiosos ressaltam que algum fator igualmente presente ou ausente nos dois grupos estudados não poderá ser indicado como uma das causas prováveis da morte, isto é, não pode ser considerado fator de risco para a 
morte neonatal em estudo. Contrariamente, a associação de um fator a um dos grupos é forte evidência para se inferir como agente causal.

Tendo os casos igual, maior ou menor chance de terem sido expostos aos fatores de risco do que outros RNs da população em geral, é necessária a comparação com a chance de qualquer pessoa desta população que não foi a óbito, ter sido exposta.

Os estudos de seguimento são onerosos devido à necessidade de se estabelecer um sistema continuado de monitorização da ocorrência de enfermidade em uma população. E, como explica ROTHMAN (1987), para a obtenção de estimações sólidas de incidência, é necessário um número substancial de casos de enfermidades, o que eleva o custo da pesquisa.

Segundo KELSEY, THOMPSON e EVANS (1986), entre os tipos de estudos epidemiológicos analíticos, os estudos de caso-controle são, consideravelmente, os mais freqüentes, pois podem ser levados a cabo em um período de tempo muito menor que os estudos de coorte, não requerem um tamanho de amostra muito grande e, conseqüentemente, são menos onerosos.

De acordo com ROTHMAN (1987), além de os estudos de casocontrole exigirem menor custo em comparação aos estudos de seguimento, produzem resultados com quase a mesma precisão. $\mathrm{E}$, também, proporcionam informação sobre uma ampla gama de exposições, potencialmente etiológicas, que poderiam estar relacionadas a uma enfermidade específica, ao contrário do estudo de seguimento, que se centra só em uma exposição.

Estudos realizados sobre os fatores de risco para a mortalidade infantil e, mais especificamente neonatal, utilizando o método caso-controle, comprovaram que a escolha dessa metodologia é adequada para o estudo do tema (CESAR 1989; MONTERO 2000). 
Diante destes aspectos, optou-se pelo estudo de caso-controle para investigar os fatores de risco para a mortalidade neonatal no município de Maringá.

\subsection{População e local de estudo}

A população de estudo foi extraída do conjunto de nascidos vivos, em hospitais de Maringá, filhos de mães residentes neste município, no período de 01 de janeiro de 1997 a 31 de dezembro de 2000.

\subsubsection{Definição de caso}

Foi considerado caso todo RN vivo em um dos hospitais de Maringá, filho de mãe residente neste município, cujo nascimento ocorreu entre 01/01/1997 e $31 / 12 / 2000$ e cuja morte se deu antes de completar 28 dias de vida. Foram excluídos do grupo de casos os óbitos neonatais oriundos de gestações múltiplas e, ainda, aqueles que não ocorreram no município de Maringả. Com estes critérios de seleção dos casos, chegou-se a 120 óbitos neonatais.

A exclusão das mortes registradas fora do município de Maringá deveu-se ao alto custo e inexeqüibilidade de uma busca em todo o Estado do Paraná e, eventualmente, em outros estados da União. A opção pelo ano de 1997 como início do período de estudo levou em consideração a utilização, a partir desse ano, da Décima Revisão da Classificação Estatística Internacional de Doenças e Problemas Relacionados à Saúde - CID -10 (OMS 1994), para categorização de causa básica de morte e melhor análise, segundo esta última revisão.

Decidiu-se estender o estudo por um período de 4 anos, tendo-se em vista a ocorrência de reduzido número do evento objeto de investigação (morte neonatal) no município de Maringá. $O$ aumento da amostragem poderia evitar a produção de indicadores de pouca estabilidade, como explica PEREIRA (1995), 
considerando-se as flutuações nos valores a comprometer a validade externa do estudo, caso houvesse a escolha de um ano atípico.

\subsubsection{Definição de controle e obtenção da amostra}

Após a definição dos 120 casos, foram sorteados os controles entre os nascimentos hospitalares em Maringá ocorridos no mesmo período de escolha dos óbitos (01/01/97 a 31/12/00), sobreviventes ao período neonatal, filhos de mães residentes e de gestação única. A proporção foi de dois controles para cada caso.

Para obtenção da amostra de controles neste banco de dados, realizouse o sorteio aleatório pelo Staticalc do Programa Epi-Info, Versão No 6 (DEAN e col. 1994) e foram obtidos os 240 controles, totalizando 360 binômios (mães e recémnascidos).

A razão da seleção baseada em sorteio aleatório de DNs procurou evitar o "overmatching" que poderia ocorrer na escolha baseada no nascimento imediatamente anterior ou subseqüente a um caso, no mesmo hospital (AXEMO e col. 1995).

\subsection{Fontes de dados}

As informações relativas aos casos foram coletadas dos prontuários hospitalares de internação para o parto (prontuário da mãe e do RN), dos documentos originais dos eventos de morte - Declaração de Óbito (DO) (Anexo5) e nascimento Declaração de Nascido Vivo (DN). No período estudado, foram encontradas duas versões da DN: o modelo antigo (Anexo 6) e o modificado (Anexo 7).

Os dados referentes aos controles foram extraídos dos prontuários hospitalares da gestante/parturiente, do RN e das DNs. 


\subsection{Procedimento de coleta de dados}

O primeiro passo para a coleta de dados foi o envio de oficio (Anexo 3) ao secretário municipal de saúde e aos diretores clínicos dos hospitais de Maringá, solicitando autorização para consulta às fontes de dados para a pesquisa. Todas as solicitações foram atendidas, porém houve demora na resposta de alguns diretores. Além disso, em todos os hospitais, o acesso aos prontuários dependeu da disponibilidade de pessoal dos serviços de arquivo médico - SAME para separação e controle dos prontuários durante a consulta aos mesmos. Em um dos hospitais não foram localizados os prontuários referentes aos óbitos ocorridos no período do estudo. E, ainda, a coleta de dados dos prontuários do hospital público foi interrompida devido à paralisação de atividades, por motivo de greve, por um período de 5 meses.

As declarações de nascimento e óbito foram consultadas na Gerência de Vigilância à Saúde - Coordenação de Epidemiologia da Secretaria Municipal de Saúde de Maringá. Este setor é responsável pela coleta e processamento de dados do SIM e do SINASC, dos eventos ocorridos em Maringá, onde não houve dificuldades para a coleta de informações necessárias à pesquisa.

Em relação às DOs foram selecionados os óbitos neonatais ocorridos em Maringá, nos anos de 1997 a 2000, de crianças nascidas em hospitais desse município, filhas de mães residentes, oriundas de gestação única. De 143 óbitos neonatais ocorridos em Maringá, excluíram-se 18 crianças que eram gemelares. De posse de 125 DOs que atendiam aos critérios de inclusão no estudo, realizou-se a consulta aos prontuários hospitalares.

Nessa investigação foram excluídos 5 casos, pois não atendiam às condições estabelecidas, sendo detectado durante consulta aos prontuários que 2 partos foram domiciliares e 3 ocorreram em 2 pronto-atendimentos municipais. Tendo sido definido o hospital como único local de ocorrência para inclusão no 
estudo e o reduzido número de nascimentos não hospitalares em Maringá, esses 5 casos foram excluídos da análise (Figura 2).

Figura 2 - Limpeza do banco de dados de óbitos neonatais de residentes em Maringá - Pr, 1997 - 2000.

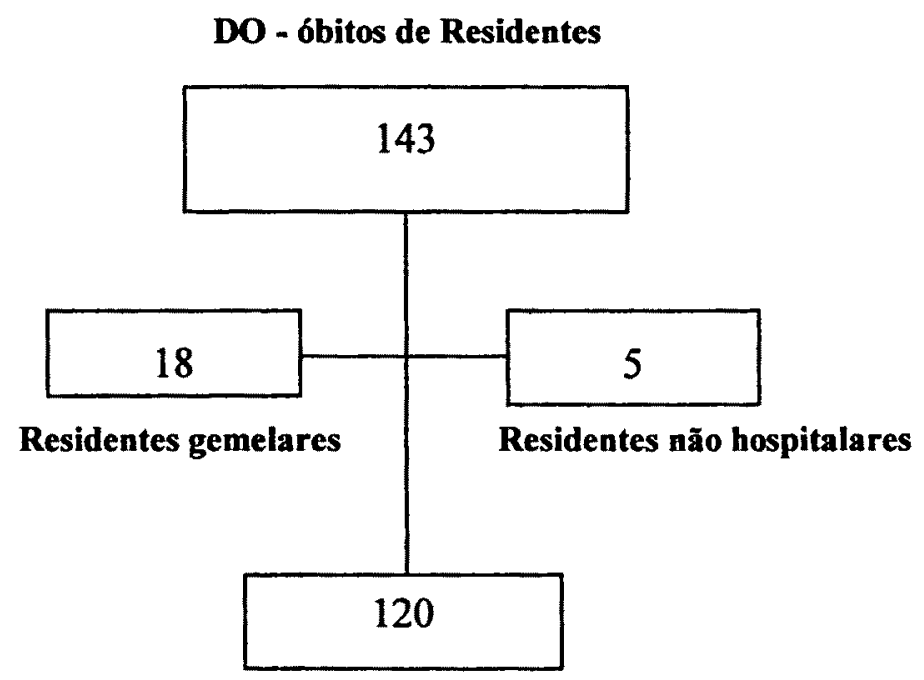

Amostra dos óbitos neonatais

Concluída a coleta nos prontuários hospitalares, tendo-se em vista a ausência de anotação em elevado número de casos, para algumas variáveis de interesse de estudo (Tabela 1), foram utilizadas a DN e a DO como fontes complementares. Além dessas fontes secundárias, foi consultado o cadastro informatizado das parturientes, realizado no momento de internação para o parto, para acrescentar informações não incluídas nas outras fontes ou de prontuários não encontrados, como tipo de financiamento e situação conjugal. 
Tabela 1- Distribuição dos casos e controles segundo variáveis de estudo* e presença da informação no prontuário hospitalar. Maringá-PR, 1997-2000.

\begin{tabular}{|c|c|c|c|c|c|c|c|c|}
\hline \multirow[t]{3}{*}{ VARIÁVEL } & \multicolumn{4}{|c|}{$\begin{array}{c}\text { Caso } \\
\text { Informação }\end{array}$} & \multicolumn{4}{|c|}{$\begin{array}{c}\text { Controle } \\
\text { Informação }\end{array}$} \\
\hline & \multicolumn{2}{|c|}{ Existe } & \multicolumn{2}{|c|}{ Inexiste } & \multicolumn{2}{|c|}{ Existe } & \multicolumn{2}{|c|}{ Inexiste } \\
\hline & $\mathrm{N} .^{\circ}$ & $\%$ & N. ${ }^{\circ}$ & $\%$ & N. ${ }^{\circ}$ & $\%$ & N. ${ }^{\circ}$ & $\%$ \\
\hline Idade materna & 106 & 88,33 & 14 & 11,67 & 240 & 100,00 & - & - \\
\hline Escolaridade & 45 & 37,50 & 75 & 62,50 & 51 & 21,25 & 189 & 78,75 \\
\hline $\begin{array}{c}\text { Estado } \\
\text { conjugal }\end{array}$ & 95 & 79,17 & 25 & 20,83 & 220 & 91,67 & 20 & 8,33 \\
\hline $\begin{array}{c}\mathrm{N} .^{\circ} \mathrm{de} \\
\text { consultas de } \\
\text { pré-natal }\end{array}$ & 19 & 15,83 & 101 & 84,17 & 37 & 15,42 & 203 & 84,58 \\
\hline $\begin{array}{c}\text { Duração da } \\
\text { gestação }\end{array}$ & 93 & 77,50 & 27 & 22,50 & 193 & 80,42 & 47 & 19,58 \\
\hline Tipo de parto & 105 & 87,50 & 15 & 12,50 & 240 & 100,00 & - & - \\
\hline Sexo & 106 & 88,33 & 14 & 11,67 & 238 & 99,17 & 2 & 0,83 \\
\hline Peso ao nascer & 104 & 86,67 & 16 & 13,33 & 240 & 100,00 & - & - \\
\hline $\begin{array}{c}\text { Apgar no } 10^{\circ} \\
\text { minuto }\end{array}$ & 97 & 80,83 & 23 & 19,17 & 229 & 95,42 & 11 & 4,58 \\
\hline $\begin{array}{c}\text { Apgar no } 5 .^{\circ} \\
\text { minuto }\end{array}$ & 93 & 77,50 & 27 & 22,50 & 225 & 93,75 & 15 & 6,25 \\
\hline
\end{tabular}

*selecionadas apenas as variáveis da DN

Relativamente aos controles, procedeu-se à junção dos arquivos referentes aos anos de estudo, conforme fluxograma (Figura 3). Desse banco de dados foram excluídos: as crianças cujas mães residiam fora do município de Maringá; os partos de residentes ocorridos em hospitais de outros municípios ou ocorridos em Maringá, mas fora das instituições hospitalares; os partos gemelares e 
as DNs de crianças que foram a óbito no período neonatal e que fariam parte do grupo de casos. A seguir, do conjunto de nascimentos no período, realizou-se o sorteio aleatório das 240 crianças que constituíram o grupo controle. Assim como no caso dos óbitos, as informações das DNs serviram como fonte complementar ao prontuário hospitalar.

No período decorrido entre a definição do grupo controle e a descrição dos resultados da pesquisa, foram inseridos 37 nascimentos ao SINASC de Maringá, diferença que pode ser observada comparando-se o número de nascidos vivos citado na Figura 3 e o contido na Tabela 2.

Figura 3 - Limpeza do banco de dados da nascidos vivos em Maringá - PR, 1997-2000.

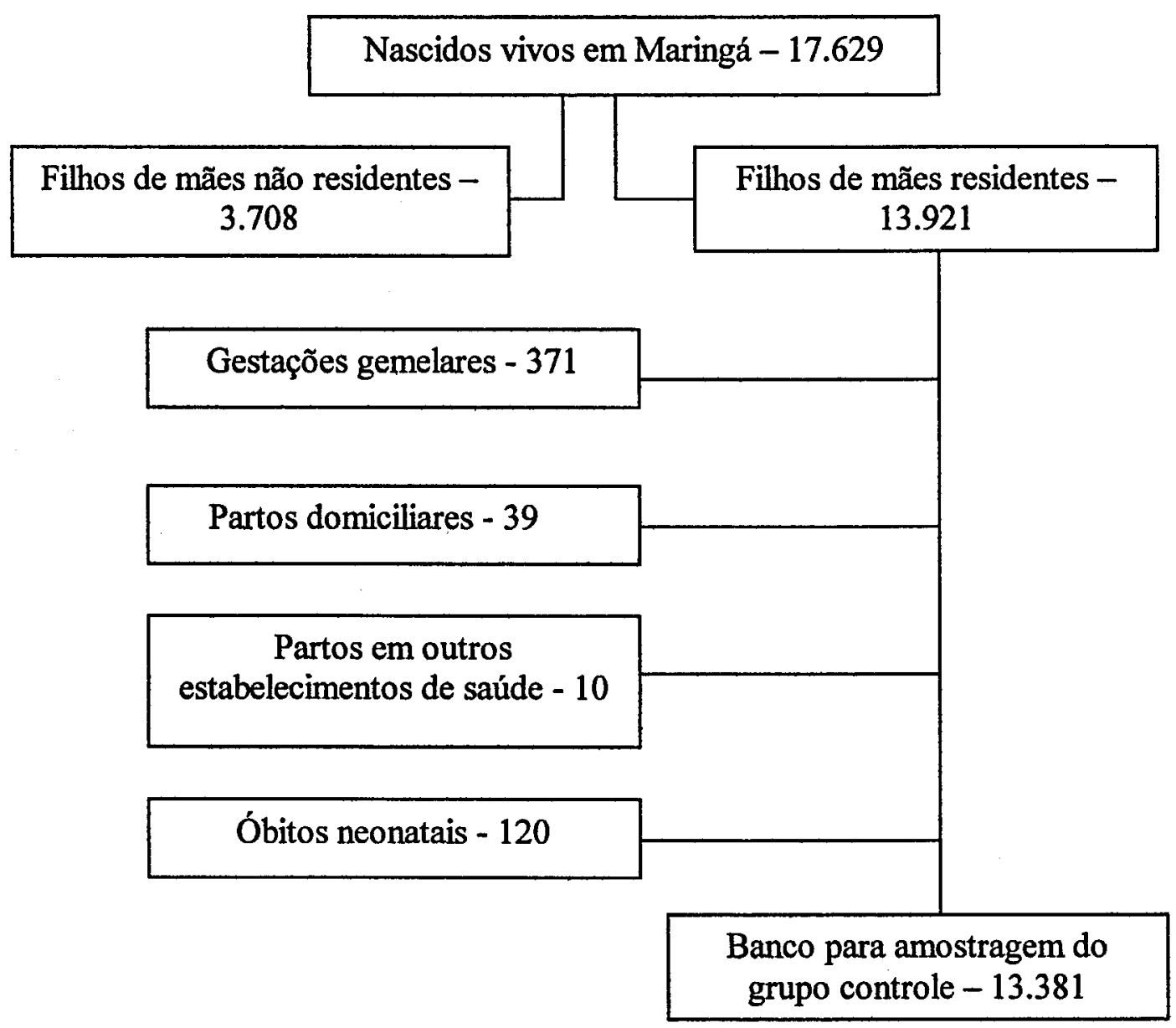




\subsection{Variáveis de estudo}

Selecionaram-se variáveis relacionadas a algumas características do RN, da mãe; da assistência pré-natal e do parto, com a finalidade de se verificar a associação das mesmas à mortalidade neonatal (Anexo 4).

Foram consideradas as informações registradas nos prontuários hospitalares e complementadas com registro da DN e DO. Utilizaram-se, porém, as categorizações existentes na DN.

\subsubsection{Variáveis relativas aos óbitos neonatais e ao $\mathbf{R N}$}

- Caracterização dos óbitos

1 - ANO E HOSPITAL DE NASCIMENTO:

Foram relacionados os óbitos por ano de nascimento e por hospital onde ocorreu o parto.

\section{2 - HOSPITAL DO ÓBITO:}

Variável relacionada à distribuição dos casos de acordo com o estabelecimento onde ocorreu o óbito.

\section{3 - IDADE DO RN AO MORRER:}

Essa variável foi representada pelo total de horas ou dias vividos pelo $\mathrm{RN}$ desde o seu nascimento até a ocorrência da morte e categorizada em: menos de 1 dia, 1 a 6 dias e 7 a 27 dias completos.

\section{4 - CAUSA BÁSICA DE MORTE:}

Definida como "(a) a doença ou lesão que iniciou a cadeia de acontecimentos patológicos que conduziram diretamente à morte, ou (b) as circunstâncias do acidente ou violência que produziram a lesão fatal" (OMS 1994). As informações referentes a essa variável foram obtidas na DO, onde estavam classificadas de acordo com a $10^{a}$ Revisão da CID. 


\section{- Características do RN}

1 - SEXO:

Esta variável foi categorizada em masculino e feminino.

\section{2 - PESO AO NASCER:}

Foi considerada a primeira medida de peso ao nascer registrada no prontuário hospitalar. Essa medida foi utilizada para obtenção da média de peso ao nascer. Para outras análises, essa variável foi categorizada em intervalos de classes de $500 \mathrm{~g}$ e agrupadas segundo a recomendação da OMS (CID-10 1994) em:

$\checkmark$ Baixo peso ao nascer: inferior a $2500 \mathrm{~g}$.

$\checkmark$ Não baixo peso ao nascer: igual ou superior a $2500 \mathrm{~g}$.

\section{3 - DURAÇÃO DA GESTAÇÃO:}

Essa variável é calculada a partir do primeiro dia do último ciclo menstrual normal até a data do parto, sendo expressa em semanas completas e categorizadas em: pré-termo (gestação menor de 37 semanas); a termo (gestação de 37 a 41 semanas) e pós-termo (gestação de 42 semanas e mais) de acordo com a classificação adotada pela OMS.

\section{4 - ÍNDICE DE APGAR:}

A classificação pelo Índice de Apgar mostra a vitalidade da criança ao nascer e, portanto, a eventual necessidade de reanimação da mesma. A avaliação é feita por meio de escores que são anotados no $1^{\circ}$ e $5^{\circ}$ minuto após o nascimento. Foram considerados os dois índices na seguinte categorização:

$\checkmark$ 0-3: gravemente anoxiado

$\checkmark 4$ - 7: anóxia neonatal moderada

$\checkmark$ 8-10: boas condições de vitalidade

$\checkmark$ sem registro 


\subsubsection{Variáveis relativas à mãe}

\section{- Caracterização sociodemográfica}

1 - IDADE:

A idade materna foi representada pelo total de anos vividos desde o nascimento até a data do parto. Essa variável foi registrada em anos completos, sendo utilizada para o cálculo da idade média das mães. Foi categorizada nas seguintes faixas etárias: 10 a 14, 15 a 19, 20 a 24, 25 a 29,30 a 34, 35 a 39,40 a 44 anos de idade. Para algumas análises foi agrupada nas seguintes categorias:

$\checkmark<20$ anos: adolescentes

$\checkmark 20$ a 34 anos: idade reprodutiva ótima

$\checkmark 35$ anos e mais: mães idosas

\section{2 - ESCOLARIDADE}

Foi agrupada nas seguintes categorias: nenhuma, $1^{\circ}$ grau incompleto, $1^{\circ}$ grau completo, $2^{\circ}$ grau, superior e ignorado. Em algumas analises utilizou-se essa variável dicotonozada em:

$\checkmark$ até $1^{\circ}$ grau completo

$\checkmark 2^{\circ}$ grau e mais anos de escolaridade

\section{3 - ESTADO CONJUGAL:}

Essa variável foi coletada segundo o estado civil registrado em prontuário hospitalar como: solteira, casada, separada, viúva e outros. Em virtude do pequeno número de mães separadas e nenhuma em estado de viuvez, optou-se pelas categorias:

$\checkmark$ com companheiro

$\checkmark$ sem companheiro 


\subsubsection{Variáveis relativas à assistência pré-natal e ao parto}

\section{1 - CONSULTAS DE PRÉ-NATAL:}

Foi considerado o número de consultas de pré-natal realizadas desde o início da gravidez até o momento do parto, e adotada a categorização existente no novo modelo da DN:

$\checkmark$ nenhuma

$\checkmark$ 0 a 3

$\checkmark 4 \mathrm{a} 6$

$\checkmark 7$ e mais consultas

$\checkmark$ ignorado

\section{2 - TIPO DE PARTO:}

Essa variável se refere ao tipo de parto que possibilitou o nascimento da criança. Foi categorizada em vaginal, cesárea e fórceps.

\section{3 - FONTE FINANCIADORA:}

Esta variável se refere à fonte pagadora da assistência utilizada na internação para o parto. Foi categorizada em SUS, Convênio de Saúde e Particular. Para algumas discussões, essa variável foi categorizada em:

$\checkmark$ pacientes atendidas pelo SUS

$\checkmark$ pacientes não SUS (convênios de saúde e particulares).

\section{4 - HOSPITAL DE NASCIMENTO:}

O tipo de hospital onde ocorreu o parto foi categorizado de acordo com a entidade mantenedora do hospital, sendo categorizado como:
$\checkmark$ público
$\checkmark$ privado
$\checkmark$ privado/conveniado com o SUS
$\checkmark$ filantrópico. 
Os hospitais privados/conveniados com o SUS foram agrupados ao hospital privado. A opção por esse agrupamento ocorreu devido ao caráter não público desses hospitais, ou seja, funcionam de acordo com a lógica de mercado.

\section{5 - INTERCORRÊNCIAS DURANTE A GESTAÇÃO:}

Foram relacionadas as patologias que ocorreram durante a gestação.

\section{6 - INTERCORRÊNCIAS DURANTE O TRABALHO DE PARTO E PARTO:}

Foram consideradas as intercorrências ocorridas durante o $1^{\circ}$ e $2^{\circ}$ períodos clínicos do parto.

As variáveis relacionadas foram analisadas tanto para os casos como para os controles, com exceção do ano e hospital onde ocorreu a morte, da idade da criança ao morrer e causa básica de morte, variáveis que foram estudadas somente para o grupo de casos.

\subsection{Análise de dados}

Utilizou-se o intervalo de confiança para definir a associação do fator de risco às mortes neonatais, considerando-se um valor de $\mathrm{p}$ menor que $0,05 \mathrm{e}$ intervalos de confiança de $95 \%$.

Após a definição dos fatores de risco significativos, calculou-se a "Odds Ratio" (OR), que é a razão de probabilidades de ocorrência e não-ocorrência de um evento, também denominada "razão dos produtos cruzados" (ROTHMAN 1987). Para tanto, foram confeccionadas tabelas $2 \times 2$, onde a variável de exposição é dicotomizada em casos e controles, como demonstrado abaixo: 
Tabela $2 \times 2$

\begin{tabular}{cc|ccc|c}
\multicolumn{2}{r|}{ Fator de Risco } & \multicolumn{3}{|c|}{ Efeito } & Total \\
\hline Exposição & + & $\mathrm{a}$ & - & \\
\hline & - & $\mathrm{c}$ & $\mathrm{b}$ & $\mathrm{a}+\mathrm{b}$ \\
& Total & $\mathrm{a}+\mathrm{c}$ & $\mathrm{d}$ & $\mathrm{c}+\mathrm{d}$ \\
\hline & & & $\mathrm{b}+\mathrm{d}$ & $\mathrm{N}$
\end{tabular}

Quando houve diferentes níveis de exposição a um fator de risco (Tabela $2 \times \mathrm{K}$ ), realizou-se um desdobramento desta tabela, utilizando-se uma categoria de referência com menor grau de exposição, de acordo com a literatura, para comparação com os demais níveis de exposição (CESAR 1989; MONTERO 2000).

Realizou-se a análise multivariada para verificar a existência de variáveis de confusão e definir aquelas que representam fatores de risco à mortalidade neonatal.

\subsection{Aspectos éticos}

$\mathrm{O}$ desenvolvimento do estudo atendeu aos requisitos da Resolução $\mathrm{N}^{\circ}$ 196/96 do Conselho Nacional de Saúde, tendo o projeto sido aprovado pelo Comitê de Ética em Pesquisa - COEP, da Faculdade de Saúde Pública da USP (Anexo 1) e, posteriormente, pelo Comitê Permanente de Ética em Pesquisa envolvendo Seres Humanos da Universidade Estadual de Maringá (Anexo 2).

Foram encaminhadas correspondências ao Secretário Municipal de Saúde e aos diretores clínicos dos hospitais de Maringá, contendo os objetivos da pesquisa e solicitando autorização para o acesso às fontes de dados (Anexo 3).

Todos os cuidados foram tomados para que a análise fosse feita para o conjunto dos dados, garantindo, dessa forma, a não-identificação de casos isolados. 
4. RESULTADOS E DISCUSSÃO 


\section{RESULTADOS E DISCUSSÃO}

\subsection{Caracterização dos óbitos}

Entre 1997 e 2000, 120 crianças nascidas em hospitais de Maringá, filhos de mães residentes, frutos de gestações únicas, faleceram nos primeiros 28 dias de vida (Tabela 2). Estes óbitos corresponderam a 67,4\% dos 178 óbitos neonatais registrados, segundo os dados oficiais, nos 4 anos estudados. A tabela 2 mostra as mortes por ano de ocorrência. Observa-se que estes eventos distribuíram-se de forma irregular, expressando coeficientes cujos valores variaram de 12,33 por mil NV a 8,46 por mil NV.

Tabela 2 - Distribuição do número de nascidos vivos, dos óbitos neonatais e coeficiente de mortalidade neonatal, filhos de mães residentes. Maringá-PR, 1997-2000.

\begin{tabular}{cccc}
\hline Ano & $\begin{array}{c}\mathbf{N}^{\circ} \text { de nascidos } \\
\text { vivos }\end{array}$ & $\mathrm{N}^{\circ}$ de óbitos & $\begin{array}{c}\text { CMI Neonatal } \\
\text { (por mil NV) }\end{array}$ \\
\hline 1997 & 4541 & 56 & 12,33 \\
1998 & 4493 & 38 & 8,46 \\
1999 & 4228 & 39 & 9,22 \\
2000 & 4404 & 45 & 10,22 \\
\hline TOTAL & 17666 & 178 & 10,08 \\
\hline
\end{tabular}

*Fonte: SINASC/SIM

Considerando a coorte de 13.501 nascimentos vivos ocorridos entre 1997 e 2000, da qual selecionou-se, após excluir os casos, a população de controles (conforme fluxograma apresentado nos procedimentos metodológicos), e os 120 óbitos ocorridos no período neonatal, é possível estimar uma probabilidade de morrer de 8,84 por mil NV. Este valor está abaixo do Coeficiente de Mortalidade Neonatal obtido a partir dos dados oficiais para o mesmo período, que foi de 10,08 por mil NV 
(Tabela 2). A diferença observada provavelmente decorre da diferença entre o cálculo de probabilidade e coeficiente (que considera todos os óbitos ocorridos no ano calendário) e, principalmente, da exclusão, no presente estudo, dos nascimentos com risco aumentado de morrer como as crianças nascidas de partos gemelares e aquelas cujos partos ocorreram fora do município. Conforme comentam CARVALHO e col. (1998), a procura por hospitais de outros municípios tem sido conseqüência da dificuldade de obter internação, pelo SUS, em hospitais de Maringá, os quais, apesar de contarem com elevado número de leitos obstétricos, têm colocado poucos à disposição do sistema público.

Relativamente aos 120 óbitos estudados, verifica-se na tabela 3 que, em concordância com o observado no conjunto das mortes de residentes, $o$ ano de 1997 concentrou $31,66 \%$ e, 1998 , com menores taxas, $19,16 \%$ das mortes do quadriênio.

Tabela 3 - Distribuição de casos segundo ano de ocorrência do óbito. Maringá-PR, 1997-2000.

\begin{tabular}{ccc}
\hline ANO & N $^{\text {o }}$ & $\%$ \\
\hline 1997 & 38 & 31,66 \\
1998 & 23 & 19,16 \\
1999 & 27 & 22,50 \\
2000 & 32 & 26,67 \\
\hline TOTAL & 120 & 100,00 \\
\hline
\end{tabular}

Quanto à distribuição dos óbitos por local de ocorrência (Tabela 4), observa-se que $65 \%$ das mortes estudadas ocorreram em dois dos 7 hospitais (B e C). Comparando-se os dados do local de nascimento e de óbito, verifica-se, em relação ao hospital B que, apesar de corresponder ao local de ocorrência de $28,33 \%$ dos óbitos, apenas $12,5 \%$ das crianças falecidas no período estudado nasceram nessa instituição, diferentemente dos hospitais D, F e G, cuja proporção de nascimentos é superior à de óbitos. O fato do hospital $\mathrm{C}$ responder por mais de $35 \%$ dos óbitos e nascimentos era esperado, tendo-se em vista tratar-se de hospital universitário, de 
caráter público, a colocar à disposição do SUS $100 \%$ dos 15 leitos existentes, sendo responsável pelo atendimento à saúde de mulheres economicamente desfavorecidas e, conseqüentemente, com maior risco de morte neonatal. Além disso, assim como o hospital B, conta com Unidade de Terapia Intensiva Neonatal - UTI neonatal, sendo a instituição de referência no município e região para atendimento às gestantes de alto risco.

Todos os óbitos ocorridos no hospital $\mathrm{E}$ referem-se a nascidos nesse mesmo local, o que indica não ter havido transferência de bebês, mesmo considerando-se que o hospital não dispõe de UTI neonatal. Em consulta à DO foi possível verificar que a maioria das crianças (4 casos) nasceu de parto prematuro, vindo a falecer nas primeiras horas de vida, expressando, em certa medida, a nãotransferência de crianças com risco aumentado de morrer após o nascimento para outro hospital com melhor organização tecnológica.

Tabela 4- Distribuição dos óbitos neonatais segundo local de nascimento e óbito. Maringá-PR, 1997-2000.

\begin{tabular}{ccccc}
\hline HOSPITAL & \multicolumn{2}{c}{ Local do Nascimento } & \multicolumn{2}{c}{ Local do óbito } \\
& No $^{\circ}$ & $\%$ & N $^{\circ}$ & $\%$ \\
\hline A & 1 & 0,83 & - & - \\
B & 15 & 12,50 & 34 & 28,33 \\
C & 42 & 35,00 & 44 & 36,67 \\
D & 5 & 4,17 & 3 & 2,50 \\
E & 6 & 5,00 & 6 & 5,00 \\
F & 24 & 20,00 & 16 & 13,33 \\
G & 27 & 22,50 & 17 & 14,17 \\
\hline TOTAL & 120 & 100,00 & 120 & 100,00 \\
\hline
\end{tabular}

A tabela 5 mostra a idade ao morrer. Constata-se que a maior parte dos óbitos (52,5\%) ocorreu no $1^{\circ}$ dia de vida, sendo, respectivamente, $36,5 \%$ e $16,0 \%$ na primeira e segunda hora. A proporção encontrada no estudo é bastante superior aos 35\% citados por REIS (2000) para o município de Diadema. Este 
resultado sugere uma boa qualidade dos dados, pois conforme destaca LEAL (1996), a probabilidade de sobrevivência aumenta com o passar dos dias e um ,baixo percentual de mortes no primeiro dia pode ser indicativo de subnotificação de óbitos neonatais, em especial, entre as pessoas em piores condições socioeconômicas, em relação às quais a classificação de uma criança que falece logo após o nascimento como natimortalidade nem sempre adquire a importância devida, seja por parte dos profissionais seja dos familiares.

Tabela 5 - Distribuição de casos segundo idade da criança ao morrer. Maringá - PR, 1997-2000.

\begin{tabular}{ccc}
\hline IDADE AO MORRER (dias) & $\mathrm{N}^{\circ}$ & $\%$ \\
\hline$<1$ & 63 & 52,50 \\
$1-6$ & 34 & 28,33 \\
$\geq 7$ & 23 & 19,17 \\
\hline TOTAL & 120 & 100,00 \\
\hline
\end{tabular}

Ilustram bem tal situação, conforme constatado em consulta ao prontuário, 3 casos de crianças nascidas vivas que vieram a falecer logo após o nascimento, onde se verificou que as informações registradas pela equipe eram contraditórias, ora sendo descritas como natimortas, ora como falecidas minutos após o nascimento. Estas contradições no registro em prontuário, fonte principal para outros documentos ou pesquisas, mostram o despreparo de alguns profissionais para a assistência neonatal, tendo conseqüências graves no tocante a condutas de atendimento e distorções nas estatísticas de saúde, como sub-registro de nascimento e óbito e super-registro de óbito fetal.

Não obstante, a comparação dos resultados do presente estudo aos do realizado no município em 1989 indica uma melhoria na situação de registro, haja vista o aumento no percentual de óbitos no primeiro dia que, conforme referido por SOUZA (1992), havia sido de $48 \%$ naquele ano. 
LEAL e SZWARCWALD (1996), em estudo sobre a mortalidade neonatal no Estado do Rio de Janeiro, no período de 1979 a 1996, concluíram que a estabilidade da mortalidade neonatal precoce e o discreto aumento nas primeiras horas após o parto estavam relacionados à baixa resolutividade dos programas de pré-natal, de atenção ao parto e ao recém-nascido.

A análise sobre as causas de morte levou em consideração as informações contidas nas declarações de óbito das crianças estudadas, uma vez que o registro em prontuário deste dado se mostrou precário. A codificação da causa básica de morte utilizada na DO é baseada na classificação internacional de doenças - CID 10 (OMS 1997).

Gráfico 1 - Distribuição de casos de óbitos segundo a causa básica da morte (Capítulos da CID -10) Maringá-PR, 1997-2000.

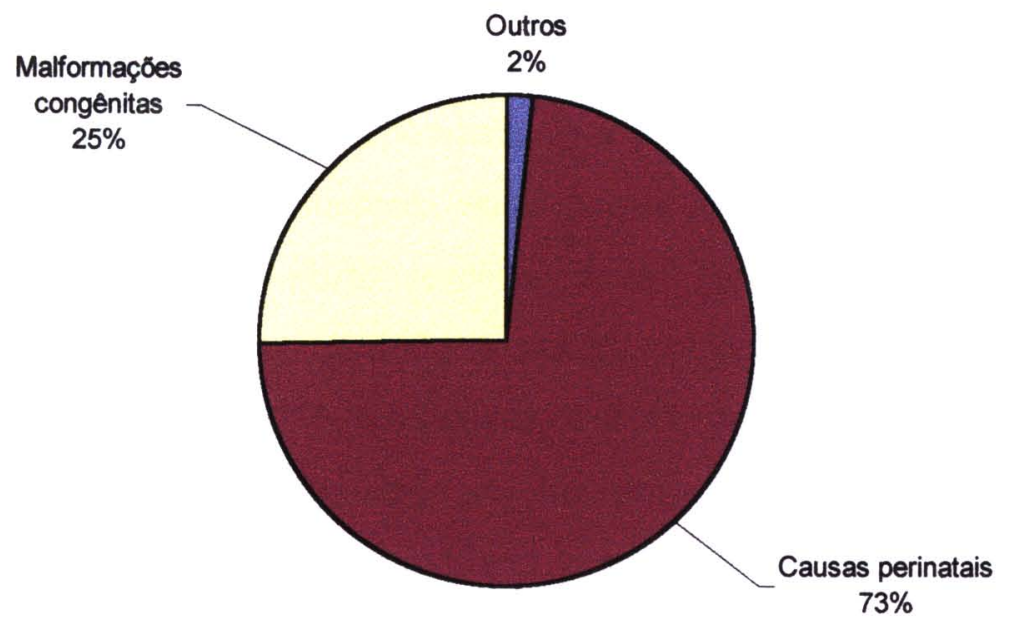

As mortes ocorridas no período neonatal foram devidas principalmente às afecções do período perinatal $(73,11 \%)$ e às malformações congênitas, deformidades e anomalias cromossômicas $(25,21 \%)$, assemelhando-se aos resultados obtidos para os anos de 1989 (SOUZA, 1992), 1990 (BERCINI, 1993) e 1995 (ISOLANI, 1997), anos nos quais as afecções do período perinatal responderam, respectivamente, por $83,3 \%, 83,2 \%$.e $70,0 \%$ e as anomalias congênitas por $15,3 \%, 10,8 \%$ e $18 \%$ da mortalidade infantil neonatal em Maringá. 
Os resultados obtidos são concordantes com estudos referentes a outras localidades nas quais as afeç̧ões originadas no período perinatal e as malformações vêm figurando como as principais causas básicas de morte neonatal, a exemplo dos municípios de Santo André e São Paulo, com percentuais bastante próximos (respectivamente, $81,8 \%$ e 10,9\%, em Santo André, $78,7 \%$ e 12,9\%, em São Paulo) (ALMEIDA, 1995; FERNANDES, 2002).

Especificamente em relação ao município de Maringá, vale ressaltar que o coeficiente de mortalidade neonatal por causas perinatais vem apresentando reduções importantes nos últimos anos. Ao estabelecer uma comparação com os valores referentes aos anos de 1989 e 2000 , verifica-se uma redução da ordem de $40,94 \%$, passando de 12,31 por mil NV (SOUZA 1992) para 7,27 por mil NV (MARINGÁ 2001a).

Ao estratificar os dados segundo agrupamentos da CID 10 (OMS, 1997), é possivel verificar que no grupo das afecções originadas no período perinatal, os transtornos respiratórios responderam por 63\% dos óbitos (Gráfico 2). Vale lembrar que estes transtornos incluem, entre outros problemas, hipóxia intrauterina, asfixia ao nascer, desconforto respiratório do recém-nascido e outras afecções respiratórias originadas no periodo perinatal, como hipoplasia pulmonar. Segundo MARANHÃO e col. (1999), esta causa de óbito neonatal figura entre as principais em todo o Brasil, destacando-se em primeiro lugar as afecções respiratórias, em que a síndrome do desconforto respiratório representa $25 \%$ das mortes. A ocorrência deste distúrbio está ligada à prematuridade e ao baixo peso ao nascer. 
Gráfico 2 - Distribuição de casos de óbitos por afecções originadas no período perinatal segundo agrupamentos da CID - 10. Maringá-PR, 1997-2000.

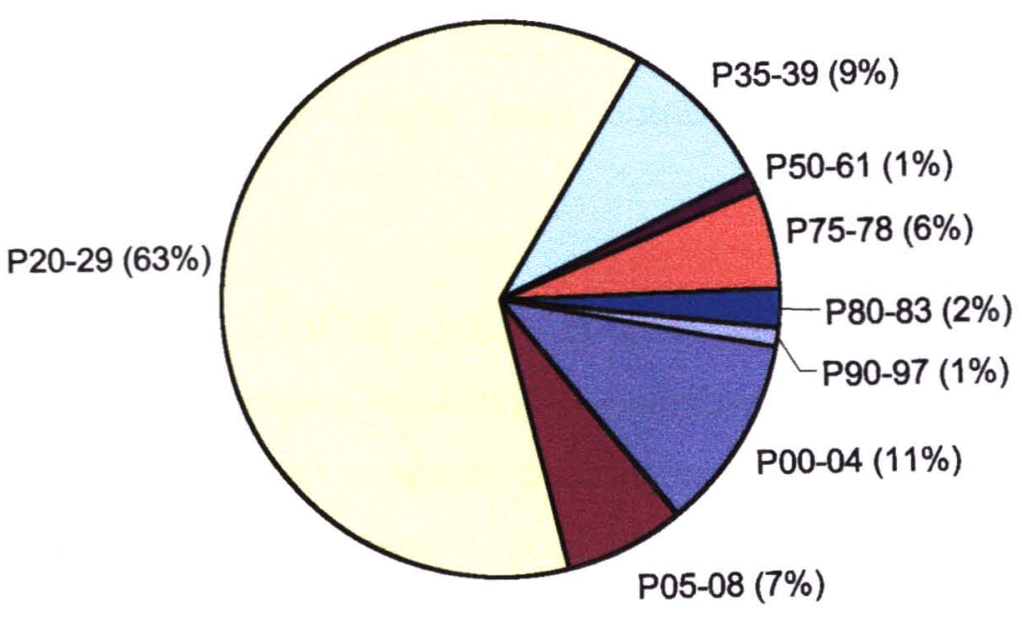

CAP. XVI (P00-P97) - ALGUMAS AFECÇÕES ORIGINADAS NO PERÍODO PERINATAL

P00-04 - Feto e recém-nascido afetados por fatores maternos e por complicações da gravidez, do trabalho de parto e do parto

P05-08 - Transtornos relacionados com a duração da gestação e com o crescimento fetal

P20-29 - Transtornos respiratórios e cardiovasculares específicos do período perinatal

P35-39 - Infecções específicas do período perinatal

P50-61 - Transtornos hemorrágicos e hematológicos do feto e do $\mathrm{RN}$

P75-78 - Transtornos do aparelho digestivo do feto e do recém-nascido

P80-83 - Afecções comprometendo o tegumento e a regulação térmica do feto e do $\mathrm{RN}$

P90-97 - Outros transtornos originados no período perinatal

Comparando-se com as informações contidas em prontuários, verificou-se que este grupo de causa básica, muitas vezes, está encobrindo outras causas ligadas a afecções maternas associadas diretamente ao risco de óbito neonatal, 
como rotura prematura de membranas, trabalho de parto prematuro, hemorragias da segunda metade da gravidez ou estados hipertensivos. GUILLAUMON E SEGRE (2002) lembram que os fatores maternos pré-concepcionais, da gravidez, do parto e do próprio $\mathrm{RN}$ estão interligados e, muitas vezes, afecções maternas como anemia crônica, infecção na gravidez, hemorragia, entre outras não são citadas nas declarações de óbito.

CARVALHO e SILVER (1995) também encontraram um alto percentual $(87 \%)$ de causas perinatais e, em estudo comparativo sobre a causa básica do óbito neonatal registrada na DO e aquela indicada no prontuário hospitalar, constataram no registro de prontuário maior peso das afecções e complicações maternas, complicações relacionadas com a placenta, cordão, trabalho de parto ou parto. Este resultado elevou em $58 \%$ o percentual de óbitos considerados "reduzíveis" pela classificação de mortalidade neonatal proposta pela Fundação SEADE. Os autores entendem que a precariedade de informações em prontuário, apesar de prejudicar a avaliação e a compreensão dos eventos que levaram à morte, ajuda a conhecer bem mais de perto os problemas relacionados à falta de adequação no cuidado perinatal e suas graves conseqüências em muitas situações.

No tocante à segunda maior causa entre as mortes neonatais do presente estudo, os agrupamentos mais freqüentes foram as malformações congênitas do sistema nervoso e do aparelho cardiocirculatório, ambas com $26,50 \%$, seguidas pelas malformações do aparelho digestivo (13\%) (Gráfico 3). 
Gráfico 3- Distribuição de casos de óbitos por malformações congênitas segundo agrupamentos da CID-10. Maringá-PR,1997-2000.

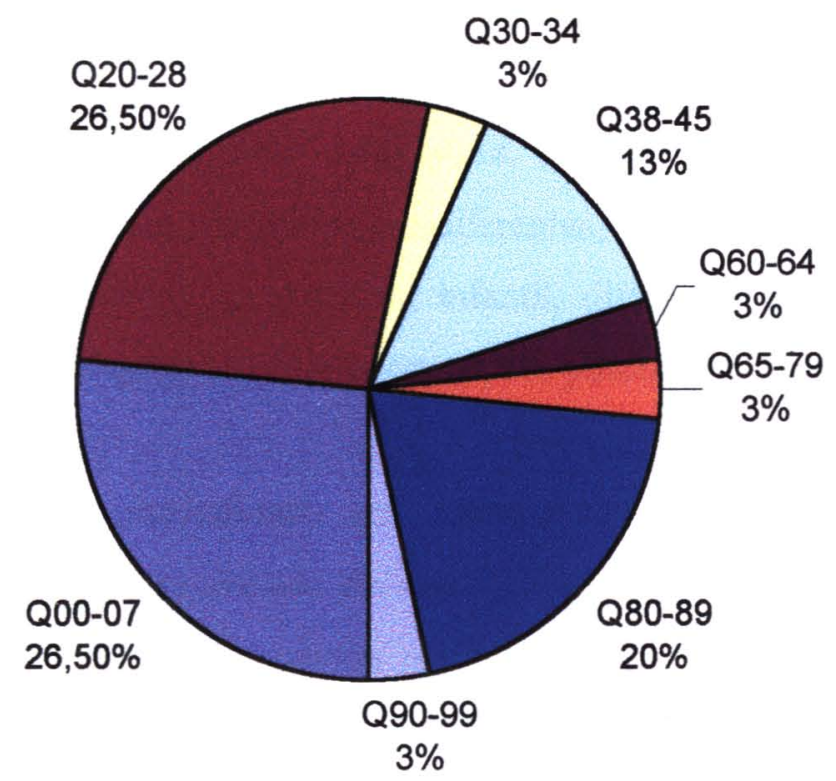

CAP. XVII (Q00-Q99): MALFORMAÇÕES CONGÊNITAS, DEFORMIDADES E ANOMALIAS CROMOSSÔMICAS

Q00-07 - Malformações congênitas do sistema nervoso

Q20-28 - Malformações congênitas do aparelho circulatório

Q30-34 - Malformações congênitas do aparelho respiratório

Q38-45 - Outras malformações congênitas do aparelho digestivo

Q60-64 - Malformações congênitas do aparelho urinário

Q65-79 Malformações congênitas e deformidades do aparelho osteomuscular Q80-89 - Outras malformações congênitas

Q90-99 - Anomalias cromossômicas, não classificadas em outra parte 
VICTORA (2001) comenta que as mortes conseqüentes às malformações são extremamente dificeis de prevenir e seu peso relativo tende a aumentar quando a mortalidade diminui.

Assim sendo, na atual conjuntura, para as malformações congênitas, que incluem vários problemas de etiologias diferentes, possíveis medidas não teriam impactos importantes sobre a mortalidade infantil, diferentemente das mortes por causas perinatais, para as quais existem intervenções potencialmente efetivas.

Embora a mortalidade em crianças venha se reduzindo, os níveis atuais são indicativos da necessidade de atuar sobre vários fatores que concorrem para a ocorrência das mortes por causas perinatais e que a identificação destes em distintas realidades irá possibilitar a implementação de medidas de maior potencial que assegurem a sobrevivência infantil (VICTORA, 2001).

A análise que se segue focaliza fatores relacionados às crianças, às mães e à assistência prestada durante o pré-natal e o parto que guardam relação com a mortalidade neonatal.

Ainda que as mortes neonatais devidas às anomalias congênitas tenham determinantes específicos, em relação às causas perinatais, no presente estudo não foram excluídas as 30 crianças que faleceram devido a esse grupo de causas, uma vez que se objetivou, inicialmente, a caracterização dos fatores de risco para o conjunto das mortes neonatais, a exemplo de várias outras investigações sobre o tema (FERNADES, 2002; MONTERO, 2000; ALMEIDA, 1995). 


\subsection{Características do recém-nascido}

\subsubsection{Sexo}

Entre as 120 crianças estudadas, que faleceram no período neonatal, predominaram as do sexo masculino $(66,67 \%)$, diferentemente dos controles, nos quais a distribuição de crianças por sexo foi praticamente a mesma, coincidindo com o que ocorre na população em geral (Tabela 6). A situação de nascimentos e óbitos reflete a sobremortalidade masculina observada em todas as faixas etárias. Conforme LAURENTI e col. (1987), a mortalidade masculina é sempre mais elevada em todas as idades.

Tabela 6 - Distribuição de casos e controles segundo sexo. Maringá-PR, 1997-2000.

\begin{tabular}{ccccc}
\hline SEXO & \multicolumn{2}{c}{ Caso } & \multicolumn{2}{c}{ Controle } \\
& $\mathrm{N}^{\circ}$ & $\%$ & $\mathrm{~N}^{\circ}$ & $\%$ \\
\hline Masculino & 80 & 66,67 & 122 & 50,83 \\
Feminino & 40 & 33,33 & 118 & 49,17 \\
\hline TOTAL & 120 & 100,00 & 240 & 100,00 \\
\hline
\end{tabular}

De acordo com PEREIRA (1995), em qualquer população humana são concebidos e nascem mais homens do que mulheres. Este autor explica que, em termos médios, a razão de masculinidade é de 115 na concepção, decrescendo para 105 ao nascimento, devido ao maior número de abortamentos e óbitos fetais do sexo masculino. Entre as explicações para esta diferença pode-se citar a de que a mulher seria biologicamente mais forte do que o homem, o que traduziria maiores taxas de mortalidade fetal, perinatal e infantil no sexo masculino. Teorias no campo genético sugerem a possibilidade de que no cromossomo $\mathrm{Y}$ haja um gene que seria desvantajoso neste sentido. Fatores humorais e imunológicos também permeiam a condição de maior fragilidade masculina. A razão de masculinidade do grupo 
controle foi de 103,4 sendo, ao contrário dos casos, um valor representativo da população total.

Segundo SEGRE (2002), o sexo masculino se encontra entre os fatores de risco para taquipnéia transitória e infecções como septicemia e meningite do RN.

Conforme os dados da Tabela 7, a variável sexo apresentou associação estatisticamente significativa com a mortalidade neonatal (OR de 1,93 [1,23 - 3,05]), corroborando as explicações dos autores referidos (LAURENTI e col. 1987; PEREIRA 1995; SEGRE 2002), que atribuem tal situação à maior vulnerabilidade dos conceptos e RNs do sexo masculino.

Tabela 7 - Número de casos e controles, OR e intervalo de confiança segundo sexo. Maringá-Pr, 1997-2000.

\begin{tabular}{cccccc}
\hline SEXO & Casos & Controles & OR & IC (95\%) & p \\
\hline Masculino & 80 & 122 & 1,93 & $1,23-3,05$ & 0,005 \\
Feminino & 40 & 118 & 1,00 & & \\
\hline TOTAL & 120 & 240 & & & \\
\hline
\end{tabular}

\subsubsection{Peso ao nascer}

Relativamente ao peso ao nascer, verifica-se na tabela 8 que $72,5 \%$ dos casos nasceram com peso abaixo de $2500 \mathrm{~g}$, considerado pela OMS como de baixo peso ao nascer (MELLO JORGE e col. 1992; OMS 1994; MELLO JORGE e GOTLIEB, 2000). Entre os controles, este percentual foi de apenas 5\%. Merece atenção o fato de $31,67 \%$ das crianças que faleceram terem pesado ao nascer menos de $1000 \mathrm{~g}$, com destaque para uma criança nascida com $300 \mathrm{~g}$, duas com $350 \mathrm{~g}$ e uma com $370 \mathrm{~g}$. Entre os casos, o peso médio foi de $1.743 \mathrm{~g}$, bem abaixo de $3.248 \mathrm{~g}$ 
observado entre as crianças que sobreviveram ao período. Estes resultados sugerem grande parcela de recém-nascidos prematuros no grupo de casos.

Tabela 8 - Distribuição de casos e controles segundo o peso ao nascer. Maringá-PR, 1997-2000.

\begin{tabular}{ccccc}
\hline PESO & \multicolumn{2}{c}{ Caso } & \multicolumn{2}{c}{ Controle } \\
(em gramas) & $\mathrm{N}^{\circ}$ & $\%$ & $\mathrm{~N}^{\circ}$ & $\%$ \\
\hline 300 a 499 & 5 & 4,17 & - & - \\
500 a 999 & 33 & 27,5 & - & - \\
1000 a 1499 & 22 & 18,33 & 1 & 0,42 \\
1500 a 1999 & 15 & 12,5 & - & - \\
2000 a 2499 & 11 & 9,17 & 5 & 2,08 \\
2500 a 2999 & 14 & 11,67 & 52 & 21,66 \\
3000 a 3499 & 13 & 10,83 & 115 & 47,92 \\
3500 a 3999 & 6 & 5,00 & 57 & 23,75 \\
4000 e mais & 1 & 0,83 & 10 & 4,17 \\
\hline TOTAL & 120 & 100,00 & 240 & 100,00 \\
\hline
\end{tabular}

O peso ao nascer tem sido considerado uma das principais medidas de predição da sobrevivência infantil. $\mathrm{O}$ aumento do risco de mortalidade para recémnascidos com baixo peso é referido em todos os estudos que analisam tal casuística (LAURENTI e BUCHALLA 1985; ALMEIDA e MELLO JORGE 1998; MENEZES e col. 1998; ARAÚJO 1999; FERNANDES 2002; GUILLAUMON e SEGRE 2002)).

É relevante a observação de que nos países desenvolvidos, embora cerca de $6 \%$ das crianças venham a nascer com baixo peso, a mortalidade infantil encontra-se próxima a 6 óbitos por mil NV (VICTORA 2001).

Os resultados da tabela 9 mostram uma associação estatisticamente significativa entre peso ao nascer e mortalidade neonatal em Maringá, com OR de 
$98,62[20,00$ - 243,11] na relação entre nascidos vivos com baixo peso relativamente a todos os demais nascimentos.

Tabela 9 - Número de casos e controles, OR e intervalo de confiança segundo peso ao nascer. Maringá-Pr, 1997-2000.

\begin{tabular}{cccccc}
\hline PESO & Casos & Controles & OR & IC (95\%) & p \\
\hline$<2500 \mathrm{~g}$ & 86 & 6 & 98,62 & $40,00-243,11$ & $<0,001$ \\
$\geq 2500 \mathrm{~g}$ & 34 & 234 & 1,00 & & \\
\hline TOTAL & 120 & 240 & & & \\
\hline
\end{tabular}

Ressalta-se que a prevalência de baixo peso ao nascer no município, em 2000, foi de 7,4\% (Maringá 2001a), sendo bastante próxima à referida por SOUZA (1992) em 1989 (7\%), demonstrando que há mais de uma década o município encontrava-se em situação semelhante à prevalência de 7,6\%, para 1996, mencionada por VICTORA (2001) para a Região Sul do país. Enfatiza o autor que, quando a prevalência é relativamente baixa, ou seja, próxima àquela de países desenvolvidos, que situa entre 4\% e 6\% (MONTEIRO e col. 2000), a prevenção de baixo peso ao nascer é tarefa difícil.

Além dos aspectos referidos, de acordo com MELLO JORGE e col. (1992), outra questão que se reveste de importância é a relação entre peso ao nascer e a idade gestacional, por possibilitar a avaliação da ocorrência da prematuridade, bem como do crescimento intra-uterino inadequado, que pode levar ao nascimento de baixo peso.

\subsubsection{Duração da gestação}

Segundo ROSELLI e SEGRE (2002), o conceito clássico de prematuridade baseava-se apenas no peso. A partir de 1970, após reavaliação, a OMS decide estabelecer como prematuro todo recém-nascido vivo que nasce antes da $37 .^{\mathrm{a}}$ 
semana de gestação. No presente estudo, $75 \%$ dos casos nasceram com menos de 37 semanas de gestação, com destaque para os $35 \%$ com menos de 28 semanas (Tabela 10), sugerindo tratar-se especialmente de partos prematuros que apresentaram elevado risco de morte no período neonatal.

De acordo com SEGRE (2002), nos dias de hoje há grande preocupação com os recém-nascidos pré-termo (RNPT) com $1.000 \mathrm{~g}$ ou menos, pois com o avanço tecnológico, ocorre cada vez mais a sobrevivência de crianças com pesos cada vez menores. Estes RNPT são denominados de RNs de muito muito baixo peso (RNMMBP), RNs de muitíssimo baixo peso, RNs de extremo baixo peso, de extrema prematuridade ou, ainda, de RNs "fetais". Lembra a autora que estas crianças podem apresentar problemas funcionais variados, dependendo da maior ou menor idade gestacional.

Tabela 10 - Distribuição do número e percentual de casos e controles segundo duração da gestação. Maringá-PR, 1997-2000.

\begin{tabular}{ccccc}
\hline $\begin{array}{c}\text { DURAÇÃ DA } \\
\text { GESTAÇÃO }\end{array}$ & \multicolumn{2}{c}{ Caso } & \multicolumn{2}{c}{ Controle } \\
(semanas) & $\mathrm{N}^{\circ}$ & $\%$ & $\mathrm{~N}^{\circ}$ & $\%$ \\
\hline 22 a 27 & 42 & 35,00 & - & \\
28 a 31 & 20 & 16,66 & 3 & 1,25 \\
32 a 36 & 27 & 22,50 & 23 & 9,58 \\
37 a 41 & 31 & 25,84 & 212 & 88,34 \\
42 e + & - & - & 2 & 0,83 \\
\hline TOTAL & 120 & 100,00 & 240 & 100,00 \\
\hline
\end{tabular}

COOPER e col. (1993), em seu estudo sobre a prematuridade como fator de risco para a mortalidade neonatal, verificaram que a duração da gestação era um preditor da mortalidade neonatal mais importante que o peso ao nascer para os RNs com idade gestacional inferior a 29 semanas. 
Conforme se aprecia na tabela 11 , o valor da OR obtido na relação entre os nascidos com menos de 37 semanas foi da ordem de 23,63 [13,27 - 42,07] comparativamente aos conceptos com idade gestacional a termo. Este resultado seria o esperado, pois à prematuridade associa-se um aumento da mortalidade em decorrência da imaturidade dos sistemas, com conseqüências nas funções gastrintestinais, renais, hepáticas, metabólicas, respiratórias, neurológicas, termoreguladoras, hematológicas, imunológicas e nutricionais do RN (ROSELLI e SEGRE 2002).

Tabela 11 - Número de casos e controles, OR e intervalo de confiança segundo duração da gestação. Maringá-PR, 1997-2000.

\begin{tabular}{cccccc}
\hline $\begin{array}{c}\text { DURAÇÃO DA } \\
\text { GESTAÇÃO } \\
\text { (semanas) }\end{array}$ & Casos & Controles & OR & IC (95\%) & p \\
\hline$<37$ & 89 & 26 & 23,63 & $13,27-42,07$ & $<0,001$ \\
$37 \mathrm{e}+$ & 31 & 214 & 1,00 & & \\
\hline TOTAL & 120 & 240 & & & \\
\hline
\end{tabular}

Além dos aspectos referentes à prematuridade, há que considerar os nascimentos com peso inferior a $2500 \mathrm{~g}$ com crescimento fetal inadequado, denominado pequeno para idade gestacional (PIG). A Tabela 12 mostra a relação entre peso e idade gestacional. Observa-se que entre os casos, das 30 crianças nascidas com 37 e mais semanas de gestação, $16,67 \%$ pesaram menos de $2500 \mathrm{~g}$, distintamente dos controles, entre os quais este percentual foi de apenas $0,46 \%$.

Na relação entre peso ao nascer e a idade gestacional, ARAÚJO (1999) verificou que os RNPIGs tiveram um risco de morrer 2,5 vezes maior do que os RNs com peso adequado para a idade gestacional (AIG), lembrando que os prematuros PIG foram o grupo de maior risco de morte neonatal. 
Tabela 12 - Distribuição de casos e controles, segundo peso ao nascer e duração da gestação. Maringá-PR, 1997-2000.

\begin{tabular}{ccccccc}
\hline DURAÇÃO DA & \multicolumn{2}{c}{$<2500 \mathrm{~g}$} & \multicolumn{2}{c}{$\geq 2500 \mathrm{~g}$} & \multicolumn{2}{c}{ TOTAL } \\
GESTAÇÃO & N. ${ }^{\circ}$ & $\%$ & N. $^{\circ}$ & $\%$ & N. $^{\circ}$ & $\%$ \\
\hline Caso & & & & & & \\
$<37$ sem & 80 & 89,89 & 9 & 10,11 & 89 & 100,00 \\
37 e mais & 6 & 19,36 & 25 & 80,64 & 31 & 100,00 \\
TOTAL & 86 & 71,67 & 34 & 28,33 & 120 & 100,00
\end{tabular}

\section{Controle}

$\begin{array}{crrrrrr}<37 \text { sem } & 4 & 15,38 & 22 & 84,62 & 26 & 100,00 \\ 37 \text { e mais } & 1 & 0,46 & 213 & 99,54 & 214 & 100,00 \\ \text { TOTAL } & 5 & 2,08 & 235 & 97,92 & 240 & 100,00\end{array}$

Dentre as razões que levam ao parto prematuro destacam-se as relacionadas aos fatores maternos (infecções), fetais, placentários (a hemorragia decidual e descolamento prematuro da placenta), iatrogênicos e "antecipação deliberada do parto" (LIPPI e col. 2002).

Assim, no presente estudo, uma investigação mais detalhada a partir da consulta aos prontuários, sobre as intercorrências no parto, permitiu verificar que, entre os casos, o trabalho de parto prematuro (TPP) esteve registrado em $24,17 \%$, seguido pela rotura prematura de membrana $(19,17 \%)$, descolamento prematuro da placenta (DPP) (8,34\%) e hemorragia (7,5\%). Relativamente aos controles, a freqüência de registro desta informação foi da ordem de 2,08\%; 8,33\%;0,42\% e $0,42 \%$, respectivamente (Quadro 1).Outras intercorrências importantes citadas no momento do parto, com proporções distintas para os casos e controles, foram o sofrimento fetal $(22,50 \%$ e $11,25 \%)$, a distocia de progressão $(0,83 \%$ e $10,42 \%)$ e a desproporção cefalopélvica. (DCP) (5\% e 9,17\%). 
Entre os casos que apresentaram sofrimento fetal, $89,28 \%$ nasceram de parto cesárea e os demais de parto vaginal. Entre os controles, este percentual foi de $81,48 \%$ para os RNs de parto cirúrgico e $18,52 \%$ para os de parto vaginal.

A avaliação da vitalidade ao nascer pelo boletim de Apgar, no $1^{\circ}$ minuto, para os três casos de sofrimento fetal e nascimento de parto vaginal, mostrou pontuação entre $0-3$. No $5^{\circ}$ minuto, os valores se tornaram favoráveis apenas para uma criança (Apgar 8), sendo que os demais permaneceram com Apgar entre 0 - 4 . Entre os casos que nasceram de parto operatório $80 \%$ apresentaram Apgar de 0-6, e os demais nasceram em boas condições (Apgar entre 7 e 9).

Entre as crianças do grupo controle que foram diagnosticadas com sofrimento fetal nascidas de parto vaginal, não houve resultados de Apgar inferiores a 6 no $1^{\circ}$ minuto, pois os escores se apresentaram no intervalo de 8 a 10 . No $5^{\circ}$ minuto, todos os Apgar foram registrados com a nota máxima. Para os RNs de parto cesárea, os escores de $8-10$ do Apgar no $1^{\circ}$ minuto tiveram elevada representatividade $(81,81 \%)$ e no $5^{\circ}$ minuto esse percentual aumentou para $90,91 \%$.

O diagnóstico de sofrimento fetal é bastante complexo. MARIANI NETO (2002) enfatiza que a cardiotocografia anteparto pode ser utilizada como método propedêutico de rastreamento para avaliação da vitalidade fetal durante a gestação. Explica que esse exame identifica os fetos não comprometidos do ponto de vista de oxigenação, não indicando, necessariamente, a presença de hipóxia fetal. Porém, ressalta a importância dessa monitorização anteparto e exemplifica estudo realizado em maternidade do município de São Paulo, onde foram observadas diferenças importantes nos neonatos acompanhados e seus registros realizados até sete dias antes do parto, quanto ao índice de Apgar $<7$ no $1^{\circ}$ e $5^{\circ}$ minutos, à ocorrência de restrição de crescimento intra-uterino e à mortalidade perinatal não corrigida.

A desproporção cefalopélvica e a distocia de progressão dependem de acompanhamento criterioso para serem diagnosticadas, sendo possível detectá-las 
precocemente, impedindo que sejam causas diretas de sofrimento fetal e posterior óbito neonatal. Dessa maneira, a assistência à gestante, em nível ambulatorial e na internação para o parto, deve contemplar exames e avaliação permanente para a identificação precoce dos problemas de saúde materno-fetais e intervenção adequada. Essa medida exige o preparo e a dedicação constante de profissionais da área junto à população-alvo.

Quadro 1.' Intercorrências durante o trabalho de parto e parto dos casos e controles, registradas em prontuários. Maringá-PR, 1997-2000.

\begin{tabular}{|c|c|c|c|c|}
\hline \multirow{2}{*}{$\begin{array}{l}\text { INTERCORRÊNCIAS DURANTE } \\
\text { TRABALHO DE PARTO E PARTO }\end{array}$} & \multicolumn{2}{|c|}{ Caso } & \multicolumn{2}{|c|}{ Controle } \\
\hline & $\mathrm{N} .^{\circ}$ & $\%$ & N. ${ }^{\circ}$ & $\%$ \\
\hline Trabalho de parto prematuro & 29 & 24,17 & 5 & 2,08 \\
\hline Sofrimento fetal & 27 & 22,50 & 27 & 11,25 \\
\hline Rotura prematura de membranas & 23 & 19,17 & 20 & 8,33 \\
\hline Distocia de progressão & 1 & 0,83 & 25 & 10,42 \\
\hline Descolamento prematuro da placenta & 10 & 8,34 & 1 & 0,42 \\
\hline Hemorragia & 9 & 7,50 & 1 & 0,42 \\
\hline Desproporção cefalopélvica & 6 & 5,00 & 22 & 9,17 \\
\hline DHEG + Hipertensão arterial & 6 & 5,00 & 4 & 1,67 \\
\hline Apresentação pélvica & 5 & 4,17 & 3 & 1,25 \\
\hline Circular de cordão & 3 & 2,50 & 6 & 2,50 \\
\hline Expulsivo prolongado & 3 & 2,50 & 3 & 1,25 \\
\hline Retenção placentária & 2 & 1,17 & - & - \\
\hline Diabetes & 2 & 1,17 & - & - \\
\hline Outros & 3 & 2,50 & 1 & 0,42 \\
\hline Sem registro & 5 & 4,17 & 130 & 54,16 \\
\hline
\end{tabular}

Entre as intercorrências da gestação, as infecções maternas, mais especificamente as urogenitais, figuraram em $4,17 \%$ dos prontuários dos casos. Este percentual foi menor entre os controles $(1,25 \%)$. 
A situação descrita sugere que a redução da mortalidade neonatal em Maringá passa, necessariamente, pela redução dos partos prematuros, identificação das gestantes de risco e acompanhamento pré-natal e ao parto adequado às necessidades dessa clientela.

Como salientam LIPPI e col. (2002), a melhor estratégia de prevenção do trabalho de parto prematuro é uma assistência pré-natal adequada e hierarquizada, ou seja, em nível primário para controlar os fatores de risco; secundário para cuidados especiais a gestantes de risco elevado, e terciário, que abrange o tratamento do trabalho de parto logo após seu início. E, ainda, conforme CARVALHO e SILVER (1995), o investimento na melhoria da qualidade da informação, seja da DO ou prontuário dos serviços de saúde é medida indispensável para a melhoria da atenção e prevenção do trabalho de parto prematuro.

\subsection{3 Índice de Apgar}

O boletim de Apgar foi concebido em 1953 pela Dra.Virgínia Apgar (APGAR 1953), anestesista preocupada com a assistência ao RN na sala de parto. Consta de uma escala de avaliação das condições do $\mathrm{RN}$ ao nascer e indica os procedimentos necessários nos primeiros minutos de vida (GUILLAUMON e SEGRE 2002).

Este boletim é adotado como rotina pelos profissionais da saúde de Maringá que prestam os cuidados imediatos ao $\mathrm{RN}$ em sala de parto. Nos prontuários consultados, o índice de Apgar no $1^{\circ}$ e $5^{\circ}$ minuto de vida constava na maioria das fichas de registro do atendimento do RN na sala de parto dos hospitais. Por isso optou-se pelos dados do prontuário.

Entre os casos, verifica-se que o Apgar no $1^{\circ}$ minuto teve percentual mais elevado nas categorias de $\mathrm{RN}$ gravemente anoxiados (escores entre 0 e 3) e com 
anóxia moderada (escores entre 4 e 7$)(52,54 \%$ e $26,27 \%)$ relativamente aos controles $(2,09 \%$ e $2,91 \%$, respectivamente $)$.

No $5^{\circ}$ minuto, a grande maioria dos RNs sobreviventes $(99,17 \%)$ encontrava-se em boas condições de vitalidade, opostamente ao grupo de casos em que apenas 38,13\% encontrava-se nessas condições (Tabela 13). O Apgar no $5^{\circ}$ minuto denota a real gravidade do estado de saúde do $\mathrm{RN}$, sendo que no grupo de casos $61,87 \%$ das crianças nasceram em más condições ou com anóxia neonatal moderada (Tabela 14).

Tabela 13 - Distribuição do número e percentual de casos e controles segundo índice de Apgar no $1^{\circ}$ minuto. Maringá -PR, 1997-2000.

\begin{tabular}{ccccc}
\hline $\begin{array}{c}\text { APGAR NO } 1^{\circ} \\
\text { MINUTO }\end{array}$ & $\mathrm{N}^{\circ}$ & $\%$ & $\mathrm{~N}^{\circ}$ & $\%$ \\
\hline $0-3$ & 62 & 52,54 & 5 & 2,09 \\
$4-6$ & 31 & 26,27 & 7 & 2,91 \\
$7-10$ & 25 & 21,19 & 228 & 95,00 \\
\hline TOTAL & 118 & 100,00 & 240 & 100,00 \\
\hline
\end{tabular}

Nota: excluídos 2 casos por falta de informação.

Tabela 14 - Distribuição do número e percentual de casos e controles segundo índice de Apgar no $5^{\circ}$ minuto. Maringá -PR, 1997-2000.

\begin{tabular}{ccccc}
\hline $\begin{array}{c}\text { APGAR NO } 5^{\circ} \\
\text { MINUTO }\end{array}$ & N $^{\text {C }}$ & $\%$ & $\mathrm{~N}^{\circ}$ & $\%$ \\
\hline $0-3$ & 45 & 38,13 & - & - \\
$4-6$ & 28 & 23,74 & 2 & 0,83 \\
$7-10$ & 45 & 38,13 & 238 & 99,17 \\
\hline TOTAL & 118 & 100,00 & 240 & 100,00
\end{tabular}

Nota: Excluídos 2 casos por falta de informação.

A ocorrência de baixo peso e imaturidade pode ter influenciado o predomínio de Apgar baixo nos casos e, por conseqüência, os elevados valores da 
OR no $1 .^{\circ}$ minuto, com notável aumento no $5 .^{\circ}$ minuto, de 70,68 e 193,00, respectivamente, ambas estatisticamente significativas (Tabelas 15 e 16).

Tabela 15 - Número de casos e controles, OR, intervalo de confiança segundo Apgar no $1^{\circ}$ minuto. Maringá-PR, 1997-2000.

\begin{tabular}{cccccc}
\hline APGAR $1^{\circ}$ & Casos & Controles & OR & IC (95\%) & p \\
\hline Até 6 & 93 & 12 & 70,68 & $34,08-146,57$ & $<0,001$ \\
$7-10$ & 25 & 228 & 1,00 & & \\
\hline TOTAL & 118 & 240 & & & \\
\hline
\end{tabular}

Nota: excluídos 2 casos por falta de informação.

Tabela 16 - Número de casos e controles, OR, intervalo de confiança segundo Apgar no $5^{\circ}$ minuto. Maringá-PR, 1997-2000.

\begin{tabular}{cccccc}
\hline APGAR 5 $^{\circ}$ & Casos & Controles & OR & IC (95\%) & p \\
\hline $0-6$ & 73 & 2 & 193,00 & $45,71-814,83$ & $<0,001$ \\
$7-10$ & 45 & 238 & 1,00 & & \\
\hline TOTAL & 118 & 240 & & & \\
\hline
\end{tabular}

Nota: excluídos 2 casos por falta de informação.

Tal fato pode ser constatado ao comparar os dados referentes à distribuição das crianças, segundo valores de Apgar no $1^{\circ}$ e $5^{\circ}$ minuto, apresentados nas tabelas 13 e 14 . Verifica-se que, entre os controles, no $1^{\circ}$ minuto, 12 crianças foram classificadas com escores abaixo de 7 . Todavia, no $5^{\circ}$ minuto, verificou-se resposta favorável ao meio extra-uterino e apenas 2 crianças mantiveram-se em moderadas condições de vitalidade (Apgar de 4 a 6). Especificamente em relação a essas crianças, constatou-se que uma é filha de mãe em idade reprodutiva ótima (25 anos), com baixa escolaridade, que se internou pelo SUS, com idade gestacional de 40 semanas. O Apgar de 3, no $1^{\circ}$ minuto, passou para 6 , no $5^{\circ}$ minuto. Esses valores do Apgar podem ter sido decorrentes do sofrimento fetal agudo, conforme registrado no prontuário. Quanto à outra criança, observou-se presença de vários fatores de risco a dificultar a sobrevivência infantil, como: prematuridade (35 semanas), baixo 
peso ao nascer, filho de mãe adolescente, que se internou pelo SUS e apresentou como intercorrência a rotura prematura de membranas, tendo o feto apresentado sofrimento agudo.

Situação bastante diferente ocorreu entre os que faleceram. Conforme tabela 17, entre os casos, cujos valores de Apgar no $1^{\circ}$ minuto foram inferiores a 4 , predominaram os nascimentos prematuros $(87,10 \%)$. Das 54 crianças prematuras, com Apgar de 0 a 3, 55,55\%, tratava-se de conceptos com 22 a 27 semanas, 18,52\% de 28 a 31 semanas e $25,92 \%$ de 32 a 36 semanas.

Tabela 17. Distribuição dos casos segundo Apgar no $1^{\circ}$ minuto e duração da gestação. Maringá-PR, 1997-2000.

\begin{tabular}{cccccccccc}
\hline $\begin{array}{c}\text { DURAÇÃO DA } \\
\text { GESTAÇÃO }\end{array}$ & \multicolumn{2}{c}{0 a 3} & \multicolumn{2}{c}{4 a 6} & \multicolumn{2}{c}{7 a 10} & \multicolumn{2}{c}{ TOTAL } \\
(em semanas) & $N^{\circ}$ & $\%$ & No & $\%$ & $N^{\circ}$ & $\%$ & $N^{\circ}$ & $\%$ \\
\hline 22 a 27 & 30 & 48,39 & 6 & 19,35 & 4 & 16,00 & 40 & 33,90 \\
28 a 31 & 10 & 16,13 & 6 & 19,35 & 4 & 16,00 & 20 & 16,95 \\
32 a 36 & 13 & 20,97 & 10 & 32,26 & 4 & 16,00 & 27 & 22,88 \\
37 e mais & 9 & 14,51 & 9 & 29,04 & 13 & 52,00 & 31 & 26,27 \\
\hline TOTAL & 62 & 100,00 & 31 & 100,00 & 25 & 100,00 & 118 & 100,00
\end{tabular}

Nota: excluídos 2 casos por falta de informação.

Relativamente aos 87 nascimentos prematuros que faleceram, 12 nasceram em boas condições, de acordo com os valores do Apgar no $1^{\circ}$ minuto (Tabela 17). Ao considerar os valores no $5^{\circ}$ minuto (Tabela 18), o percentual passa de $13,79 \%$ para $29,88 \%$, insinuando que se trata de crianças que poderiam vir a sobreviver caso recebessem adequada assistência, principalmente de cuidados intensivos nas primeiras horas de vida. Vale ressaltar que o município conta com apenas 6 leitos de UTI neonatal, no hospital público, e 8 leitos pediátricos no hospital filantrópico que disponibiliza parte dos leitos ao atendimento neonatal. 
Tabela 18. Distribuição dos casos segundo Apgar no $5^{\circ}$ minuto e duração da gestação. Maringá-PR, 1997-2000.

\begin{tabular}{cccccccccc}
\hline $\begin{array}{c}\text { DURAÇÃO DA } \\
\text { GESTAÇÃO }\end{array}$ & \multicolumn{2}{c}{0 a 3} & \multicolumn{2}{c}{4 a 6} & \multicolumn{2}{c}{7 a 10} & \multicolumn{2}{c}{ TOTAL } \\
(em semanas) & N. ${ }^{\circ}$ & $\%$ & N..$^{\circ}$ & $\%$ & N..$^{\circ}$ & $\%$ & N. ${ }^{\circ}$ & $\%$ \\
\hline 22 a 27 & 22 & 48,89 & 11 & 39,28 & 7 & 15,55 & 40 & 33,90 \\
28 a 31 & 5 & 11,11 & 7 & 25,00 & 8 & 17,78 & 20 & 16,95 \\
32 a 36 & 12 & 26,67 & 4 & 14,28 & 11 & 24,44 & 27 & 22,88 \\
37 e mais & 6 & 13,33 & 6 & 21,43 & 19 & 42,22 & 31 & 26,27 \\
\hline TOTAL & 45 & 100,00 & 28 & 100,00 & 45 & 100,00 & 118 & 100,00
\end{tabular}

Nota: excluídos 2 casos por falta de informação.

$\mathrm{Na}$ tabela 18, ainda, chama a atenção o fato de 19 crianças que nasceram com idade gestacional superior a 36 semanas e avaliados com Apgar de 7 a 10 , no $5^{\circ}$ minuto, terem vindo a falecer, sugerindo necessidade de melhor conhecer as características dessas crianças, bem como a condição da assistência prestada ao recém-nascido na sala de parto. É essencial investir na capacitação de profissionais para manobras de reanimação e a intervenção nas complicações como medidas de prevenção da mortalidade neonatal (GUILLAUMON e SEGRE 2002).

\subsection{Características maternas}

\subsubsection{Idade}

Um indicador bastante importante para a detecção do risco gravídico é a idade da mãe (BARROS e col 1987; LIPPI e col. 1989). No presente estudo, a média e a mediana das idades das mães dos casos foi de 25,54 e 21 anos, respectivamente, e dos controles, de 26,7 e 28 anos, respectivamente. Observa-se que as médias de idade materna foram semelhantes nos dois grupos, porém o valor mediano revela que metade das mães das crianças que faleceram tinham 21 anos ou menos, ou seja, bem mais jovens do que as das crianças sobreviventes. 
A tabela 19 mostra o conjunto de nascimentos do estudo segundo a idade materna. A faixa etária que compreendeu maior proporção dos nascimentos entre casos e controles foi aquela entre 20 e 34 anos, considerada como fase reprodutiva ótima. Observa-se ainda que $19,17 \%$ das mães das crianças que faleceram no período neonatal tinham menos de 20 anos, sendo que, destas, uma era "menina" de 13 anos.

Tabela 19 - Distribuição de casos e controles segundo idade materna. Maringá -PR, 1997-2000.

\begin{tabular}{ccccc}
\hline IDADE & \multicolumn{2}{c}{ Caso } & \multicolumn{2}{c}{ Controle } \\
MATERNA & $N^{\circ}$ & $\%$ & $N^{\circ}$ & $\%$ \\
\hline 13 a 14 & 1 & 0,83 & 1 & 0,41 \\
15 a 19 & 22 & 18,33 & 26 & 10,83 \\
20 a 24 & 41 & 34,17 & 55 & 22,92 \\
25 a 29 & 20 & 16,67 & 88 & 36,67 \\
30 a 34 & 22 & 18,33 & 53 & 22,08 \\
35 a 39 & 11 & 9,17 & 13 & 5,43 \\
40 a 44 & 2 & 1,67 & 3 & 1,25 \\
45 e mais & 1 & 0,83 & 1 & 0,41 \\
\hline TOTAL & 120 & 100,00 & 240 & 100,00 \\
\hline
\end{tabular}

A idade materna é um fator importante na determinação da condição nutricional, porque engloba uma série de eventos adversos que vão se acumulando à medida que a mãe apresenta mais idade e/ou maior número de gestações (NOBREGA e col. 1991).

Segundo WESSEL e col. (1996); NÓBREGA e col. (1991), as mães adolescentes não apresentam ainda uma formação orgânica para permitir a nutrição adequada da criança. Por estarem em fase de crescimento ou adequação corpórea, pressupõe-se que não tenham um suporte nutricional adequado para uma gestação, 
acarretando danos nos resultados gestacionais, com nascimentos prematuros ou crianças com malformações congênitas.

WESSEL e col. (1996) observaram em seu estudo que as mulheres que tinham idade menor ou igual a 19 anos apresentavam um risco 3 vezes maior a ter crianças com baixo peso ao nascer, e este risco aumentava para as mulheres nulíparas e também para aquelas que já tinham antecedentes obstétricos de baixo peso ao nascer. FERRAZ e col.(1990) verificaram que, entre mães jovens, o risco de ocorrência de partos prematuros estava significativamente aumentado. Além de maiores taxas desses eventos em adolescentes grávidas estudadas por GALLO e col. (2000), no ano de 1995, foi constatado menor número de consultas de pré-natal em relação às mulheres adultas.

Tendo por categoria de referência a faixa etária entre 20 e 34 anos, observou-se que as mulheres com idade inferior a 20 anos apresentaram um risco aumentado de óbitos neonatais (OR de 2,01 [1,09 - 3,71]). Associação estatisticamente significativa não foi observada quando comparado o grupo cujas mães tinham idade reprodutiva ótima com o das mulheres com 35 anos e mais (OR de $1,94[0,92-4,13])$ (Tabela 20).

Tabela 20 - Número de casos e controles, OR e intervalo de confiança segundo idade materna. Maringá-PR, 1997-2000.

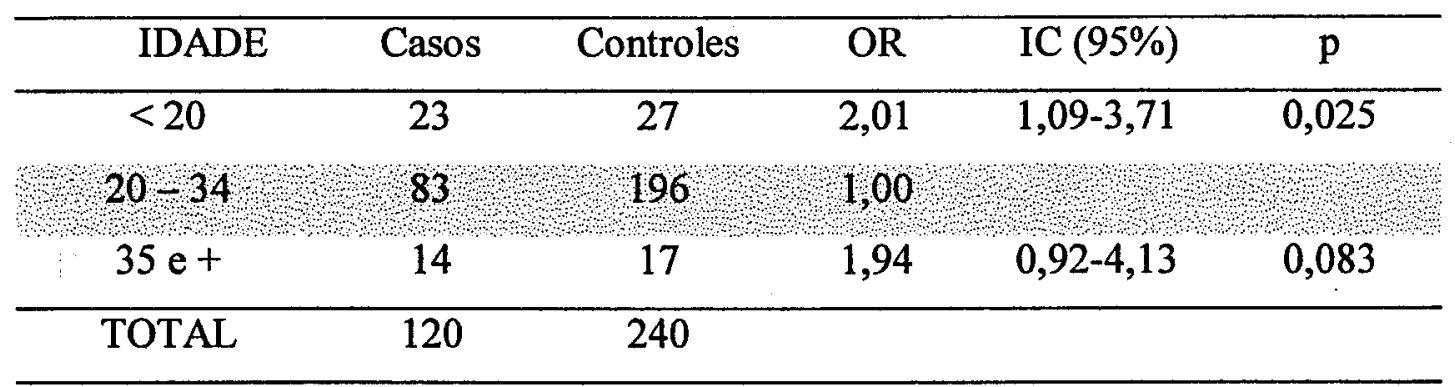

Apesar de a gestação na adolescência ser referida como fator de risco para a mortalidade neonatal, o risco pode estar aumentado ou confundido por fatores presentes nessa faixa etária como a condição socioeconômica desfavorável, procura 
tardia da assistência pré-natal, o desconhecimento dos riscos advindos da gestação em adolescentes e também a escolaridade, entre outros que podem influenciar na morbimortalidade neonatal (FERRAZ 1990; BURGOS e CARREÑO RIMAUDO 1997). Possivelmente, ao se controlarem variáveis de confusão, como renda e escolaridade, o comportamento reprodutivo dessas mulheres torna-se satisfatório. Essa associação adolescência/resultados desfavoráveis tem sido registrada com maior força para gestantes de menos de 15 anos (UZCÁTEGUI 1997).

\subsubsection{Escolaridade}

A correlação entre escolaridade materna e indicadores obstétricos foi estudada por HAIDAR, OLIVEIRA e NASCIMENTO (2001), onde o menor grau de instrução apresentou-se significativamente associado com baixo peso ao nascer, maior número de partos e menor frequeência ao pré-natal. Estes autores lembram que a associação significativa da menor escolaridade com a mortalidade perinatal, neonatal e infantil pode ser decorrente também da menor condição social e do acesso mais difícil aos serviços de saúde.

A tabela 21 mostra a distribuição de casos e controles segundo escolaridade materna. Observa-se que $50,83 \%$ das mães das crianças falecidas no período neonatal não chegaram a ingressar no segundo grau. Este percentual foi de $40,75 \%$ entre os controles.

Em estudo sobre a mortalidade neonatal, em São Paulo, realizado por MONTERO (2000), utilizando metodologia semelhante, constatou-se uma maior frequêencia de casos e controles na categoria de $1^{\circ}$ grau incompleto, ocorrendo um predomínio de controles nas categorias superiores ao $1^{\circ}$ grau incompleto. 
Tabela 21 - Distribuição de casos e controles segundo a escolaridade materna.

Maringá-PR, 1997-2000.

\begin{tabular}{ccccc}
\hline ESCOLARIDADE & \multicolumn{2}{c}{ Caso } & \multicolumn{2}{c}{ Controle } \\
& $\mathrm{N}^{\circ}$ & $\%$ & $\mathrm{~N}^{\circ}$ & $\%$ \\
\hline Nenhuma & - & - & 3 & 1,26 \\
$1^{\circ}$ grau incompleto & 39 & 32,50 & 72 & 30,25 \\
$1^{\circ}$ grau completo & 22 & 18,33 & 22 & 9,24 \\
$2^{\circ}$ grau & 40 & 33,33 & 92 & 38,65 \\
Superior & 19 & 15,83 & 49 & 20,59 \\
\hline TOTAL & 120 & 100,00 & 238 & 100,00 \\
\hline
\end{tabular}

Nota: excluídos 2 controles por falta de informação.

As crianças cujas mães cursaram até o primeiro grau completo apresentaram um risco $50 \%$ maior de óbito neonatal do que aquelas com escolaridade mínima equivalente ao ingresso no segundo grau, porém a associação não foi estatisticamente significativa (OR de 1,50 [0,94-2,39]) (Tabela 22).

Tabela 22 - Número de casos e controles, OR, e intervalo de confiança segundo escolaridade materna. Maringá-PR, 1997-2000.

\begin{tabular}{cccccc}
\hline ESCOLARIDADE & Casos & Controles & OR & IC (95\%) & p \\
\hline Até $1^{\circ}$ grau & 61 & 97 & 1,50 & $0,94-2,39$ & 0,069 \\
$2^{\circ}$ grau e superior & 59 & 141 & 1,00 & & \\
\hline TOTAL & 120 & 238 & & &
\end{tabular}

Nota: excluídos 2 controles por falta de informação.

Segundo MONTEIRO (1988), o uso da variável escolaridade na estratificação dos resultados não implica atribuir papel hegemônico na determinação do estado de saúde de um indivíduo, mas no nível de conhecimento formal, a escolaridade está indicando um conjunto de dados referentes à saúde do indivíduo, podendo ser considerada marcador da situação socioeconômica de uma população. 
MORAES e SOUZA (1996) referem que maior acesso às informações divulgadas pelos meios de comunicação mantém o indivíduo mais ativo e também mais participante, favorecendo o exercício da cidadania. No campo específico da saúde, a alfabetização torna o indivíduo mais sensível às ações de educação sanitária e é possível que os níveis crescentes de escolaridade atuem como fatores protetores, devido à assimilação de informações sobre as diferentes alternativas disponíveis para a assistência à saúde e normas individuais de conduta saudável.

No presente estudo observou-se que, apesar da importância da variável, esta não é valorizada para fins de registro pelos profissionais que prestam assistência hospitalar ou incluída no cadastro da parturiente no momento da internação. Conforme apresentado na tabela 1, em apenas 37,5\% dos casos e $21,25 \%$ dos controles a anotação constava nos prontuários consultados. Este percentual diferiu sobremaneira entre os hospitais, destacando-se o hospital público, no qual, via de regra, o registro desta variável constava nas anotações de enfermagem. Salienta-se que geralmente o item escolaridade no prontuário é preenchido às pressas pelo funcionário que presta atendimento na sala de parto para cumprir uma tarefa predeterminada.

Todavia, os resultados obtidos na população de estudo, relativamente ao maior percentual de mães sem nenhuma escolaridade entre os controles, sugerem cautela na interpretação desses dados, que pode ser uma casualidade devida ao pequeno número de eventos analisados, mas recomendam estudos posteriores para averiguar a confiabilidade desse dado nas DNs. Tal questão reveste-se de importância, principalmente ao considerar-se que, quando da concepção da $\mathrm{DN}$, pretendia-se, a partir da análise desse dado, destacar a participação das condições sócio-econômicas na determinação da sobrevivência infantil, elegendo o grau de instrução por ser de mais fácil obtenção (MELLO JORGE e col. 1992). 


\subsubsection{Estado conjugal}

Tradicionalmente, em estudos epidemiológicos, a condição conjugal tem sido considerada uma importante variável a explicar diferentes taxas de ocorrência de agravos à saúde, face aos comportamentos distintos de acordo com a situação conjugal. O critério adotado pelo IBGE para a designação estado conjugal inclui em uma mesma categoria os que vivem em companhia do cônjuge em decorrência do casamento ou união consensual (PEREIRA 1995).

No caso das gestantes, o estado conjugal é uma condição que pode ter influência na evolução gravídica, e a ausência de companheiro pode acarretar dificuldades para a grávida, por constituir o apoio emocional e financeiro importante fator a influenciar a vivência satisfatória da gestação. Na população de estudo, a condição de solteira foi referida com maior frequência entre os casos $(25,8 \%)$ do que entre os controles $(17,92 \%)$, assim como de separada (respectivamente, $3,33 \%$ e 0,83\%) (Tabela 23).

Tabela 23 - Distribuição de casos e controles segundo estado conjugal. Maringá-PR, 1997-2000.

\begin{tabular}{ccccc}
\hline ESTADO CONJUGAL & \multicolumn{2}{c}{ Caso } & \multicolumn{2}{c}{ Controle } \\
& $\mathrm{N}^{\circ}$ & $\%$ & $\mathrm{~N}^{\circ}$ & $\%$ \\
\hline Solteira & 31 & 25,83 & 43 & 17,92 \\
Casada & 85 & 70,84 & 195 & 81,25 \\
Separada & 4 & 3,33 & 2 & 0,83 \\
\hline TOTAL & 120 & 100,00 & 240 & 100,00 \\
\hline
\end{tabular}

A variável condição conjugal foi agrupada em duas categorias, ou seja, com companheiro e sem companheiro. No presente estudo, não foi verificada uma associação estatisticamente significativa, porém foi constatado risco aumentado de morte entre as crianças cujas mães se encontravam sem companheiro. Supõe-se 
que estas mulheres não contavam com o apoio de um companheiro (OR de 1,78 [1,07 - 2,97]) (Tabela 24) e, conseqüentemente, se encontram em condições muitas vezes desfavoráveis, uma vez que, segundo LIPPI (2002) e SIQUEIRA (1994), essa variável social guarda relação com mortalidade perinatal.

Tabela 24 - Número de casos e controles, OR e intervalo de confiança segundo estado conjugal. Maringá-PR, 1997-2000.

\begin{tabular}{cccccc}
\hline ESTADO CONJUGAL & Casos & Controles & OR & IC(95\%) & p \\
\hline Sem companheiro & 35 & 45 & 1,78 & $1,07-2,97$ & 0,026 \\
Com companheiro & 85 & 195 & 1,00 & & \\
\hline TOTAL & 120 & 240 & & & \\
\hline
\end{tabular}

\subsection{Características da Assistência Pré-natal e ao Parto}

\subsubsection{Número de consultas de pré-natal}

De forma geral, o número de consultas de pré-natal realizadas pela gestante não foi registrado no prontuário da parturiente. Assim, a maior parte dos dados em relação a esta variável foi coletada da DN e analisada considerando-se as categorias estabelecidas nessa fonte. Entre os casos, 10,26\% realizaram até 3 consultas médicas durante o pré-natal, percentual um pouco menor em relação ao controle (14,7\%). Estes valores estão bem acima dos 4,2\% divulgados na Agenda Municipal de Saúde - (MARINGÁ 2002a), tendo por base os dados preliminares, referentes ao ano de 2001, do SINASC. Chama a atenção ainda o fato de mais da metade das mães das crianças que correspondem aos casos de óbito $(50,42 \%)$ ter realizado 7 ou mais consultas, percentual bem superior aos $24,37 \%$ observado entre os controles (Tabela 25). 
Tabela 25 - Distribuição de casos e controles segundo o número de consultas prénatais. Maringá-PR, 1997-2000.

\begin{tabular}{ccccc}
\hline $\begin{array}{c}\text { CONSULTAS DE PRÉ- } \\
\text { NATAL }\end{array}$ & \multicolumn{2}{c}{ Caso } & \multicolumn{2}{c}{ Controle } \\
No & $\%$ & $\mathrm{~N}^{\circ}$ & $\%$ \\
\hline Nenhuma & 6 & 5,13 & 2 & 0,84 \\
Até 3 & 6 & 5,13 & 33 & 13,86 \\
$4-6$ & 46 & 39,32 & 145 & 60,93 \\
7 e mais & 59 & 50,42 & 58 & 24,37 \\
\hline TOTAL & 117 & 100,00 & 238 & 100,00 \\
\hline
\end{tabular}

Nota: excluídos 3 casos e 2 controles por falta de informação.

Estudo realizado por SAPATA (1999), em uma das 21 Unidades Básicas de Saúde do município, revelou que, de todas as gestantes inscritas em 1997, $47,3 \%$ haviam realizado 7 ou mais consultas médicas durante o periodo gestacional, com uma concentração média de 6,6 consultas médicas.

Ao se estabelecer o número de 7 e mais consultas como categoria de referência observou-se no estudo que as crianças cujas mães realizaram entre 4 e 6 consultas estavam mais protegidas (OR de $0,31[0,19-0,51]$ ) sendo tal proteção, estatisticamente significativa, verificada também no grupo de crianças no qual as mães realizaram até 3 consultas (OR de 0,34 [0,16-0,71]) (Tabela 26).

Tabela 26 - Número de casos e controles, OR e intervalo de confiança segundo número de consultas de pré-natal. Maringá - PR, 1997-2000.

\begin{tabular}{|c|c|c|c|c|c|}
\hline $\mathrm{N}^{\circ}$ CONSULTAS & Casos & Controles & OR & IC (95\%) & $\mathrm{p}$ \\
\hline Até 3 & 12 & 35 & 0,34 & $0,16-0,71$ & 0,004 \\
\hline $4-6$ & 46 & 145 & 0,31 & $0,19-0,51$ & $<0,001$ \\
\hline $7 \mathrm{e}+$ & 59 & 58 & 1,00 & & \\
\hline TOTAL & 117 & 238 & & & \\
\hline
\end{tabular}

Nota: foram excluídos 3 casos e 2 controles cuja informação é desconhecida. 
VICTORA (2001), após revisão, destaca que $4,9 \%$ das mães da Região Sul do Brasil não freqüentaram nenhuma consulta pré-natal, sendo o número médio de consultas de 8,3 por gestante. Além disso, as mães com menos de cinco consultas apresentaram um risco 2,5 vezes maior do que as demais. Estes estudos, realizados em diferentes locais, revelam associação protetora da maior frequêencia à atenção pré-natal, diferindo da observada no presente estudo, o que recomenda cautela na análise dos dados obtidos, pois podem estar indicando, a exemplo do comentado no caso da escolaridade, confiabilidade questionável do dado referente ao número de consultas de pré-natal constante na DN que, geralmente por depender da memória, pode não expressar com exatidão a freqüência da assistência recebida, principalmente entre as mulheres cujas crianças foram a óbito, para as quais, provavelmente, o fornecimento da informação reveste-se de pouca importância. Vale lembrar, ainda, que a informação desta variável em prontuário é coletada por membros da equipe multiprofissional e em diferentes ocasiões e, quando registrada, consta até mesmo na ficha de atendimento do $\mathrm{RN}$ em sala de parto.

Corrobora tais questões a situação descrita por BERCINI (1993), que ao pretender utilizar os prontuários hospitalares, encontrou dificuldade na coleta de dados devido a letra ilegível e descrição sucinta sobre a gestação, o parto e as condições do nascimento. Essa situação pode estar refletindo a qualidade dos serviços prestados, pois a omissão de registro, bem como a não-confiabilidade dos dados que este contém, constitui indicativo da qualidade da assistência.

$\mathrm{Na}$ organização da assistência pré-natal devem ser valorizados não somente os procedimentos técnicos realizados à gestante, mas também o atendimento dos aspectos emocionais distintos que essa clientela vivencia. Esse enfoque depende do compromisso profissional da equipe responsável pela assistência, o que aumentaria a adesão das mulheres ao pré-natal, reduzindo, dessa maneira, os índices de mortalidade materna e perinatal no país (MINISTÉRIO DA SAÚDE 2000a). Segundo recomendação de especialistas do MS, o intervalo entre as consultas deve ser de quatro semanas e, após a $36^{\mathrm{a}}$ semana de gestação, a cada 15 dias. Preferencialmente, o pré-natal deve ser iniciado no $1^{\circ}$ trimestre da gravidez. 
SCOCHI (1996), avaliando a assistência pré-natal no município, observou uma concentração média de consultas médicas bastante superior ao recomendado, pois $80 \%$ das mulheres entrevistadas verbalizaram receber mais de seis consultas, das quais $38 \%$ ultrapassaram dez consultas, sugerindo uma superutilização da rede de atendimento pré-natal. Ressalta ainda que, embora a expansão dos serviços de saúde de Maringá tenha propiciado maior acesso da população aos mesmos, não é o serviço que tenta captar a população de gestantes para o acompanhamento sistemático, mas a valorização da gestante pelo pré-natal é que tem motivado a busca da atenção. Afirma que a postura adotada pelo serviço vem refletindo na baixa cobertura de gestantes nas unidades de saúde da rede municipal.

No tocante à satisfação revelou que as gestantes que realizaram prénatal nas unidades básicas de saúde ficaram moderadamente satisfeitas. Porém, destaca os aspectos negativos, como o tempo de espera prolongado e a descontinuidade do cuidado, no momento do parto. Já entre as que receberam atendimento nas clínicas privadas a satisfação foi maior (SCOCHI 1996).

Nos anos recentes, a implantação do Programa Saúde da Família no município de Maringá, provavelmente, tem propiciado o aumento da cobertura, todavia a identificação de gestantes pelas equipes ainda está bastante abaixo do esperado. Em estudo realizado por SCALASSARA e col. (2002), verificou-se que a identificação das gestantes residentes nas áreas abrangidas pelo programa (aproximadamente $70 \%$ da população do município) situa-se abaixo de $50 \%$.

Todas as questões abordadas reforçam a idéia de que o impacto da atenção pré-natal na mortalidade neonatal ultrapassa assegurar determinado número de consultas, mas passa necessariamente pela melhoria do acesso/cobertura e da qualidade dos serviços oferecidos, primordialmente pela rede pública. 


\subsubsection{Tipo de parto}

A tabela 27 refere-se ao tipo de parto. A proporção de cesarianas foi mais elevada na população de controles $(76,25 \%)$ do que entre os casos $(58,34 \%)$. Para BETTIOL e col. (1998), o aumento importante na proporção de cesáreas é preocupante, uma vez que essa intervenção, teoricamente, deveria ser reservada para situações de risco para a mãe e/ou feto.

Tabela 27 - Distribuição de casos e controles segundo tipo de parto. Maringá-PR, 1997-2000.

\begin{tabular}{ccccc}
\hline TIPO DE PARTO & \multicolumn{2}{c}{ Caso } & \multicolumn{2}{c}{ Controle } \\
& $\mathrm{N}^{\circ}$ & $\%$ & $\mathrm{~N}^{\circ}$ & $\%$ \\
\hline Normal & 50 & 41,67 & 57 & 23,75 \\
Cesárea & 70 & 58,33 & 183 & 76,25 \\
\hline TOTAL & 120 & 100,00 & 240 & 100,00 \\
\hline
\end{tabular}

As indicações clínicas mais freqüentes citadas por SAKALA (1993) para realização de cesáreas são as distocias, desproporção cefalopélvica, prematuridade, gemelaridade, restrição do crescimento intra-uterino, muito baixo ou elevado peso ao nascer. Essa autora sugere uma proporção de cesáreas, para os países industrializados, em torno de 6 a $16,5 \%$.

O coeficiente de cesarianas no Brasil é um dos mais elevados do mundo, alcançando $36,4 \%$ do total de partos, enquanto que a OMS recomenda índice não superior a $15 \%$. VENTURA (1998) comprovou a possibilidade de redução gradativa na taxa de cesáreas em maternidade pública universitária da cidade de São Paulo, por meio de auditoria interna que avaliou com maior precisão as indicações clínicas de cesárea e obteve queda de $31,8 \%$ para $28,4 \%$, sem prejuizo à saúde da mãe ou do RN. 
Altos coeficientes de cesariana indicam que muitas dessas cirurgias são voluntárias, e erros no cálculo da idade gestacional podem levar a partos prematuros. Paradoxalmente, tem-se constatado que os coeficientes de cesariana são mais baixos para gestantes de alto risco, e mesmo com a presença de coeficientes elevados, gestantes de alto risco podem ainda fazer menos cesarianas do que necessitariam (VICTORA, 2001). É bastante provável que a situação descrita explique os resultados obtidos no presente estudo, pois as crianças nascidas de cesarianas mostraram-se mais protegidas do que as nascidas de parto normal (OR de $0,44[0,27-0,69])$ (Tabela 28).

Esse resultado parece indicar que o parto normal é risco para mortalidade neonatal, porém é necessário lembrar as características das mulheres que se submetem ao parto normal e a influência no acesso à escolha do tipo de parto (OMS 1986). Investigação anterior, conduzida no município por SOUZA (1992), já revelava risco $75 \%$ superior de morte infantil entre as crianças nascidas de parto normal. Ressaltava a autora que a alta incidência de cesárea, superior a $70 \%$ em 1989, associada a maior mortalidade em crianças nascidas de parto normal; apontava existência de distorção na assistência ao parto. Em seu estudo sobre freqüência de cesáreas em Maringá, SILVA (1997) também aponta inadequação na assistência ao parto e distorções na organização dos serviços de saúde.

Tabela 28-Número de casos e controles, OR e intervalo de confiança segundo tipo de parto. Maringá-Pr, 1997-2000.

\begin{tabular}{cccccc}
\hline TIPO DE PARTO & Casos & Controles & OR & IC (95\%) & p \\
\hline Cesárea & 70 & 183 & 0,44 & $0,27-0,69$ & 0,001 \\
Normal & 50 & 57 & 1,00 & & \\
\hline TOTAL & 120 & 240 & & & \\
\hline
\end{tabular}

A estratificação de dados segundo peso ao nascer mostra que, entre as crianças com baixo peso, embora estatisticamente não significativa a cesárea é fator de proteção para a mortalidade neonatal (OR de $0,46[0,05-3,12]$ ), contrariamente ao 
verificado entre as crianças nascidas com peso superior a $2500 \mathrm{~g}$, para as quais, conforme dados da tabela 29, a cesariana aumenta o risco de morrer (OR de 1,78 $[0,62-5,53])$.

Tabela 29 - Número de casos e controles, OR e intervalo de confiança segundo peso ao nascer e tipo de parto. Maringá-Pr, 1997-2000.

$<2500 \mathrm{~g}$

\begin{tabular}{cccccc}
\hline TIPO DE PARTO & Casos & Controles & OR & IC (95\%) & p \\
\hline Cesárea & 41 & 4 & 0,46 & $0,05-3,12$ & 0,429 \\
Normal & 45 & 2 & 1,00 & & \\
\hline TOTAL & 86 & 6 & & & \\
\hline
\end{tabular}

$\geq 2500 \mathrm{~g}$

\begin{tabular}{cccccc}
\hline TIPO DE PARTO & Casos & Controles & OR & IC (95\%) & $\mathrm{p}$ \\
\hline Cesárea & 29 & 179 & 1.78 & $0,62-5,53$ & 0,352 \\
Normal & 5 & 55 & 1 & & \\
\hline TOTAL & 34 & 234 & & & \\
\hline
\end{tabular}

A mesma situação observa-se para a idade gestacional. Entre as crianças com idade gestacional inferior a 37 semanas, embora estatisticamente não significativo, a associação entre o tipo de parto e mortalidade neonatal se confirmou, apresentando-se as cesarianas como fator de proteção para nascimentos pré-termo (OR de 0,$42 ;[0,15-1,15]$ ) e fator de risco para as crianças cuja idade gestacional era igual ou superior a 37 semanas (OR de $1,49[0,51-4,71]$ ). Tais resultados sugerem que conceptos ainda imaturos vieram a nascer antecipadamente, provavelmente em decorrência no erro de cálculo da idade gestacional (Tabela 30). 
Tabela 30 - Número de casos e controles, OR e intervalo de confiança segundo duração da gestação e tipo de parto. Maringá-Pr, 1997-2000.

$<37$ semanas

\begin{tabular}{cccccc}
\hline TIPO DE PARTO & Casos & Controles & OR & IC (95\%) & p \\
\hline Cesárea & 45 & 19 & 0,42 & $0,15-1,15$ & 0,100 \\
Normal & 45 & 8 & 1,00 & & \\
\hline TOTAL & 90 & 27 & & & \\
\hline
\end{tabular}

$\geq 37$ semanas

\begin{tabular}{cccccc}
\hline TIPO DE PARTO & Casos & Controles & OR & IC (95\%) & $p$ \\
\hline Cesárea & 25 & 164 & 1,49 & $0,51-4,71$ & 0,584 \\
Normal & 5 & 49 & 1,00 & & \\
\hline TOTAL & 30 & 213 & & & \\
\hline
\end{tabular}

\subsubsection{Fonte financiadora e hospital de nascimento}

O estudo da fonte financiadora e do tipo de hospital de nascimento permite conhecer a realidade da demanda por internações do ponto de vista do sistema de saúde, podendo também ser um recurso analítico importante utilizado para evidenciar as possíveis desigualdades socioeconômicas da clientela.

A tabela 31 permite constatar que $47,5 \%$ das mulheres mães de crianças que faleceram no período neonatal tiveram o parto financiado pelo SUS, percentual que foi de $31,25 \%$ entre as crianças sobreviventes. Esta participação do financiamento público na assistência ao parto é bastante distinta da observada no município em 1989 , ano no qual mais de $80 \%$ dos partos haviam sido cobertos pelo sistema oficial. 
Tabela 31 - Distribuição de casos e controles segundo fonte financiadora. MaringáPR, 1997-2000.

\begin{tabular}{ccccc}
\hline FONTE FINANCIADORA & \multicolumn{2}{c}{ Caso } & \multicolumn{2}{c}{ Controle } \\
& $\mathrm{N}^{\circ}$ & $\%$ & $\mathrm{~N}^{\circ}$ & $\%$ \\
\hline SUS & 57 & 47,50 & 75 & 31,25 \\
Não SUS & 63 & 52,50 & 165 & 68,75 \\
\hline TOTAL & 120 & 100,00 & 240 & 100,00 \\
\hline
\end{tabular}

Conforme dados da tabela 32 , as crianças cujas mães internaram-se para o parto pelo SUS apresentaram risco aumentado de morrer no período neonatal (OR de 1,99 [1,27-3,12]). Ao considerar as crianças cujas mães tiveram o parto financiado por Plano de Saúde como categoria de referência (Tabela 33) verificou-se que na relação SUS/Plano de Saúde o valor da OR foi de 1,94 [1,14-3,28], revelando maior risco de morrer entre as crianças cujos partos foram pelo SUS. Em contrapartida, na relação particular/Plano de Saúde, embora estatisticamente não significativa, os filhos de mães que se internaram como particulares estavam mais protegidos (OR de 0,92 [0,48-1,78]). Tais diferenças, por si sós, já dão idéia da possibilidade de inferir que as mulheres cujas crianças morreram no período neonatal vêm de camadas sociais inferiores e, por isso, apresentaram maiores riscos e dificuldades no atendimento ao parto.

Todavia, na atualidade, a fonte de financiamento mostra-se insuficiente e há que se discutir estes resultados conjuntamente com o tipo de hospital. Conforme comentam YAZLLE-ROCHA e col. (1999), há fortes indícios de que se implantou uma divisão de tarefas entre o sistema público e o privado, onde o papel do primeiro é "suportar a carga maior para viabilizar o segundo". Esta divisão de tarefas seria concretizada pela seleção das clientelas e mecanismos de transferência, de casos não rentáveis, ao SUS, levando a uma seletividade negativa para os hospitais públicos, que gradualmente passaram a acolher os mais carentes financeiramente, portadores de casos mais complexos e de assistência mais custosa. 
Tabela 32 - Número de casos e controles, OR e intervalo de confiança segundo fonte financiadora. Maringá-PR, 1997-2000.

\begin{tabular}{cccccc}
\hline FONTE FINANCIADORA & Casos & Controles & OR & IC(95\%) & p \\
\hline SUS & 57 & 75 & 1,99 & $1,27-3,12$ & 0,003 \\
Não SUS & 63 & 165 & 1,00 & & \\
\hline TOTAL & 120 & 240 & & & \\
\hline
\end{tabular}

Tabela $33^{\prime}$ - Número de casos e controles, OR e intervalo de confiança segundo fonte financiadora. Maringá-PR, 1997-2000.

\begin{tabular}{|c|c|c|c|c|c|}
\hline FONTE FINANCIADORA & Casos & Controles & OR & $\mathrm{IC}(95 \%)$ & $\mathrm{p}$ \\
\hline SUS & 57 & 75 & 1,94 & $1,14-3,28$ & 0,012 \\
\hline Plano de Saude & 42 & 107 & 1,00 & & \\
\hline Particular & 21 & 58 & 0,92 & $0,48-1,78$ & 0,918 \\
\hline TOTAL & 120 & 240 & & & \\
\hline
\end{tabular}

Assim, no caso da assistência ao parto, é bastante provável que exista a seleção pelos hospitais privados, dada a sua lógica distinta do público, de gestantes do SUS que não apresentam risco aumentado de intercorrências antes, durante e após o parto. Relativamente aos hospitais de Maringá, é importante salientar que, com exceção de um, que permite internações apenas por planos de saúde e pagamento particular, todos os demais estão credenciados ao SUS - Sistema Único de Saúde, prestando atendimento à gestante e parturiente por meio deste sistema de financiamento e, também de convênios de saúde ou internações particulares.

O local de nascimento permitiu conhecer como as parturientes se distribuíram nos hospitais do município, no periodo estudado, e qual a contribuição de cada um no atendimento ao parto.

$\mathrm{Na}$ tabela 34 observa-se que, entre os casos, $35,83 \%$ dos nascimentos ocorreram no Hospital Universitário, única instituição pública do município que 
presta assistência ao parto. O mesmo não ocorreu entre os controles, sendo que a participação do setor público como local de nascimentos foi de apenas $15 \%$.

Tabela 34 - Distribuição de casos e controles segundo hospital de nascimento. Maringá-PR, 1997-2000.

\begin{tabular}{ccccc}
\hline HOSPITAL DE & \multicolumn{2}{c}{ Caso } & \multicolumn{2}{c}{ Controle } \\
NASCIMENTO & N. & $\%$ & N. & $\%$ \\
\hline Público & 43 & 35,83 & 37 & 15,42 \\
Privado & 62 & 51,67 & 161 & 67,08 \\
Filantrópico & 15 & 12,50 & 42 & 17,50 \\
\hline TOTAL & 120 & 100,00 & 240 & 100,00 \\
\hline
\end{tabular}

A Tabela 35 mostra que a associação entre o tipo de hospital de nascimento e o óbito neonatal foi estatisticamente significativa e as crianças nascidas no hospital público estavam expostas a maior risco de falecer no período neonatal do que as nascidas em outros hospitais do município (OR de 3,06 [1,78-5,28]). Sabe-se que a clientela que demanda livremente os hospitais privados, conveniados ou não com o SUS, pagam o atendimento com recursos próprios ou pelo plano de saúde adotado e são pessoas com padrão socioeconômico mais elevado.

Ao considerar o hospital filantrópico como uma categoria da variável hospital de nascimento e o hospital privado como categoria referência, observou-se que as crianças nascidas nessa instituição estavam mais protegidas que as do hospital privado. Entretanto, esta diferença não foi estatisticamente significativa (OR de 0,93 $[0,45-1,87]$ ) (Tabela 36). 
Tabela 35 - Número de casos e controles, OR e intervalo de confiança segundo hospital de nascimento. Maringá-PR, 1997-2000.

\begin{tabular}{cccccc}
\hline $\begin{array}{c}\text { HOSPITAL DE } \\
\text { NASCIMENTO }\end{array}$ & Casos & Controles & OR & IC (95\%) & $\mathrm{p}$ \\
\hline $\begin{array}{c}\text { Público } \\
\text { Privado e } \\
\text { Filantrópico }\end{array}$ & 43 & 37 & 3,06 & $1,78-5,28$ & $<0,001$ \\
\hline TOTAL & 77 & 203 & 1,00 & & \\
\hline
\end{tabular}

Tabela 36 - Número de casos e controles, OR e intervalo de confiança segundo hospital de nascimento. Maringá-PR, 1997-2000.

\begin{tabular}{ccccccc}
\hline $\begin{array}{c}\text { HOSPITAL DE } \\
\text { NASCIMENTO }\end{array}$ & Casos & Controles & OR & IC (95\%) & p \\
\hline Público & 43 & 37 & 3,02 & $1,72-5,30$ & $<0,001$ \\
\hline $\begin{array}{c}\text { Privado } \\
\text { Filantrópico }\end{array}$ & 62 & 161 & 1,00 & & & \\
\hline TOTAL & 15 & 42 & 0,93 & $0,45-1,87$ & 0,954 \\
\hline & 120 & 240 & & & \\
\hline
\end{tabular}

Vale destacar que, desde 1999, esse serviço mantém convênio de cooperação técnica e financeira com a Secretaria de Saúde do município oferecendo 21 leitos para o atendimento às parturientes do SUS. Ressalta-se que a celebração do referido convênio foi motivada pela evasão de gestantes para assistência ao parto devido à dificuldade de internação na rede privada do município. Entre 1997 e 2000, as internações de parturientes residentes em hospitais fora de Maringá foram de 21,63\%, 24,84\%, 21,22\% e 16,95\% para cada ano do período (MARINGÁ 2001c). Destaca-se o ano de 1998, quando o percentual foi maior.

Em estudo realizado por SOUZA e col. (1999), no qual foram analisados todos os 4464 nascimentos vivos ocorridos em 1998, constataram-se expressivas diferenças entre os nascidos no Hospital Universitário (HU) e aqueles nascidos nos demais hospitais do município. Concluem os autores que as 714 crianças (16\%) nascidas no HU apresentaram maior percentual de fatores que 
constituem risco de morte no periodo neonatal, com destaque para $21 \%$ de baixo peso, $31 \%$ de mães com menos de 20 anos, $17 \%$ de crianças com idade gestacional inferior a 37 semanas e $40 \%$ que realizaram menos de 6 consultas de pré-natal. Estes valores foram bastante distintos dos observados entre os nascidos em outros hospitais do município, que foram, respectivamente, $7 \%, 10 \%, 6 \%$ e $13 \%$.

Resultados assim obtidos corroboram a necessidade de analisar a mortalidade neonatal à luz de variáveis sensiveis à seletividade exercida pelos hospitais. No presente estudo, ao analisar os nascimentos pelo SUS estratificados segundo tipo de hospital e idade gestacional, observa-se que entre 45 casos prétermo, 77,78\% nasceram no hospital público. Este percentual foi mais elevado entre as crianças com idade gestacional entre 22 a 27 semanas $(85,71 \%$ ) (Tabela 37 ).

Tabela 37 - Distribuição de casos e controles internados por ocasião do nascimento pelo SUS, segundo tipo de hospital e idade gestacional menor que 37 semanas. Maringá-PR, 1997-2000.

\begin{tabular}{|c|c|c|c|c|c|c|}
\hline \multirow{3}{*}{$\begin{array}{c}\text { DURAÇÃO DA } \\
\text { GESTAÇÃO } \\
\text { (semanas) }\end{array}$} & \multicolumn{4}{|c|}{ TIPO DE HOSPITAL } & & \\
\hline & \multicolumn{2}{|c|}{ Público } & \multicolumn{2}{|c|}{ Privado } & \multicolumn{2}{|c|}{ TOTAL } \\
\hline & $\mathrm{N} .^{\circ}$ & $\%$ & N. ${ }^{\circ}$ & $\%$ & N.o & $\%$ \\
\hline \multicolumn{7}{|l|}{ Caso } \\
\hline 22 a 27 & 18 & 85.71 & 3 & 14.29 & 21 & 100,00 \\
\hline 28 a 31 & 4 & 50.00 & 4 & 50.00 & 8 & 100,00 \\
\hline 32 a 36 & 13 & 81.25 & 3 & 18.75 & 16 & 100,00 \\
\hline TOTAL & 35 & 77.78 & 10 & 22.22 & 45 & 100,00 \\
\hline \multicolumn{7}{|l|}{ Controle } \\
\hline 22 a 27 & & - & & - & & - \\
\hline 28 a 31 & 1 & 50.00 & 1 & 50.00 & 2 & 100,00 \\
\hline 32 a 36 & 5 & 71.43 & 2 & 28.57 & 7 & 100,00 \\
\hline TOTAL & 6 & 66.67 & 3 & 33.33 & 9 & 100,00 \\
\hline
\end{tabular}


Entre os controles, não houve nenhuma criança com idade gestacional inferior a 28 semanas, sendo que o hospital público concentrou a maioria dos nascimentos pré-termo $(66,67 \%)$.

Todos os resultados aqui apresentados pela análise univariada recomendam cautela, uma vez que no caso da morte neonatal, a interpretação requer o tratamento de dados que permita detectar se uma particular exposição de fato está associada à mortalidade neonatal, ou seja, livre do efeito de outras variáveis.

De acordo com RAGGIO LUIZ (2002), mesmo que se encontre um resultado estatisticamente significativo e relevante "clinicamente" na associação entre duas variáveis, é fundamental a reflexão sobre aspectos como a falta de comparabilidade e o conceito de interação. Segundo esses autores, a análise multivariada pode contornar o problema, pois estima o efeito da exposição de interesse sobre a resposta (doença). 


\subsection{Fatores de risco para mortalidade neonatal}

\subsubsection{Análise Univariada}

Tabela 38 - Análise univariada (OR bruta) dos fatores de risco para óbito neonatal. Maringá-PR, $1997-2000$.

\begin{tabular}{|c|c|c|c|c|}
\hline VARIÁVEL & Categoria & OR & IC $(95 \%)$ & $\mathbf{p}$ \\
\hline \multirow[t]{2}{*}{ Sexo } & Masculino & 1,93 & {$[1,23-3,05]$} & 0,005 \\
\hline & Feminino & 1,00 & & \\
\hline \multirow[t]{2}{*}{ Peso ao nascer (gramas) } & $<2.500$ & 98,62 & {$[40,00-243,11]$} & $<0,001$ \\
\hline & $\geq 2.500$ & 1,00 & & \\
\hline \multirow[t]{2}{*}{ Duração gestação (semanas) } & $<37$ & 23,63 & {$[13,27-42,07]$} & $<0,001$ \\
\hline & $\geq 37$ & 1,00 & & \\
\hline \multirow[t]{2}{*}{ Apgar no $1^{\circ}$ minuto } & $\leq 6$ & 70,68 & {$[34,08-146,57]$} & $<0,001$ \\
\hline & $>6$ & 1,00 & & \\
\hline \multirow[t]{2}{*}{ Apgar no $5^{\circ}$ minuto } & $\leq 6$ & 193,00 & {$[45,71-814,83]$} & $<0,001$ \\
\hline & $>6$ & 1,00 & & \\
\hline \multirow[t]{3}{*}{ Idade da mãe (anos) } & $<20$ & 2,01 & {$[1,09-3,71]$} & 0,025 \\
\hline & $20-34$ & 1,00 & & \\
\hline & $\geq 35$ & 1,94 & {$[0,92-4,13]$} & 0,083 \\
\hline \multirow[t]{2}{*}{ Estado conjugal } & Sem companheiro & 1,78 & {$[1,07-2,97]$} & 0,026 \\
\hline & Com companheiro & 1,00 & & \\
\hline \multirow[t]{2}{*}{ Escolaridade da mãe } & Até $1^{\circ}$ grau & 1,50 & {$[0,94-2,39]$} & 0,069 \\
\hline & $2^{\circ}$ grau ou mais & 1,00 & & \\
\hline \multirow[t]{3}{*}{$\mathrm{N}^{\circ}$ de consultas no pré-natal } & $0-3$ & 0,34 & {$[0,16-0,71]$} & 0,004 \\
\hline & $4-6$ & 0,31 & {$[0,19-0,51]$} & $<0,001$ \\
\hline & $>6$ & 1,00 & & \\
\hline \multirow[t]{2}{*}{ Tipo de parto } & Cesárea & 0,44 & {$[0,27-0,69]$} & 0,001 \\
\hline & Normal & 1,00 & & \\
\hline \multirow[t]{2}{*}{ Fonte financiadora } & SUS & 1,99 & {$[1,27-3,12]$} & 0,003 \\
\hline & Não SUS & 1,00 & & \\
\hline \multirow[t]{3}{*}{ Hospital de nascimento } & Público & 3,02 & {$[1,72-5,30]$} & $<0,001$ \\
\hline & Privado & 1,00 & & \\
\hline & Filantrópico & 0,93 & {$[0,45-1,87]$} & 0,954 \\
\hline
\end{tabular}


A análise estatística univariada dos resultados do estudo indicou as variáveis associadas a um aumento estatisticamente significativo do risco de óbito neonatal como: sexo do recém-nascido, peso ao nascer, duraçã́o da gestação, Apgar no $1^{\circ}$ e $5^{\circ}$ minuto de vida, idade materna $<20$ anos, estado conjugal, número de consultas de pré-natal, tipo de parto, fonte financiadora e o hospital de nascimento. A baixa escolaridade e idade da mãe $\geq 35$ anos aumentaram o risco de óbito, porém, sem significância estatística (Tabela 38).

Essa análise revelou, portanto, que estavam mais expostas ao risco de morrer as crianças do sexo masculino, nascidas de parto normal, com baixo peso, idade gestacional inferior a 37 semanas, com escores de Apgar $\leq 6$ no $1^{\circ}$ e $5^{\circ}$ minutos e cujas mães tinham idade materna inferior a 20 anos. Apresentaram-se, ainda, como fatores de risco as internações pelo SUS e em hospital público.

\subsubsection{Análise Multivariada}

Tabela 39 - Análise multivariada (OR ajustada) dos fatores de risco para óbito neonatal. Maringá -PR, 1997 - 2000.

\begin{tabular}{ccccc}
\hline VARIÁVEL & Categoria & OR $_{\text {(ajustada) }}$ & $\begin{array}{c}\text { IC 95\% } \\
\text { OR }_{\text {(ajustada) }}\end{array}$ & p \\
\hline \multirow{2}{*}{ APGAR $-1^{\circ}$ minuto } & $>6$ & 1,00 & Ref. & \\
& $\leq 6$ & 16,12 & {$[4,64 ; 55,99]$} & $<0,001$ \\
APGAR $-5^{\circ}$ minuto & $>6$ & 1,00 & Ref. & \\
Peso (gramas) & $\leq 6$ & 8,27 & {$[1,19 ; 57,17]$} & 0,032 \\
& 2.500 & 1,00 & Ref. & \\
Número de consultas & $>6$ & 70,24 & {$[18,34 ; 268,95]$} & $<0,001$ \\
no pré-natal & 4 a 6 & 1,00 & Ref. & \\
& 0 a 3 & 0,09 & {$[0,03 ; 0,26]$} & $<0,001$ \\
\hline
\end{tabular}

Teste de Hosmer-Lemeshow para adequação do modelo $-\mathrm{p}=0,948$ 
Todavia, ao se controlar o efeito dos fatores de confusão, permaneceram associados à mortalidade neonatal o baixo peso ao nascer $(<2500 \mathrm{~g})$, os escores de Apgar $\leq 6$ no $1^{\circ}$ e $5^{\circ}$ minuto e a realização de menos de 6 consultas de pré-natal (Tabela 39).

O resultado contraditório sobre a maior exposição ao óbito neonatal dos RNs das mães que realizaram mais consultas de pré-natal, provavelmente, esteve relacionado a gestações de risco que induziram ao controle pré-natal mais freqüente devido a intercorrências. Por isso, esse fator provocou uma inversão no resultado da associação.

A associação entre idade da mãe, sexo do $\mathrm{RN}$, tipo de parto, fonte financiadora e hospital de nascimento com a mortalidade neonatal desapareceu quando as variáveis foram analisadas no conjunto.

Apesar das recomendações da análise multivariada para se detectar a associação de fatores de risco ao óbito neonatal, os resultados do estudo indicam que alguns fatores, embora estatisticamente não significativos nessa análise, como o tipo de parto, a fonte pagadora da assistência e o tipo de hospital onde ocorreu o nascimento, estão associados de alguma forma a situações de risco aumentado para o óbito neonatal, podendo ser detectados e controlados com assistência pré-natal e ao parto de qualidade. 
5. CONCLUSÃO E CONSIDERAÇÕES FINAIS 


\section{CONCLUSÃO E CONSIDERAÇÕES FINAIS}

Os resultados obtidos no presente estudo permitiram constatar que dentre as 120 crianças nascidas nos hospitais de Maringá, cujas mães residiam no município, que foram a óbito no período neonatal, 36,66\% vieram a falecer no hospital público. As mortes, em sua maioria, ocorridas no $1^{\circ}$ dia de vida $(52,5 \%)$, decorreram das afecções do período perinatal $(73,11 \%)$ e anomalias congênitas $(25,21 \%)$. Predominaram, nesse grupo de estudo, o sexo masculino $(66,67 \%)$, o peso ao nascer inferior a $2.500 \mathrm{~g}(71,67 \%)$, os nascimentos pré-termo $(75 \%)$, cujos valores de Apgar no $1 .^{\circ}$ minuto concentraram-se entre 0 e $3(52,54 \%)$ e, no $5 .^{\circ}$ minuto, de 0 a 3 e 7 a 10 (ambas com 38,13\%).

Entre as mães destas crianças, as faixas etárias mais freqüentes situaram-se entre 20 e 24 anos (34,17\%), 15 e 19 anos e 30 e 34 anos (ambas com $18,33 \%$ ), sendo a média de 25,54 anos e a mediana 21 anos. Verificou-se que uma mãe tinha apenas 13 anos. Quanto à escolaridade, 32,5\% não chegaram a concluir o primeiro grau e $15,83 \%$ tinham curso superior. A maioria dessas mulheres vivia com o companheiro $(70,84 \%)$, realizou 7 ou mais consultas de pré-natal $(50,43 \%)$, submeteu-se ao parto cesárea $(58,34 \%)$ e foi assistida no momento do parto no hospital privado $(51,67 \%)$, tendo como fonte de financiamento o Plano de Saúde ou particular $(52,5 \%)$.

Distintamente dos casos, entre os controles, observou-se distribuição proporcional dos sexos $(50,83 \%$ masculino), tendo a maioria nascido com peso superior a $2.500 \mathrm{~g}(97,5 \%)$ e com idade gestacional superior a 37 semanas $(89,17 \%)$ e com Apgar no $1^{\circ}$ minuto e no $5^{\circ}$ minuto, predominantemente entre 7 a $10(95 \%$ e 99,17 , respectivamente).

A faixa etária materna mais freqüente foi de 25 a 29 anos $(36,67 \%)$, seguida pelas de 20 a 24 anos (22,92\%) e 30 a 34 anos (22,08\%). A proporção de mães com menos de 20 anos foi de $11,24 \%$, sendo que a média e a mediana foram de 
26,7 e 28 anos, respectivamente. À semelhança dos casos, observou-se que $31,51 \%$ tinham escolaridade inferior ao primeiro grau e $20,59 \%$ tinham formação superior e viviam com companheiro (81,25\%). Quanto às características da assistência, 60,93\% realizaram 4 a 6 consultas de pré-natal, foram submetidas à cesariana (76,25\%), nos hospitais privados $(67,5 \%)$, tendo como principal fonte de financiamento o Plano de Saúde ou particular $(68,75 \%)$.

Relativamente às variáveis estudadas, apresentaram-se associados à mortalidade neonatal, na análise univariada, com Intervalo de $95 \%$ de confiança, o sexo (OR de 1,93 [1,23-3,05]), o peso ao nascer (OR de 98,62 [40,00-243,11]), a idade gestacional (OR de 23,63 [13,27-42,07]), número de consultas de pré-natal de 0 a 3 (OR de 0,34 [0,19-0,51]) e de 4 a 6 (OR de 0,31 [0,16-0,71]), tipo de parto (OR de $0,44[0,27-0,69])$, o estado civil (OR de $1,78[1,07-2,97])$, Apgar no $1^{\circ}$ minuto (OR de 70,68 [34,08-146,57]), Apgar no $5^{\circ}$ minuto (OR de 193,00 [45,71-814,83]), fonte de financiamento (OR de 1,99 [1,27-3,12]) e tipo de hospital (público $x$ filantrópico/particular) (OR de 3,06 [1,78-5,28]).

Todavia, na análise multivariada, confirmaram-se como fatores de risco apenas o baixo peso ao nascer (OR de 70,24 [18,34-268,95]), escores de Apgar abaixo de 7 no $1^{\circ}$ minuto (OR de $16,12[4,64-55,99]$ ) e no $5^{\circ}$ minuto (OR de 8,27 $[1,19-57,17])$.

O presente estudo, desenvolvido na realidade de Maringá, confirma resultados de outras localidades e de investigações anteriormente desenvolvidas. Todavia, algumas associações indicaram a necessidade de melhor explorar os achados, principalmente na perspectiva da proposição de intervenções que venham a reduzir os valores atuais da mortalidade neonatal, mais especificamente em relação às causas perinatais.

Na continuidade do estudo reveste-se de importância a inclusão dos nascimentos de residentes fora do município e os ocorridos fora do ambiente hospitalar, por representarem, em certa medida, dificuldade de acesso à assistência 
hospitalar no município. Além disso, na atual situação em que os investimentos devem focalizar as causas perinatais, seria de grande valia desenvolver análises distinguindo as mortes por malformações congênitas. Este grupo, por incluir vários problemas de etiologias diferentes que requerem multiplicidade de intervenções, necessita de aprofundamentos.

$\mathrm{O}$ delineamento do tipo caso-controle mostrou-se adequado para a análise de risco entre as variáveis de estudo e a mortalidade neonatal. Todavia, alguns aspectos referentes às fontes de dados merecem destaque. $O$ primeiro referese à Declaração de Nascido Vivo. Certamente, a implantação da DN, a partir de 1994, tem permitido múltiplas abordagens para, cada vez mais, elucidar os fatores atuantes na ocorrência da morte neonatal, possibilitando, no campo das políticas da saúde, definição de estratégias que efetivamente reduzam aos níveis mínimos a mortalidade evitável nos primeiros dias de vida. Entretanto, no intuito de assegurar a qualidade dos dados, é necessário que haja por parte dos responsáveis pelo sistema de informação dos serviços, esforços conjugados para detectar a confiabilidade dos dados contidos nas DNs. O preenchimento da DN por mais de um profissional de saúde, na tentativa de confirmar, complementar e/ou corrigir os dados solicitados no documento, é uma forma de melhorar a qualidade do preenchimento das informações.

Estratégias múltiplas de pesquisa, como comparação entre fontes de dados (DN, prontuário hospitalar, prontuário de unidades de saúde da rede pública, entre outros serviços) e entrevistas domiciliares, necessitam ser desenvolvidas. Os resultados dessas pesquisas devem ser discutidos e modificações devem ser implementadas no sentido de aprimorar as fontes de dados, a exemplo da versão atual da $\mathrm{DN}$, onde foram incluídas novas categorias em algumas variáveis, porém ainda não se constitui como fonte adequada para se analisar a qualidade da assistência pré-natal e ao parto. E, ainda, esquema de auditoria no município com obrigatoriedade de controle interno e fornecimento confiável de dados deve ser implementado. 
Tais conhecimentos poderão promover $o$ aprimoramento dessas informações, através de capacitação permanente dos envolvidos no procedimento de coleta de dados e, principalmente, dos seus usuários finais. Embora concebido como instrumento de vigilância à saúde, seja no âmbito populacional (indicadores), bem como da intervenção, na prática esse procedimento não tem recebido a devida valorização dos trabalhadores, refletindo na qualidade dos dados, e muitas vezes é ainda compreendido como procedimento administrativo desvinculado da atenção à saúde.

Quanto ao segundo aspecto, ou seja, o uso de prontuários como fonte de dados, foi inadequado por não possibilitar a pretendida análise, uma vez que o registro de variáveis como escolaridade materna, estado conjugal, início e número de consultas de pré-natal, intercorrências durante a gestação, condições da criança ao nascer, causa básica do óbito, entre outras, era inexistente ou parcial. A exemplo da $\mathrm{DN}$, há necessidade de monitorar o seu preenchimento, principalmente ao vislumbrar possibilidades de integrar a assistência pretendida nos vários níveis de atenção. $\mathrm{O}$ prontuário hospitalar, que, além da finalidade administrativa, constitui importante instrumento para contra-referenciar os egressos do hospital aos serviços básicos, para a continuidade da assistência iniciada, também não tem recebido a devida valorização dos profissionais. Uma das medidas importantes para controlar esse problema é aplicar as normas de auditoria sugeridas pelos Conselhos Regionais de Medicina.

A literatura sobre o tema ressalta que a omissão de registro, bem como a não-confiabilidade dos dados que ele contém, constitui indicativo da qualidade da assistência. Assim, os resultados obtidos, embora estatisticamente não significativos, como maior mortalidade entre crianças nascidas de parto normal, atendidas pelo SUS, em hospitais públicos, merecem atenção, pois podem ser indicativos da iniquiidade à saúde das pessoas oriundas das camadas sociais desfavorecidas, que, além de menor acesso aos bens e serviços que asseguram melhor qualidade de vida, aí incluindo a sobrevivência infantil, quando acessam o 
sistema de saúde, as condições de assistência, seja no pré-natal seja no parto e ao recém-nascido, nem sempre são adequadas.

Assim, a realização de estudos que detectem a dimensão de tal desigualdade em Maringá poderá subsidiar gestores do Sistema na organização da atenção:

- No pré-natal: o conhecimento acumulado sugere que a melhoria do atendimento pré-natal, com capacitação dos profissionais, constitui intervenção de alto impacto na redução das mortes preveníveis, uma vez que para a realidade de Maringá tanto a cobertura da atenção pré-natal quanto a concentração de consultas mostram-se adequadas. Contudo, a possibilidade de intervenção sobre a mortalidade infantil desloca-se cada vez mais para a esfera do serviço público de saúde. O SUS, concebido dentro da lógica da universalização, requer esforços, seja por parte dos gestores seja dos trabalhadores, para que a universalização da assistência do setor público na área básica, aí incluindo o atendimento de todas as gestantes no pré-natal, torne-se uma realidade. É de fundamental importância serem aplicadas as normas do Ministério da Saúde para avaliar a adequação do pré-natal.

- Ao parto e recém-nascido: embora a assistência hospitalar ao parto esteja praticamente universalizada, há necessidade de assegurar acesso a esse nível de assistência no município a todas as gestantes residentes. Em uma realidade como a de Maringá, com elevado número de leitos hospitalares, a persistência da evasão de nascimentos, bem como baixa participação do SUS na assistência ao parto e altíssimo percentual de cesarianas, são indicativos da necessidade de melhorar a qualidade da assistência prestada. Além disso, considerando a população de crianças falecidas e a prevalência do baixo peso ao nascer e dos nascimentos 
prematuros, principalmente no hospital público, essa realidade está a exigir investimentos na capacitação da equipe hospitalar e em equipamentos, com ampliação de serviços neonatais de cuidados intermediários e intensivos.

Face aos resultados obtidos e ao contexto em que se analisou a mortalidade neonatal no município de Maringá, conclui-se que, para a prevenção desta mortalidade e conseqüente redução dos níveis atuais, é imprescindível modificar a lógica da atenção. Os serviços públicos, principalmente no nível básico, com capacidade instalada suficiente para cobertura universal das gestantes, precisam se responsabilizar pela saúde da população e pela promoção da equuidade. Também é fundamental implementar estratégias para a redução dos nascimentos prematuros e o estabelecimento de sistemas de referência e contra-referência entre os vários níveis de atenção. 


\section{REFERÊNCIAS}




\section{REFERÊNCIAS}

Aerts DRG de C. Investigação dos óbitos perinatais e infantis: seu uso no planejamento de políticas públicas de saúde. J Pediatr 1997; 73(6):364-6.

Alberman E. Prospects for better perinatal health. Lancet 1980; 26:189-92.

Almeida Filho N, Rouquayrol MZ. Introdução à epidemiologia moderna. Salvador/Rio de Janeiro: Apce Produtos do Conhecimento/ABRASCO; 1990. p.10611 .

Almeida MF. Mortalidade neonatal em Santo André. São Paulo; 1995. [Tese de Doutorado - Faculdade de Saúde Pública da USP].

Almeida MF, Mello Jorge MHP. Pequenos para idade gestacional: fator de risco para mortalidade neonatal Rev. Saúde Pública 1998; 32 (3): 217-24.

Almeida NMGS. Mortalidade materna em Fortaleza - CE, 1996 a 1999: estudo dos fatores de risco. São Paulo; 2002. [Tese de Doutorado - Faculdade de Saúde Pública da USP].

Apgar V. Proposal for new method of evaluation of newborn infant. Anesth \& Analg. 1953; 32:260-7.

Araújo BF. Mortalidade neonatal precoce no município de Caxias do Sul, 1995. São Paulo; 1999. [Dissertação de mestrado - Faculdade de Saúde Pública da USP]

Axemo P et al. Aetiology of late fetal death in Maputo. Gynecol Obstet Invest 1995; 39:103-9.

Backett EM, Davies AM, Petros-Barvazian A. O enfoque de risco na assistência à saúde: com especial referência à saúde materno infantil, inclusive planejamento familiar. Washington, DC, Organização Panamericana da Saúde; 1985. (OPAS Publicação Científica, 491). 
Barros CF, Victora CG. Epidemiologia da saúde infantil: um manual para diagnósticos comunitários. $3^{a}$ ed. São Paulo: Hucitec - Unicef; 1998. p.19-22, 40.

Barros FC, Victoria CG, Vanghan JP, Estanislau HJ. Bajo peso al nascer en el municio de Pelotas, Brasil: factores de riesgo. Bol. Oficina Sanit. Panam. 1987; 102: $541-53$.

Bercini LO. Mortalidade neonatal de residentes em Maringá - Paraná, no ano de 1990. São Paulo; 1993. [Dissertação de Mestrado - Escola Paulista de Medicina].

Burgos L, Carreño Rimaudo S. Comparación de factores de riesgo en dos poblaciones de embarazadas adolescentes nulíparas. Rev. Hosp. Matern. Infant. Ramon Sarda 1997; 16 (13): 104-11.

Carvalho ML, Silver LD. Confiabilidade da declaração da causa básica de óbitos neonatais: implicações para o estudo da mortalidade prevenível. Rev. Saúde Pública $1995 ; 29$ (5): 342-48.

Carvalho WO de, Mathias TAF, Souza J, Sanches VC, Sanches LMP, Carrijo AR. A busca do atendimento ao parto fora do município por mulheres residentes em Maringá. In: I Jornada Regional de Estatística de Maringá - PR, 1998 p. 28.

Cesar CLG. Fatores de risco associados à mortalidade infantil em Cotia e Vargem Grande Paulista, S.P., 1984-1985: uma proposta de instrumentos preditivos. São Paulo; 1989. [Tese de Doutorado - Faculdade de Saúde Pública da USP].

Cooper R, Goldenberg RL, Creasy RK et al. A multicenter study of preterm birth weight and gestational age-specific neonatal mortality. Am J obstet gynecol 1993; 168:78-83.

Dean AG et al. Epi info, version 6: a word processing database, and statistics program for epidemiology on microcomputers. [Computer program] Center of Disease Control and Prevention. Atlanta; 1994. 
Dragovich $D$ et al. Cuidados essenciais com o recém-nascido. Bureau for international health. Instituto per l'infanzia burlo garofalo. Trieste, Italia. Sem data.

Fernandes RMBP. Mortalidade neonatal no município de São Paulo: estudo das causas de morte segundo peso ao nascer, tipo de parto, sexo e idade ao morrer. São Paulo; 2002. [Tese de Mestrado - Faculdade de Saúde Pública da USP].

Ferraz EM, Gray RH, Cunha TM. Determinants of preterm delivery and intrauterine grow retardation in North-East Brazil. International Journal of Epidemiology, 1990, 19(1); 101-8.

Fletcher RH, Fletcher SW, Wagner EH. Epidemiologia clínica: elementos essenciais. Porto Alegre. Artes Médicas; 1990.

Gallo PR, Reis AOA, Leone C. Características de seguimento pré-natal, do parto e do recém-nascido de adolescentes grávidas, município de Joinville, Estado de Santa Catarina, Brasil, 1995. Pediatria 2000; 22(2): 123-9.

Gopal KS, Yu MS. Infant mortality. AM J Public Health 1995; 85(7):957-64.

Guillaumon MR, Segre CAM. Atendimento ao RN em sala de parto. In: Segre CAM. Perinatologia: fundamentos e prática. São Paulo: Sarvier; 2002. p 361 - 68.

Guillaumon MR, Segre CAM. Mortalidade perinatal. In: Segre CAM. Perinatologia: fundamentos e prática. São Paulo: Sarvier; 2002. p 329 - 32.

Haiddar FH, Oliveira UF, Nascimento LFC. Escolaridade materna: correlação com os indicadores obstétricos. Cad. Saúde Pública 2001; 17 (4): 1025-29.

Isolani FG. Perfil epidemiológico dos nascidos vivos e fatores de risco da mortalidade neonatal no município de Maringá - PR, no ano de 1995. Maringá; 1997. [Monografia de Especialização em Saúde Coletiva - Universidade Estadual de Maringá]. 
Kelsey J, Thompson WD, Evans AS. Métodos em epidemiologia observacional. Monografias em epidemiologia e bioestatística. New York/Oxford: Oxford University Press; 1986. v.10.

Laurenti R. Análise da informação em saúde: 1893-1993, cem anos de classificação internacional de doenças. Rev Saúde Pública, 1991; 25 (6):407-17.

Laurenti R. et al. Estatísticas de saúde. São Paulo: EPU./ EDUSP; 1987.

Laurenti R, Buchalla CM. Estudo da morbidade e da mortalidade perinatal em maternidades - II mortalidade perinatal segundo peso ao nascer, idade materna, assistência pré-natal e hábito de fumar da mãe. Rev Saúde Pública 1985; 19: 22532.

Leal MC, Szwarcwald CL. Evolução da mortalidade neonatal no Estado do RJ, Brasil (1979-1993): Análise por causa segundo o grupo de idade e região de residência. Cad. Saúde Pública. 1996; 12(2): 243-252.

Leal MC. Evolução da mortalidade infantil no Estado do Rio de Janeiro na década de 80: o componente neonatal. Rio de Janeiro; 1996. [Tese de Doutorado Escola Nacional de Saúde Pública].

Lippi UG. Enfoque de risco. In: Segre CAM. Perinatologia: fundamentos e prática. São Paulo: Sarvier; 2002. p 55-70.

Lippi VG, Andrade AS, Bertagmon Jr D, Melo E. Fatores obstétricos associados ao baixo peso ao nascer. Rev. Saúde Pública 1989; 23: 382-7.

Lippi UG, Casanova LD, Patriota RG, Barragan AM, Silva EYK. Prematuridade In: Segre CAM. Perinatologia: fundamentos e prática. São Paulo: Sarvier; 2002. p 226-32.

Maranhão AGK; Joaquim MMC; Kalume P; Castillo O; Leal MC.. Mortalidade perinatal e neonatal no Brasil: um desafio para os serviços de saúde. TEMA Radis 1999; (17): 6-10. 
Mariani Neto C. Consideraç̃̃es sobre o sofrimento fetal. In: Segre CAM. Perinatologia: fundamentos e prática. São Paulo: Sarvier; 2002. p 76-80.

Maringá. Prefeitura do Município de Maringá. Secretaria de Planejamento. Divisão de Modernização Administrativa e Controle de Qualidade. Perfil da cidade de Maringá. Maringá; 1996.

Maringá. Prefeitura Municipal, Secretaria de Saúde, Conselho Municipal de Saúde. Plano Municipal de Saúde, 2002-2003. Maringá; 2001 .

Maringá. Prefeitura Municipal, Secretaria de Saúde. Relatório de Gestão 2000. Maringá; 2001b.

Maringá. Prefeitura Municipal, Secretaria de Saúde. Perfil epidemiológico do município de Maringá - 1998 a 2000. Maringá; 2001c.

Maringá. Prefeitura Municipal, Secretaria de Saúde. Agenda Municipal de Saúde de Maringá - 2002: Quadro de Metas. Maringá, 2002a.

Maringá. Prefeitura Municipal, Secretaria de Saúde. Relatório de Gestão 2001. Maringá; 2002b.

Mello Jorge MHP. Registro dos eventos vitais: sua importância em Saúde Pública. Centro da OMS para a Classificação de Doenças em Português. Centro Brasileiro de Classificação de Doenças. São Paulo; 1990. (Série Divulgação 5).

Mello Jorge MHP, Gotlieb SLD. As condições de saúde no Brasil. Rio de Janeiro: Editora FIOCRUZ; 2000.

Mello Jorge MHP, Gotlieb SLD, Laurenti R. A saúde no Brasil: análise do período 1996 a 1999. Brasilia: Organização Pan-Americana da Saúde; 2001.

Mello Jorge MHP, Gotlieb SLD, Soboll MLMS, Baldijão MFA, Latorre MRDO. 0 sistema de informação sobre nascidos vivos - SINASC. Centro da OMS para a Classificação de Doenças em Português. Centro Brasileiro Para a de Classificação de Doenças. São Paulo; 1992. (Série Divulgação 7). 
Menezes AMB, Barros FC, Victora CG, Tomasi E, Halpern R, Oliveira ALB. Fatores de risco para mortalidade perinatal em Pelotas, RS, 1993. Rev. Saúde Pública 1998; 32 (3): 209-16.

Ministério da Saúde. Secretaria de Políticas de Saúde. Área Técnica de Saúde da Mulher. Assistência Pré-natal: Manual técnico. $3^{\mathrm{a}}$ ed. Brasilia (DF); 2000a.

Ministério da Saúde. Secretaria de Políticas de Saúde. Portaria GM-569, de 1.6.2000: dispõe sobre o Programa de humanização no pré-natal e nascimento. Brasilia; 2000b.

Ministério da Saúde. Secretaria Executiva DATASUS. SINASC. Brasilia; 1999.

Miúra E, Failace LH, Fiori H. Mortalidade perinatal e neonatal no hospital de clínicas de Porto Alegre. Rev Assoc Med Brasil 1997; 43 (1): 35-9.

Monteiro CA. A origem social. In: Saúde e nutrição das crianças de São Paulo: diagnóstico, contrates sociais e tendências. São Paulo. Hucitec, Editora da USP, 1988, pg. 21-33.

Monteiro CA et al. A mortalidade. In: Monteiro CA. Saúde e nutrição das crianças de São Paulo. São Paulo: Hucitec/Edusp; 1988. p.143-58.

Monteiro CA, Benicio MHA, Ortiz LP. Tendência secular do peso ao nascer na cidade de São Paulo (1976 - 1998). Rev. Saúde Pública 2000; 34 (6 Supl) 26-40.

Montero CV. Mortalidade neonatal: estudo de caso-controle no município de São Paulo, 1995. São Paulo; 2000. [Dissertação de Mestrado - Faculdade de Saúde Pública da USP].

Moraes AS, Souza IMP. Efeito dose resposta de fatores de risco para a doença isquêmica do coração. Rev. Saúde Pública 1996; 30 (5): 471-8.

Nobrega FJ, Vitolo J, Brasil MR, Dias AL, Lopes FA. Condição nutricional de mães e filhos: relação com o peso de nascimento, variáveis maternas e sócio-econômicas. J. Pediatr. 1991; 67 (9/10): 288-96. 
Organização Mundial da Saúde (OMS). Classificação estatística internacional de doenças e problemas relacionados à saúde: Décima revisão. São Paulo: Centro Colaborador da OMS para a Classificação de Doenças em Português/Edusp; 1994. p.1239-42. Vol 1 .

Organização Mundial de Saúde (OMS). Classificação estatística internacional de doenças e problemas relacionados à saúde. Décima revisão. São Paulo: Centro Colaborador da OMS para a Classificação de Doenças em Português/Edusp; 1997. Vol 1.

Organização Mundial da Saúde, Unicef. Assistência materna visando à redução da mortalidade perinatal e neonatal: uma declaração conjunta OMS/FNUAP/UNICEF. Genebra; 1986. 27p.

Organización Mundial de la Salud. Metodo de atención sanitaria de la madre y el ninõ basado en el concepto de riesgo. Ginebra, 1978. (Publicación Cientifica 39)

Paraná. Secretaria de Estado da Saúde. Instituto de Saúde do Paraná. Centro de Epidemiologia do Paraná. Coeficientes de mortalidade infantil e neonatal do Estado do Paraná. Curitiba; 1998.

Pelloso MCP. Avaliação da implantação do sistema de informação sobre nascidos vivos - SINASC e caracterização dos nascimentos vivos ocorridos em Maringá - PR. Maringá, 1995. [Monografia de Especialização em Saúde Coletiva Universidade Estadual de Maringá].

Pereira MG. Epidemiologia: teoria e prática. Rio de Janeiro: Guanabara Koogan; 1995.

Raggio Luiz R. Associação estatística em epidemiologia. In: Medronho RA. Epidemiologia. São Paulo: Atheneu; 2002. p 309-34.

Reis DO. Características da mortalidade neonatal de residentes no município de Diadema, segundo município de ocorrência do nascimento. São Paulo; 2000. [Dissertação de Mestrado - Faculdade de Saúde Pública da USP]. 
Roseli CAM, Segre CAM. Avaliação da idade gestacional. Classificação do recémnascido IN Segre CAM. Perinatologia: fundamentos e prática. São Paulo: SARVIER, 2002. p. 374-75.

Rothman KJ. Epidemiologia moderna. Madrid: Ediciones Diaz de Santos; 1987.

Sakala C. Medically unnecessary cesarean section births: introduction to a Symposium. Soc. Science Medicine 1993; 37 (10): 1177-98.

Sapata MPM. Avaliação da assistência ao pré-natal de baixo risco no NIS II Mandacaru - 1997. Maringá; 1999. [Monografia de Especialização em Administração da Assistência de Enfermagem - Universidade Estadual de Maringá].

Scalassara MB, Souza RKT, Baptista EKK. Algumas considerações sobre a cobertura do Sistema de Informação de Atenção Básica - SIAB, no município de Maringá - PR. [Resumo]. Rev. Brasileira Epidemiol. 2002; (Suppl Especial):56. [Apresentado no $5^{\circ}$ Congresso Brasileiro de Epidemiologia; 2002. Curitiba - PR]

Scochi MJ. Municipalização e avaliação de qualidade de serviços de saúde: uma análise localizada. Rio de Janeiro; 1996. [Tese de Doutorado - Escola Nacional de Saúde Pública - Fundação Osvaldo Cruz].

Segre CAM. Recém nascido pré-termo In: Perinatologia: fundamentos e prática. São Paulo: Sarvier; 2002. p 232 - 251.

Silva RLDT. Cesáreas: freqüência, alguns fatores que a determinam e conseqüências maternas e perinatais. Maringá - 1995. Londrina, 1997. [Dissertação de Mestrado em Saúde Coletiva - Universidade Estadual de Londrina].

Siqueira AAF. Serviços de saúde: falhas, problemas e suas repercussões sobre a saúde perinatal. In: Anais do $1^{\circ}$ Simpósio Franco-Brasileiro de Metodologias de Pesquisa em Saúde Perinatal. São Paulo; 1994. (Série Investigação em Saúde da Mulher, da Criança e Adolescência, 3).

Souza RKT. Mortalidade infantil e sub-registro de nascidos vivos no município de Maringá - PR, em 1989. São Paulo; 1992. [Dissertação de Mestrado - Faculdade 
de Saúde Pública da USP].

Souza RKT, Carvalho WO, Pereira AR, Shina MK, Inoue KC. A diferença de nascer em Hospital Universitário: as características dos nascimentos no HU de Maringá-PR. Maringá; 1999. [Apresentado no $51^{\circ}$ Congresso Brasileiro de Enfermagem, 1999.]

Tanaka AC d'A, Siqueira AAF de, Bafile PN. Situação de saúde materna e perinatal no Estado de São Paulo, Brasil. Rev Saúde Pública 1989; 23:67-75.

Tanaka AC d'A. Maternidade: dilema entre nascimento e morte. São Paulo/Rio de Janeiro: HUCITEC,ABRASCO; 1995. 107p.

Uzcátegui O. Embarazo en la adolescente precoz. Rev. obstet. ginecol. 1997; 57 (1): 19-27.

Ventura GAB. Viabilidade da redução de cesáreas em Maternidade Universitária Pública no Município de São Paulo. São Paulo; 1998. [Tese de Doutorado - Faculdade de Saúde Pública da USP]

Victora CG. Intervenções para reduzir a mortalidade infantil pré-escolar e materna no Brasil. Rev.Bras. Epidemiol. 2001; 4(1) 2001: 3-62.

Wessel H, Anattingim S, Bergstrom S, Dupret A, Reitmaier P. Maternal risk factores for pre term birth and low bikth weight in Cape Verde. Acta Obstet Gynecol Scamol 1996; 75: 360-6.

Wigglesworth JS. Monitoring perinatal mortality: a pathophysiological approach. Lancet $1980 ; 27: 684-6$.

Willrich NA. Tendência da mortalidade infantil no Paraná de 1979 a 1998 . Saúde no Paraná: Bol epidemiol Secretaria Estado Saúde. Curitiba; 1999 2(6): 3.

Yazlle Rocha JS, Simões BJG. Estudo da assistência hospitalar pública e privada em bases populacionais, 1986 - 1996. Rev. Saúde Pública 1999; 33 (1): 44-54. 
ANEXOS 


\section{ANEXO 1}

PARECER DO COMITÊ DE ÉTICA EM PESQUISA DA FACULDADE DE SAÚDE PÚBLICA DA USP

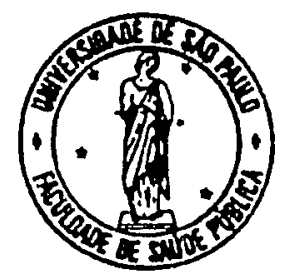

\section{UNIVERSIDADE DE SÃO PAULO}

FACULDADE DE SAÚDE PÚBLICA

COMITÉ DE ÉTICA EM PESQUISA-COEP

Av. Dr. Amaldo, 715 - sala. 18 - sub-solo - Cerqueira César

São Paulo-sP CEP: 01246-904

Telefone (oxx11) 3066-7776 - e-mail: mdgracaseusp.br

\section{Of.COEP/115/00}

17 de agosto de 2000

Pelo presente, informo que o Comitê de Ética em Pesquisa da Faculdade de Saúde Pública da Universidade de São Paulo, analisou e aprovou, em sua 3. ${ }^{\circledR} / 00$ Sessão Ordinária, de 15.08.00, de acordo com os requisitos da Resolução CNS/196/96, o protocolo de pesquisa n. ${ }^{\circ} 290$, intitulado: "MORTALIDADE NEONATAL EM MARINGÁ-PR", apresentado pela pesquisadora Deise Serafim.

Atenciosamente,

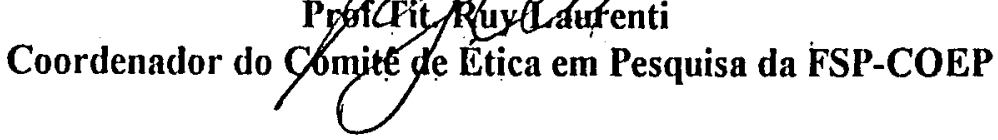




\section{ANEXO 2}

PARECER DO COMITÊ PERMANENTE DE ÉTICA EM PESQUISA DA UNIVERSIDADE ESTADUAL DE MARINGÁ

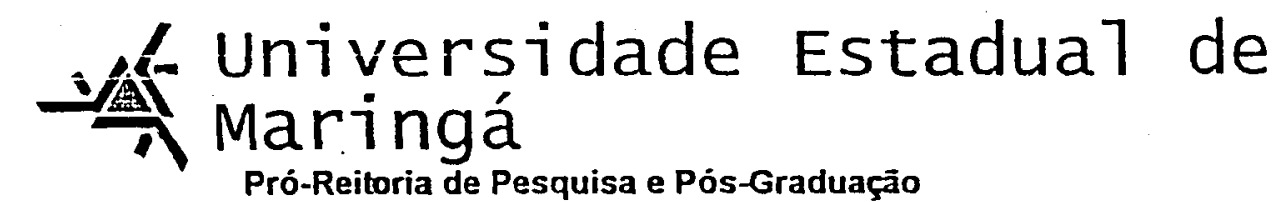

COMITÊ PERMANENTE DE ÉTICA EM PESQUISA ENVOLVENDO SERES HUMANOS

REGISTRO № $071 / 01$

PARECER N $N^{\circ}$ 071/2001

\begin{tabular}{|c|c|}
\hline $\begin{array}{l}\text { Coordenadora: } \\
\text { DEISE SERAFIM }\end{array}$ & \\
\hline $\begin{array}{l}\text { Centro/Departamento } \\
\text { CCS/Departamento de Enfermage }\end{array}$ & \\
\hline $\begin{array}{l}\text { Titulo do projeto: } \\
\text { Mortalidade neonatal em inaringá }\end{array}$ & \\
\hline $\begin{array}{l}\text { Considerações: } \\
\text { O projeto, tese de doutorado da p } \\
\text { Saúde Pública da USP-São Paulo } \\
\text { informaçōes em prontuários de in } \\
\text { prontuärios de internação hospitalar } \\
\text { assistência pré-natal de gestantes } \\
\text { vivos e de óbito. Constam da met } \\
\text { estatisticos para avaliação da amos } \\
\text { onde também consta um termo d } \\
\text { instituição solicitando permissão pa } \\
\text { pesquisadora. Esse projeto já foi a } \\
\text { Pública da USP-São Paulo; conforn } \\
\text { COPEP entende que o projeto ateno }\end{array}$ & $\begin{array}{l}\text { quisadora, desenvolvida na Faculdade de } \\
\text { terá como objeto de estudo a análise de } \\
\text { ituiçōes hospitalares de Maringá-PR; dos } \\
\text { yarturiente e recém-nascidos), do registro da } \\
\text { de amostras de declaraçōes de nascidos } \\
\text { dologia, o número amostral (384) e testes } \\
\text { Os objetivos são claros e bem delineados } \\
\text { consentimento que será enviado a cada } \\
\text { a coleta de dados. Consta o curriculo da } \\
\text { rovado pelo CEP da Faculdade de Saúde } \\
\text { documento anexado ao processo. Assim o } \\
\text { a Resoluçäo no } 196 / 96 \text { do CNS. }\end{array}$ \\
\hline $\begin{array}{l}\text { Parecer: APROVADO } \\
\text { O Comitê em sua } 47^{\mathrm{a}} \text { Reunião é de } \\
\text { tela }\end{array}$ & arecer favorável à aprovação do projeto em \\
\hline Relatório Anual/Final para Comitê & () Não (X) Sim Data: 03/07/2002 \\
\hline Data: 06/07/2001 & \\
\hline $\begin{array}{l}\text { Projeto encontra-se de acordo } \\
\text { com a Resoluçāo } n^{\circ} 196 / 96 \text { do } \\
\text { Ministério da Saúde, aprovado } \\
\text { na } 47^{a} \text { reunião. }\end{array}$ & $\begin{array}{l}\text { Prof. Dr. ValterAugusto Della Rosa } \\
\text { Presidente do COPEP }\end{array}$ \\
\hline
\end{tabular}




\section{ANEXO 3 \\ Solicitação de Consentimento de Consulta às Fontes de Dados.}

Maringá,

Ilmo. Dr.

Nome do Médico

Secretário de Saúde do Município de Maringá ou

Diretor Clínico do Hospital

MARINGÁ - PR

Prezado Secretário/Diretor,

Venho por meio deste solicitar autorização para consulta aos Prontuários Hospitalares, Declarações de Nascido Vivo (DN) e Declarações de Óbito (DO) referentes a nascidos vivos em hospitais de Maringá, no período de 01/01/97 a $30 / 12 / 00$, com a finalidade de coleta de informações essenciais à realização da pesquisa sobre "Mortalidade Neonatal em Maringá - PR, 1997 - 2000".

Sou docente do Departamento de Enfermagem da UEM e pós-graduanda no Curso de Doutorado em Saúde Pública pelo Departamento de Saúde MaternoInfantil, da Faculdade de Saúde Pública da USP. A consulta às fontes de dados visa fornecer subsídios para a análise de fatores de risco relacionados à mortalidade neonatal, de filhos de mães residentes em Maringá, tema de minha tese de doutorado, sob orientação do Prof. Dr. Arnaldo Augusto Franco de Siqueira.

Será garantida a privacidade das informações a serem consultadas, bem como a devolução dos resultados do estudo a esta instituição.

Atenciosamente.

DEISE SERAFIM

$N^{\circ}$ USP 2551534 


\section{ANEXO 4}

\section{Formulário de Pesquisa}

Informações Confidenciais

\section{MORTALIDADE NEONATAL EM MARINGÁ-PR, 1997 - 2000.}

$\mathrm{N}^{\circ}$ de Ordem:

Caso ( ) Controle ( )
No do Prontuário:
- Mãe:
- RN:

\section{- PRONTUÁRIO MÉDICO-HOSPITALAR (da Mãe)}

1. Caracterização sócio-demográfica da mãe.

1.1. Nome:

\subsection{Endereço:}

Rua: $\mathrm{N}^{\circ}:$

Bairro:

Município: Fone:

1.3. Idade: anos.
D.N: 1

1.4. Escolaridade:

1.5. Situação conjugal:

2. Caracterização obstétrica da gestante.

2.1. Duração da gestação (em semanas):

Não consta ( ) 
3. Caracterização da assistência pré-natal e evolução gravídica.

3.1. Início do pré-natal:

$1^{\circ}$ trimestre ( )

$2^{\circ}$ trimestre ( )

$3^{\circ}$ trimestre ( )

Não consta ( )

3.2. Número de consultas realizadas:

Não consta ( )

3.3. Data da Última Menstruação:

Não consta ( )

3.4. Data Provável do Parto:

Não consta ( )

3.5. Intercorrências na gestação: $\operatorname{Sim}(\quad$ Não( ) Não consta（ ）

Tipo

* Diabetes ( )

* Anemia ( )

* Hipertensão arterial ( )

* Pré-eclâmpsia ( )

* Eclâmpsia ( )

* Retardo no Crescimento Intra-Uterino ( )

* Oligodrâmnio/Polidrâmnio ( )

* Hemorragia ( ) Mês de Gestação:

* Descolamento Prematuro de Placenta ( )

* Trabalho de parto prematuro ( )

* Infecções uro-genitais ( )

* Outras infecções (especificar):

* Outras doenças (especificar):

\section{Caracterização da assistência ao parto.}

4.1. Fonte financiadora utilizada na internação para o parto:

4.2. Duração da gestação (em semanas):

Não consta ( )

4.3. Intercorrências durante o trabalho de parto e parto:

$\operatorname{Sim}($ ) Não( )

Não consta ( )

- Hemorragia ( )

- Rotura prematura de membranas ( ) Quantas horas?

- Trabalho de Parto Prematuro ( )

- Sofrimento fetal ( ) 
- Distocia de progressão ( )

- Desproporção céfalo-pélvica ( )

- Expulsivo prolongado ( )

- Descolamento Prematuro de Placenta ( )

- Outra intercorrência (especificar):
4.4. Tipo de parto: ( ) vaginal
( ) cesárea
( ) fórceps

\section{II - PRONTUÁRIO MÉDICO-HOSPITALAR (do RN)}

\subsection{Caracterizaçâo do $\mathrm{R} N$ e condiçôes de nascimento.}

2.1.1. Data do nascimento: Horário:

2.1.2. Hospital de Nascimento:

2.1.3. Sexo: Feminino ( ) Masculino ( ) Não consta ( )

2.1.4. Peso ao nascer: gramas Não consta ( )

2.1.5. Índice de Apgar: $1^{\circ}$ minuto ( $\quad$ ) Não consta ( ) $5^{\circ}$ minuto ( ) Não consta ( )

2.1.6. Reanimação na Sala de Parto:

$\operatorname{Sim}($ ) Não ( ) Não consta ( )

- Em caso afirmativo:

. Oxigênio terapia ( )

. Entubação ( )

. Cateterização venosa ( )

. Cateterização arterial ( )

. Outros procedimentos:

2.1.7. Tempo de permanência no hospital: hs. dias. Não consta ( )

2.1.8. Condições de saida do RN
Alta ( )
Óbito ( )
Transferência ( ) 
3. Em caso de transferência:

Especificar o estabelecimento:

Fonte financiadora na internação:

Motivo da transferência:

Condições gerais da criança à admissão:

Diagnóstico/hipóteses diagnósticas:

4. Em caso de morte:

Data da morte: 1

Horário:

Idade ao morrer:

( ) horas (menor de 1 dia)

( ) dias (dias completos)

Causa básica de morte: 


\section{ANEXO 5 \\ DECLARAÇÃO DE ÓBITO - DO}

República Federativa do Brasil

Ministério da Saúde

• via - Secretaria de Saúde

1 章 11 corrorio

(4) Municloio

7 Tipo to Ohito 8 Obito

Declaracaád de Óbit

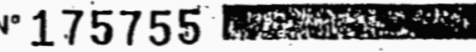

$1^{\text {Honn }}$

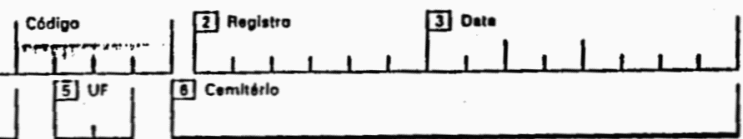

ii] Nomia da Iolinckito

17. Nome do pai

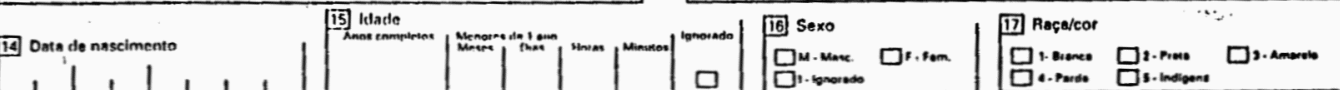

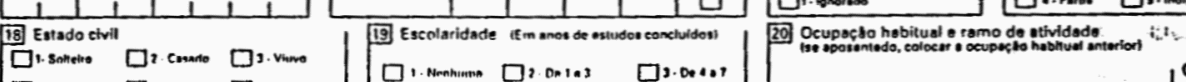

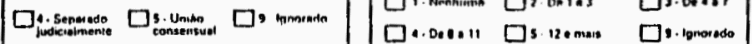

in

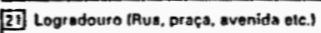

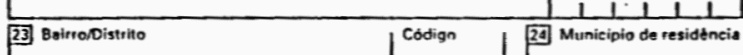
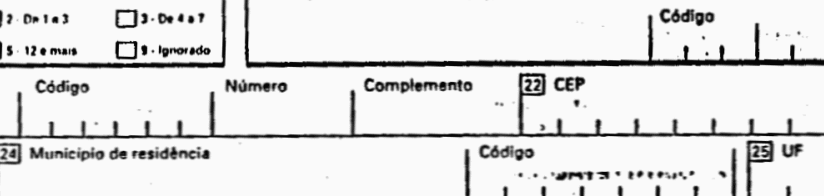

2 Local do ocoritincis do oblito

27] Estabelecimento

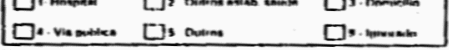

IV

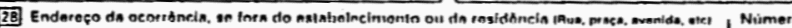

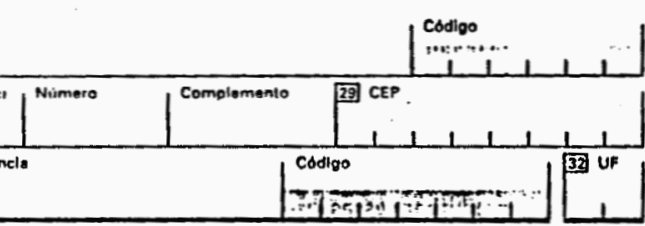

300 8oirro/0istrito

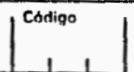

3i] Municlipio de ocorrencls

100

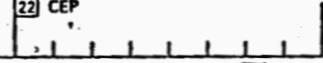

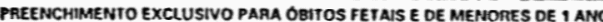

NERORMACOES SOBAE A MKE

33 Idado 3ad Escolaridade (Em anos de estudo concluidos)

口. Nentums 口i. Da I.,

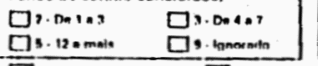

35. Ocupaçbo hobitual o romo do atividede de mato

|

Dursecto da pessiscto (Em sernenas?

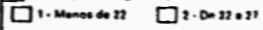

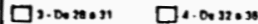

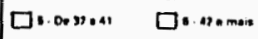

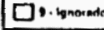

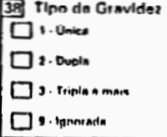

D. monomente

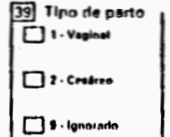

口. Ionoratio

OBITOS EM MUZHERES

43 A morte ocorreu durante e gravidez, parto ou aborto? A4] A morie ocorreu durante o Duerptrio?

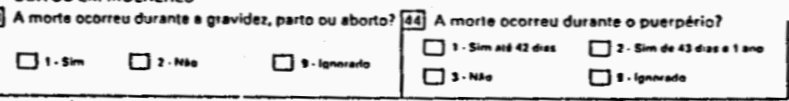
46 EIAGNOSTICO CONFIRMADO POR: codigo

VI

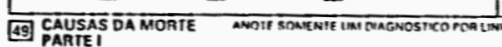

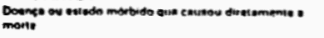

CAUSAS ANTECToENTES

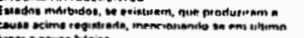
now receves besice

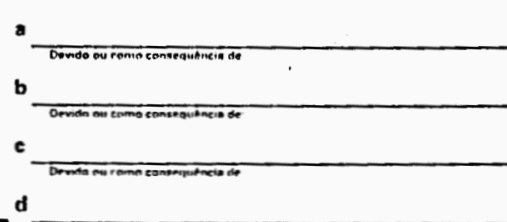

to 00 port

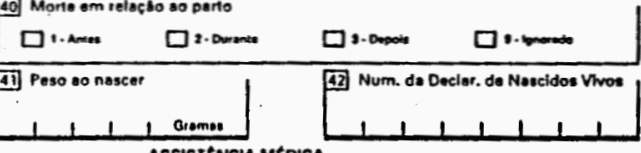

45] Recebou assist. mbdica durante a doença que ocasionou a morte?
口.1.5m

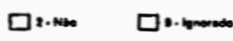

48 Necrópsio?

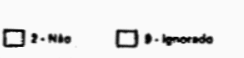

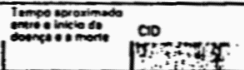

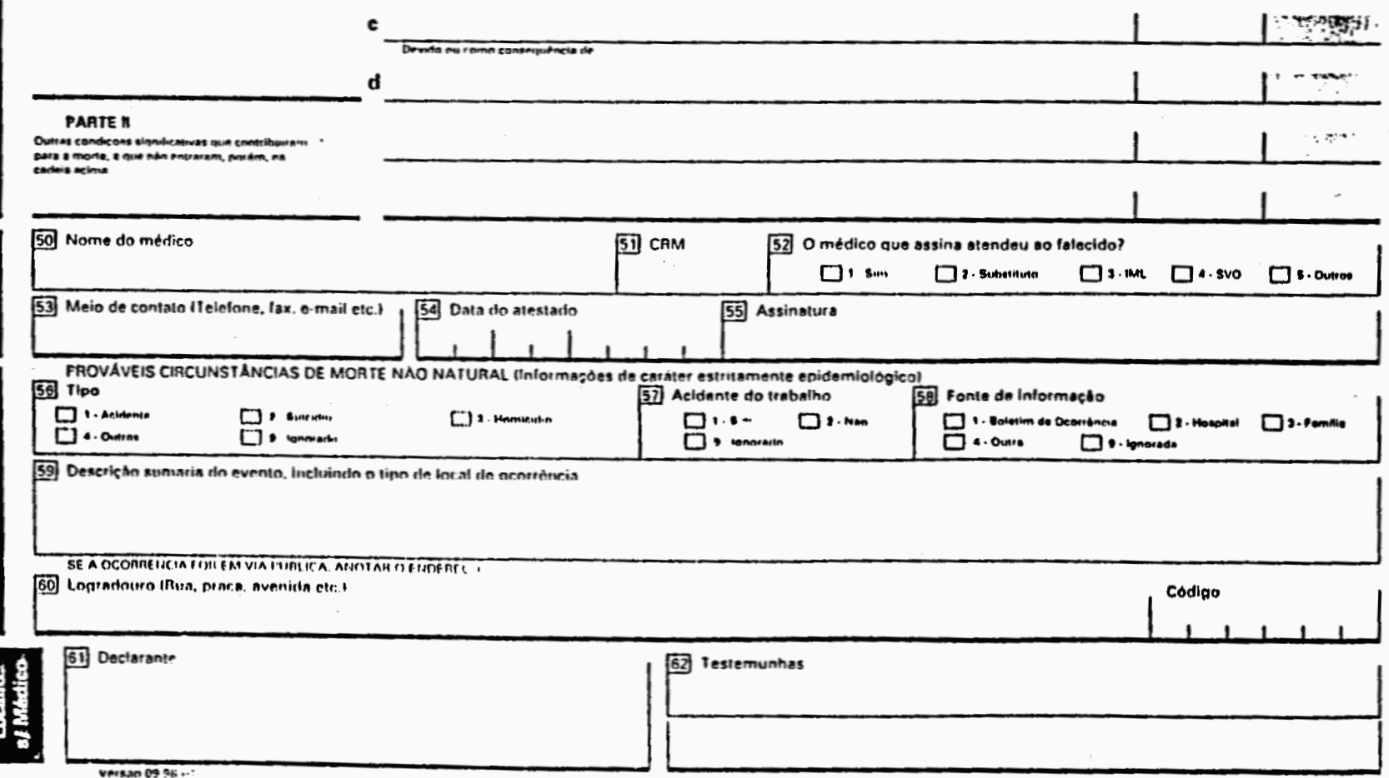




\section{DEFINIÇÕES}

(De acordo com a CLASSIFICAC̣ȦO INTERNACIONAL DE DOENÇAS E PROBLEMAS RELACIONADOS Ȧ SAUUDE (10* REVISĀO)

\section{NASCIMENTO VIVO}

Nascimento vivo é a expulsăo ou extraça completa de um produto de concepção do corpo materno, independentemente da duraçāo da gravidez, o qual, depois da separaçāo, respire ou dê qualquer outro sinal de vida, tal como batimentos do coraçäo, pulsaçōes ou do cordão umbilical ou movimentos efetivos dos músculos de contração voluntária, estando ou nào cordào umbilical e estando ou nào desprendida a placenta. Cada produto de um nascimento que reúna essas condiçóes se considera como uma criança nascida viva.

\section{2. ÓBITO FETAL}

Óbito fetal é a morte de um produto da concepção, antes da expulsão ou de sua extração completa do corpo materno, independentemente da duração da gravidez; indica o óbito o fato de, depois da separaçào, o feto năo respirar nem dar nenhum outro sinal de vida, como batimentos do coração, pulsaçóes do cordáo umbilical ou movimentos efetivos dos mús. culos de contraçào voluntária.

\section{3. causas de morte}

As causas de morte a serem registradas no Atestado Médico de causa de morte, são todas aquelas doenças, estados mór. bidos ou lesōes que produziram a morte, ou que contribuiram para ela e as circunstàncias do acidente, ou da violência que produziram essas lesōes.

\section{CAUSA BÁSICA DE MORTE}

Define-se como causa básica de morte; (a) a doença ou lesōes que iniciou a cadeia de acontecimentos patológicos que conduziram diretamente à morte, ou; (b) as circunstâncias do acidente ou violència que produziram a lesão fatal.

\section{LEGISLAÇÃO}

(Lei $n^{\circ} 6.015$, de 31 de dezembro de $1973 \mathrm{com}$ as corrigendas da Lei $n^{\circ} 6.216$, de 30 de junho de 1975)

\section{CAPITULOIX}

\section{Do óBITO}

Art. 77. Nenhum sepultamento será feito sem certidảo de oficial de registro do lugar do falecimento, extraida após a lavratura do assento de óbito, em vista do atestado de médico se houver no lugar, ou em caso contrário de duas pessoas qualificadas
que tiverem presenciado ou verificado a morte.

19 ) Antes de proceder ao assento de óbito de criança de menos de 1 ano, o oficial verificará se houve registro de nascimento que, em caso de falta, será previamente feito.

$\left.2^{\circ}\right)$ A cremaça de cadáver somente será feita daquele que houver manifestado a vontade de ser incinerado ou no interesse da saúde pública e se o atestado de óbito houver sido firmado por 2 (dois) médicos ou por 1 (um) médico legista, no caso de morte violenta, depois de autorizada pela autoridade judiciária. 


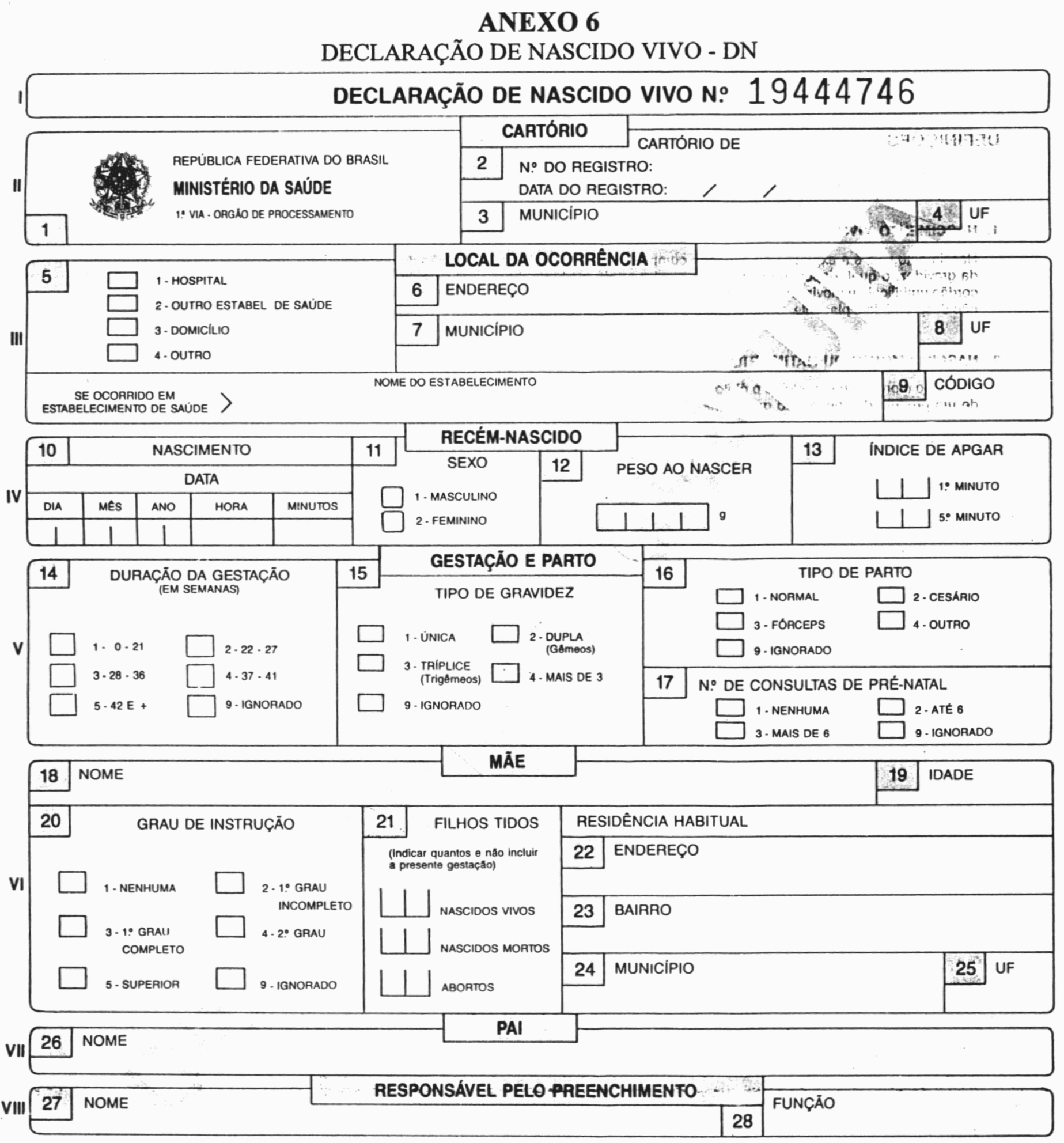

Para registrar esta criança (obrigatório por lei), o pai ou responsável deverá levar este documento ao Cartório de Registro Civil.

Atenção: $\square$ Este documento não substitui a Certidão de Nascimento. 


\section{DEFINIÇŌES}

(De acordo com a CLASSIFICAÇĀO INTERNACIONAL DE DOENÇAS - REVISĀO 1975)

\section{NASCIMENTO VIVO}

Nascimeillo viro é a expuisāo ou extraçāo completa de um produto de concepção do corpo materno, independentemente da duração da gravidez, o qual, depois da separaçäo, respire ou de qualquer outro sinal de vida, tal como batimentos do coraçăo, pulsaçðes do cordão umbilical ou movimentos efetivos dos músculos de contraçăo voluntária, estando ou năo cortado o cordão umbilical $\theta$ estando ou năo desprendida a placenta. Cada produto de um nascimento que reúna esśas condiçōes se considera como uma criança nascidáviva.

\section{NASCIDO MORTO OU NATIMORTO}

"Nascido morto ou natimorto" é o óbito fetal tardio ou seja, o óbito ocorrido antes da expulsão ou extraçāo completa do corpo materno. de um produlo da concepçăo que tenha alcançado 28 semanas completas ou mais de gestaçāo. 


\section{ANEXO 7 \\ DECLARAÇÃO DE NASCIDO VIVO - DN (MODELO ATUAL)}

República Federativa do Brasil

Ministério da Saúde

3* Via - Unidade de Saúde

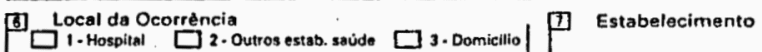
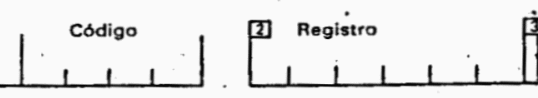

角 Data

口4.Outros $\square$ g.lgnorsdo

(8) Endereço da ocorrencia, se fora do estab. ou da resid. da máe (Rua, praça, aven

111

.
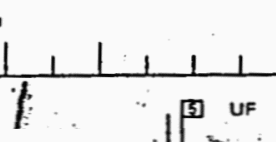

Endere da ocom sora do ostabou da regi

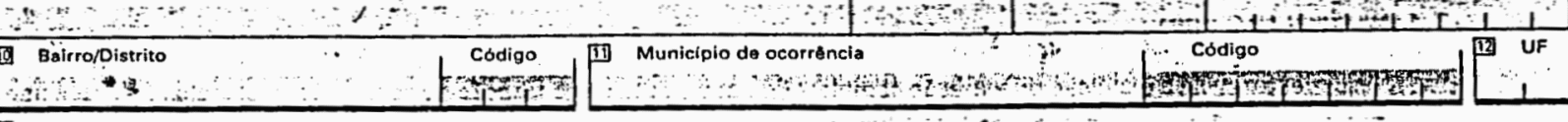

if Nome da maso

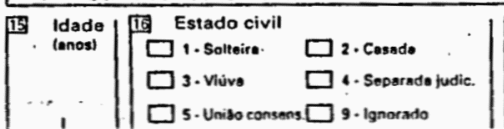

$\frac{1}{\text { sidencia da màe }}$

[0] Logradouro

ए0.$$
\text { 227 }
$$

\begin{tabular}{|c|c|}
\hline $\begin{array}{l}\text { Bairro/distrito } \\
\text {. }\end{array}$ & \\
\hline \multicolumn{2}{|c|}{ Duraçăo da gestaçăo 1 em semanas ! } \\
\hline$\square$ 1. Menos de 22 & $\square 2 \cdot D e 22: 27$ \\
\hline$\square 3.0028031$ & $\square 4.0032=36$ \\
\hline$\square$ s.D. 37.41 & $\square 8.42$ emais \\
\hline$\square$ 9.Ignorado & ' \\
\hline
\end{tabular}

\begin{tabular}{|c|c|c|c|c|}
\hline 29 & \multicolumn{2}{c}{ Nascimento } \\
Dato \\
1
\end{tabular}

32. Raça/cor

$\square$ 1.8rancs $\square$ 2.Prsta $\square$ 3.Amarels $\square$ 4.Parda $\square$ 5.Indigens

26] Tipo de gravidez

$\square$ i.Uंnica $\square$ 2.Dupla

$\square$ 3. Tripla e mais $\square$ 9.Ignorado

3. Détéctada alguma malformaçâo congenita e/ou anomalia cromossômica?

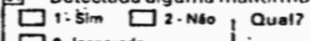

9:lonoradio
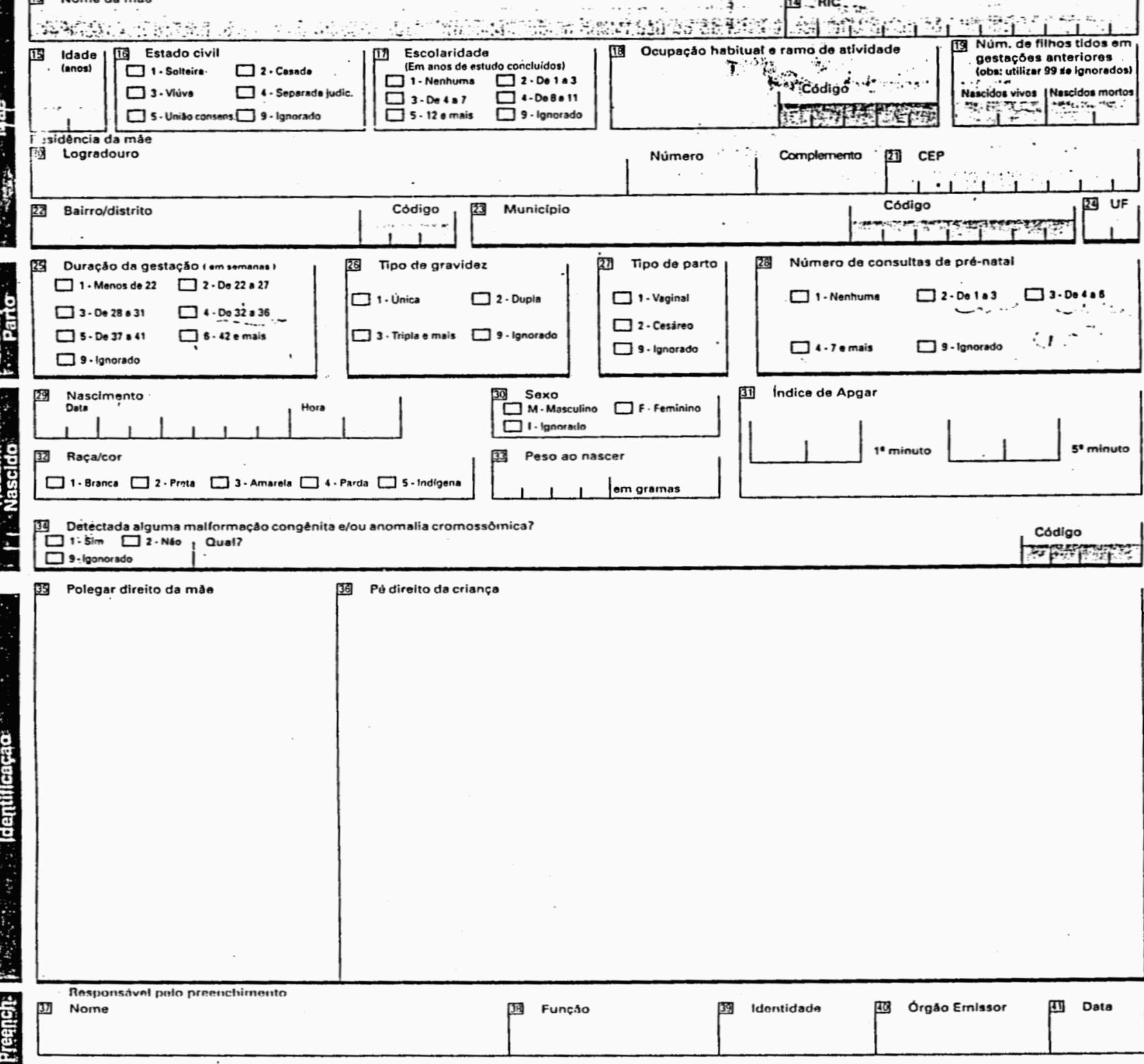

[36] Pè đireito da criança

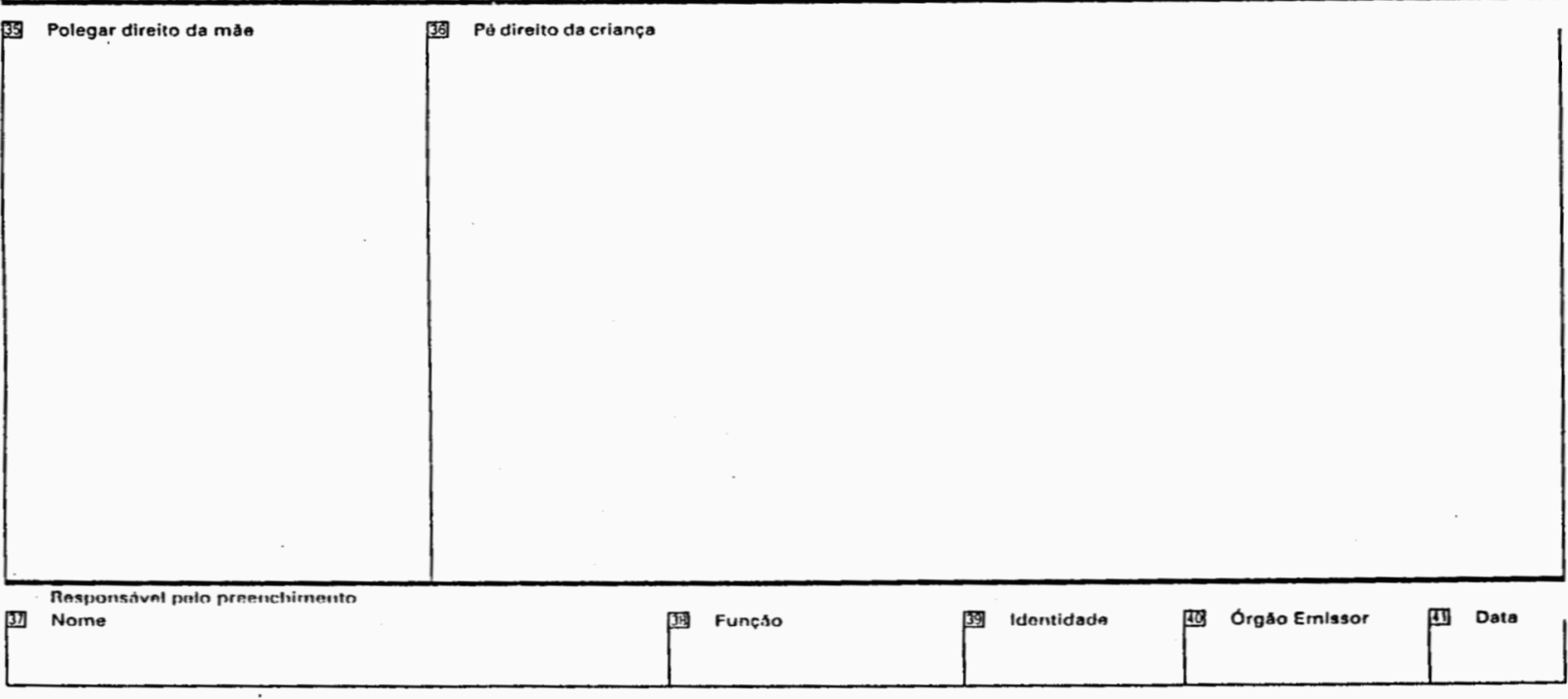

ATENÇÃO : ESTE DOCUMENTO NÃO SUBSTITUI A CERTIDÃO DE NASCIMENTO

O Registro de Nascimento é obrigatório por lei.

Para registrar esta criança, o pai ou responsável deverá levảr este documento ao cartório de registro civil. 


\section{DEFINIÇÕES}

\section{De acor to com a CLASSIFICAÇÃO INTERNACIONAL DE DOENÇAS - REVISÃo 1975 .}

\section{NASCIMENTO VIVO}

Nascimento vivo é a expulsăo ou extraçăo completa de um produto de concepção do corpo materno, independentemente da duração da gravidez, o qual, depois da separação, respire ou dè qualquer outro sinal de vida, tal como batimentos do coração, pulsaçōes do cordảo umbilical uu movimentos efetivos dos músculos de contração voluntária, estando ou nạ́o cortado o cordāo umbilical e estando ou nảo desprendida a placenta. Cada produto de um nascimento que reúna essas condiçóes se considera como uma criança nascida viva.

\section{NASCIDO MORTO OU NATIMORTO}

" Nascido morto ou natimorto" é o óbito fetal tardio, ou seja, o óbito ocorrido antes da expulsāo ou extraçāo completa da corpo materno de um produto da concepcáo que tẹnha alcançado 28 semanas completas ou mais de gestação. 